\title{
FIRST DATES, PROMESA DE MATRIMONIO Y DERECHO INTERNACIONAL PRIVADO
}

\author{
FIRST DATES, PROMISE OF MARRIAGE AND PRIVATE \\ INTERNATIONAL LAW
}

\author{
JaVier CARrascosa GonzÁlez \\ Catedrático de Derecho internacional privado \\ Universidad de Murcia \\ ORCID ID: 0000-0002-0347-7985 \\ Recibido:02.03.2021/Aceptado:23.04.2021 \\ DOI: https://doi.org/10.20318/cdt.2021.6248
}

\begin{abstract}
Resumen: Este trabajo expone la actual regulación jurídica de la promesa de matrimonio en Derecho internacional privado. Tras un análisis de las muy abundantes y profundas polémicas sobre la naturaleza jurídica de esta curiosa institución, el presente trabajo desvela que la ruptura de la promesa de matrimonio genera obligaciones extracontractuales. De ese modo, se explica la aplicación del Reglamento Bruselas I-bis para concretar los tribunales competentes y la aplicación del Reglamento Roma II para precisar la Ley aplicable al fondo de la cuestión. En dicho análisis emerge cono solución óptima para la mayor parte de los casos la aplicación de la Ley del país de la residencia habitual de la víctima, que es la ley del país donde se ha verificado el daño mayor.

Palabras clave: promesa de matrimonio, teoría de la ubicuidad, lugar del daño, residencia habitual común, obligaciones extracontractuales.

Abstract: This essay deals with the legal regulation of the promise of marriage today in cases involving foreign elements. After an analysis of the very deep controversies about the legal essence of this curious institution, the present work reveals that the breaking of the promise to marry generates extra-contractual obligations. Accordingly, the Brussels I-bis regulation is to be applied in order to specify the courts hearing the case. In addition to that, the Rome II regulation must be applied to specify the Law applicable to the substance of the matter. In this perspective, not only should the bulk of the damage be localized in the country where the victim has his/her habitual residence but also, in accordance with that, the application of the law of the country of habitual residence of the victim emerge as the optimal and more efficient solution for most cases.
\end{abstract}

Keywords: promise of marriage, theory of ubiquity, place of damage, common habitual residence, non-contractual obligations.

Sumario: I. Promesa de matrimonio y esponsales en Derecho internacional privado. Aspectos previos. II. Calificación jurídica de la promesa de matrimonio. 1. Bienvenidos a la batalla de calificaciones. 2. Calificación de la promesa de matrimonio y de los esponsales en Derecho internacional privado europeo. A) Primacía de Derecho internacional privado europeo y calificación de la promesa de matrimonio. B) El método unilateral europeo de calificación "reglamento por reglamento". 3. La concreta calificación de la promesa de matrimonio en Derecho internacional privado europeo. A) Posibles calificaciones jurídicas de la cuestión. B) Calificación contractual. C) Calificación como cuestión de régimen económico. D) Calificación de tipo familiar, matrimonial y personal. a) La calificación matrimonial. (a) Aplicación de la Ley personal / Ley nacional común 
de los prometidos. (b) Ley aplicable en defecto de nacionalidad común de los prometidos. b) Calificación como cuestión familiar autónoma. c) Calificación como cuestión relativa a la persona individual. d) Perspectiva europea: rechazo de la calificación familiar. E) Calificación propia: the proper law. F) Calificación extracontractual. III. Competencia judicial internacional. 1. Reglamento Bruselas I-bis y responsabilidad extracontractual. 2. Foros de competencia internacional y ruptura de la promesa de matrimonio. A) Foros generales: sumisión y domicilio del demandado. B) Foro del lugar donde ha ocurrido el hecho dañoso. a) Teoría de la ubicuidad. b) Precisión del lugar donde ha ocurrido el hecho causal. c) Precisión del lugar donde se ha verificado el daño. IV. Ley aplicable a la ruptura de la promesa de matrimonio. Reglamento Roma II. 1. Responsabilidad extracontractual y aplicación del Reglamento Roma II. 2. Primer punto de conexión. Ley elegida por las partes y promesa de matrimonio. 3. Segundo punto de conexión. Ley de la residencia habitual común de las partes y promesa de matrimonio. 3. Tercer punto de conexión. Ley del país donde se ha producido el daño y promesa de matrimonio. A) Aspectos previos. Justificación del punto de conexión "lugar del daño". B) Daños morales y emocionales y promesa de matrimonio. Conexión residencia habitual de la víctima. C) Daños económicos y promesa de matrimonio. a) Aspectos generales. El lugar del daño económico. b) Daños económicos producidos en el mismo país. (a) Daños económicos producidos íntegramente en el país de la residencia habitual de la víctima. (b) Daños económicos producidos realizados íntegramente en un país distinto al de la residencia habitual de la víctima. c) Daños económicos producidos en varios países. (a) Daños en varios países incluido el país de residencia habitual de la víctima. (b) Daños en varios países excluido el país de residencia habitual de la víctima. D) Daños morales, emocionales y económicos. F) Daños recíprocos. V. Ámbito de la Ley aplicable a la ruptura de la promesa de matrimonio. 1. Cuestiones reguladas por la Ley que rige la reclamación por ruptura de la promesa de matrimonio. 2. Ley aplicable a la capacidad para formular una promesa de matrimonio. 3. Ley aplicable a la forma de la promesa de matrimonio. 4. Aplicación de la Ley reguladora de la reclamación por ruptura de la promesa de matrimonio. A) Lex Causae y segunda calificación. B) Prohibición del reenvío tradicional y del reenvío de calificaciones. C) Orden público internacional y reclamaciones tras la ruptura de la promesa del matrimonio. a) Negación de la actio matrimonialis. Admisión e inadmisión de la demanda. b) Restricciones a nuevos matrimonios. c) Indemnizaciones especiales. d) Leyes extranjeras que permiten reclamar daños morales y emocionales. e) Leyes extranjeras que impiden reclamar daños derivados de la ruptura de la promesa de matrimonio. f) Leyes extranjeras que imponen indemnizaciones elevadas y daños punitivos. g) Leyes extranjeras que permiten la ruptura de la promesa de matrimonio. 6. Rechazo de la consideración de los arts. 42 y 43 CC como leyes de policía. 7. Ruptura de la promesa de matrimonio y obligación natural. 8. Donaciones por razón de matrimonio y ruptura de la promesa de matrimonio. VI. Reflexiones finales.

\section{Promesa de matrimonio y esponsales en Derecho internacional privado. Aspectos previos}

1. La promesa de matrimonio puede definirse como la declaración de la voluntad unilateral de contraer matrimonio con persona determinada ${ }^{1}$. Por otro lado, los esponsales constituyen un pacto, acuerdo o contrato por el que se acuerda la celebración de un matrimonio entre los protagonistas del mismo. Los esponsales constituyen, por tanto, un intercambio de promesas unilaterales de matrimonio entre los prometidos.

2. Ambas instituciones, esponsales y promesa de matrimonio (engagement to marry, contract to marry, promise of marriage, fiançailles, promessa di matrimonio, sponsali), fueron habituales en Europa en otros tiempos. Así, los acuerdos entre miembros de las familias reales europeas para la cele-

${ }^{1}$ Este trabajo se ha realizado en el marco del Proyecto de investigación LOGOS (Fundación BBVA) "Los principios del Derecho romano en el Derecho europeo del siglo XXI" (Proyecto Roma-Europa: IP Javier Carrascosa). https://proyectoromaeuropa.com/), del Grupo de Innovación Docente GID 22 "Ciencia jurídica aplicada y docencia creativa" de la Universidad de Murcia (coordinador: Javier Carrascosa), del Grupo de investigación de la Universidad de Murcia E070-05 "Derecho internacional privado europeo" (IP Javier Carrascosa), de la "Red Europa-España de Derecho internacional privado", (coordinador: Javier Carrascosa). http://www.redespañaeuropa.es/), así como del Grupo Accursio: investigación, docencia y práctica del Derecho internacional privado (www.accursio.com), dirigido por Javier Carrascosa. 
bración de matrimonios entre sus mismos eran un paso necesario y habitual antes del enlace matrimonial entre personas de la realeza y de la nobleza. Sin embargo, se ha dicho y se ha escrito que estas instituciones jurídicas son, hoy día, poco frecuentes en los países europeos y que, por ello son anacrónicas y poco interesantes para juristas, sociólogos y economistas. Son signos y reliquias, se dice, de otros tiempos pasados y olvidados que nunca volverán. También se ha dicho y se ha escrito que los casos de ruptura de promesa de matrimonio son muy escasos en la práctica judicial, como destacan R.H. GRAVESON y P.R.H. Webb / D.J. Latham Brown². También es cierto que, frente a ello, se ha subrayado que la doctrina de los autores sobre la promesa de matrimonio y los esponsales en Derecho internacional privado es más abundante de lo que en principio pueda suponerse y más numerosa de lo que merece esta extraña institución jurídica que hoy parece superada. Ello se explica por la tendencia de los especialistas en Derecho internacional privado a estudiar las instituciones jurídicas que resultan más complicadas desde el punto de vista de la dogmática jurídica. La complejidad es un desafío para el jurista intelectual, de modo que es, precisamente, la presencia de esas "dificultades doctrinales", en palabras de J.D. GonzÁLEz CAMPOS, lo que estimula el análisis de esta peculiar y controvertida institución ${ }^{3}$.

3. La promesa de matrimonio y los esponsales son contemplados con reticencia por el Derecho ya desde hace tiempo, como observó M. DE LASALA Llanas ${ }^{4}$. Ello se debe a varias causas. En primer lugar, estas instituciones han sido empleadas como instrumentos de coacciones morales y económicas entre los contrayentes y/o sus familias. En particular, esponsales y promesas de matrimonio han sido con frecuencia utilizadas como mecanismos para recortar, coartar y condicionar, de una u otra manera, la libertad de contraer matrimonio en régimen de plena igualdad jurídica. En segundo término, estas figuras mezclan de modo impropio, se dice, cuestiones jurídicas y emocionales y no parece conveniente que el Derecho regule sentimientos ni pensamientos, sino actos y acciones.

4. No obstante, la promesa de matrimonio conoce hoy día, ya en pleno siglo XXI, un interés creciente. Ello se debe a por tres factores, muy bien destacados por F. Mosconi / C. CAMPIGLIO 5 .

${ }^{2}$ P.R.H. Webb / D.J. Latham Brown, "Engagements to Marry and the Conflict of Laws", The International and Comparative Law Quarterly, vol. 15, n. 4, 1966, pp. 947-995, con cita de R.H. Graveson en su comentario a la sentencia Kremezi vs. Ridgway, 1949, así como E. Siro, "Breach of Promise (Based on Guggenheim v. Rosenbaum", The International and Comparative Law Quarterly, 1962, vol. 11, n.1 (January 1962), pp. 260-266. También A. SARAVALLE, “Articolo 26”, en Riforma del sistema italiano di diritto internazionale privato legge 31 maggio 1995 n. 218, Rivista di Diritto internazionale privato e processuale, 1995, pp. 1043-1046: "Sorprende la previsione di una norma sulla promessa di mattimonio nella legge di riforma visto che l'istituto è oggi sicuramente desueto. Già sono rare le controversie di diritto interno in materia, ancor di piu lo sono, poi, quelle nelle quali possa sorgere un problema di conflitto di leggi (ad oggi, si riscontra in giurisprudenza un solo precedente, per di piu ormai datato)".

${ }^{3}$ J.D. GonzÁlez Campos, "El matrimonio en el Derecho civil internacional”, en M. Aguilar Navarro, Derecho civil internacional, Facultad de Derecho, Universidad Complutense, Madrid, $4^{a}$ ed, 1975 (reimpresión 1979), pp. 243-371, esp. pp. 258262: "En la perspectiva del Derecho internacional privado, se ha dicho no sin ironía que jamás un tema de tan escaso interés práctico ha provocado tantas dificultades doctrinales".

${ }^{4}$ M. De Lasala Llanas, Sistema español de Derecho civil internacional e interregional, Ed. Rev. Derecho privado, Madrid, 1933, pp. 110-111: "La institución de las promesas de futuro matrimonio, además de carecer propiamente de contenido jurídico, cuando se hacian clandestinamente o en forma privada, eran ocasión propicia para censurables abusos y combinaciones familiares. El código civil, aceptando este criterio prohibitivo, establece una regla de orden público internacional, que, por consiguiente, no sólo es obligatoria para los españoles, "aunque residan en el extranjero (Iey personal art. 9 u orden publico interno), sino también para los extranjeros en España, como ley "prohibitiva" de orden moral o costumbres" (párrafo tercero del art. 11)". El autor se refiere a la versión originaria del Código Civil español tal y como fue publicado en 1889.

${ }^{5}$ F. Mosconi / C. CAmpiglio, Diritto internazionale privato e processuale. Vol. 2: Statuto personale e diritti reali, $4^{\mathrm{a}} \mathrm{ed}$., Utet, Torino, 2016, pp. 85-86: "Il fatto che il Capo della legge n. 218 dedicato ai rapporti di famiglia si apra con un articolo concernente la promessa di matrimonio può apparire anacronistico. Ma quella scelta di politica legislativa-che dal 2004 vanta un corrispondente nell'art. 45 del codice belga di d.i.pr.- trova conferma della propria utilità da un lato nella prassi dei c.d. accordi prematrimoniai, che sta avendo crescente diffusione tra personaggi noti e meno noti, e d'altro lato nella frequenza con la quale il nostro ordinamento giuridico viene trovarsi interessato (o semplicemente toccato) da relazioni tra soggetti appartenenti a realtà socio-culturali diverse dalla nostra. Infatti, per alcune di quelle realtà, da promesse matrimoniali -talvolta addirittura nemmeno formulate diretti interessati- possono derivare conseguenze significative anche d'ordine legale". También B. BARel / ST. ARMELlini, Manuale breve Diritto internazionale privato: tutto il programma d'esame con domande e risposte commentate, Milano, Giuffrè, 2006, p. 136: “L'art. 26 legge 218/1995 detta la disciplina di conflitto per la promessa di 
En primer lugar, la promesa de matrimonio es habitual en otros países con culturas no europeas, como los que disponen de un ordenamiento jurídico de raíz islámica o hinduista. Cuando sujetos procedentes de tales países llegan a Europa, la cuestión se suscita en toda su realidad. Así lo demuestra el estudio de D. FuDICKAR sobre las reclamaciones en Alemania de los padres de novias de nacionalidad turca cuando se rompe un compromiso de matrimonio, y también el trabajo, pionero, de F. GAMILlscheG, que vincula el creciente atractivo de esta institución para el Derecho internacional privado al notable aumento del número de matrimonios entre europeos y no europeos ${ }^{6}$.

En segundo lugar, el progresivo auge de los contratos prematrimoniales, prenups y similares celebrados entre personas famosas y no famosas, contratos en los que suele incluirse una promesa de matrimonio, también plantean la cuestión de la responsabilidad civil por ruptura de la misma, como indica N. BOSCHIERO?

En tercer lugar, el notorio auge de las webs de contactos, citas y matrimonios, visibles en todo el mundo, ha vuelto a traer al primer plano del análisis jurídico, en los países occidentales, los aspectos legales de la promesa de matrimonio y los esponsales en Derecho internacional privado ${ }^{8}$. En efecto, son

matrimonio. Si tratta di una disposizione anacronistica dal punto di vista italiano, considerato che la coscienza sociale non attribuisce più significato impegnativo ai comportamenti pre-matrimoniali; tuttavia, non è così per molti ordìnamenti stranieri”.

${ }^{6}$ D. FudicKar, “Ansprüche des Brautvaters bei Auflösung des Verlöbnisses türkischer Verlobter", IPRax, 1985, pp. 253262; F. GamillscheG, "Das Verlöbnis im deutschen internationalen privatrecht”, RabelsZ, 1968, pp. 473-487.

${ }^{7}$ N. Boschiero, "Sulla disciplina internazionalprivatistica della promessa di matrimonio e delle donazioni", en GAJA (a cura di), La riforma del diritto internazionale privato e processuale, Raccolta in ricordo di E. Vitta, Milano, 1994, pp. $277-287$.

${ }^{8}$ La doctrina sobre la promesa de matrimonio y los esponsales en Derecho internacional privado es más abundante de lo que en principio pueda suponerse. Los estudios sobre este tema comenzaron a ver la luz en la primera mitad del siglo XIX, lo que se explica por el hecho de que la promesa de matrimonio y los esponsales, instituciones hoy poco utilizadas, contaban antaño con una difusión notable en todo el mundo y especialmente en occidente. Los primeros trabajos académicos sobre estas cuestiones y la jurisprudencia más antigua de diversos países y sistemas de Derecho internacional privado de todo el mundo pueden encontrarse muy bien analizados y sistematizados en la formidable y muy brillante obra de E. RABeL, The conflict of laws: A comparative study. Vol. 1: Introduction: Family Law, $2^{\mathrm{a}}$ ed., Ann Arbor, The University of Michigan press, Chicago, Callaghan \& company, 1958, pp. 215-221. En la doctrina francesa sigue siendo hoy día un trabajo absolutamente fundamental la muy profunda aportación, llena de matices, de A. WeIll, "Fiançailles", Encyclopedie Dalloz droit international, París, $1968-69$ (dir. Ph. Franceskakis), vol.II, 1969, pp. 22-24, así como la de H. BATIFFOL, Aspects philosphiques du droit international privé, Paris, Dalloz, 1956, pp. 35-36, que se detiene con atención puntillosa en los problemas de primera y segunda calificación de estas instituciones. Los manuales franceses de Derecho itnernacional privado, antiguos y actuales, tratan este tema con una intensidad muy sugestiva. Entre ellos pueden citarse J. Derrupé / J.-P. LABORDE, Droit international privé, Dalloz, 16 a ed., 2008, pp. 138139; P. Courbé, Droit international privé, Colin-Dalloz, Paris, 2007, p. 225; F. MÉlin, Droit international privé: droit des conflits de juridictions, droit des conflits de lois, droit de la nationalité, condition des étrangers en France, $8^{\mathrm{a}}$ ed., Issy-les-Moulineaux, Gualino, 2018, p. 156: D. Bureau / H. Muir Watt, Droit international privé, Tome II Partie spéciale, $3^{\text {a }}$ ed., Presses universitaires de France (PUF), Paris, 2014, p. 114; D. Holleaux / J. Foyer / G. De Geoufrré de Lapradelle, Droit international privé, París, Masson, 1987, pp. 276-277; B. AudIT, Droit international privé, $5^{\mathrm{a}}$ ed., Issy-les-Moulineaux, LGDJ, 2006, p. 514. La doctrina italiana sobre este tema es notable en cantidad y sobresaliente en calidad. Antes de la legge 218/1995 pueden verse los estudios de G. Balladore Pallieri, Diritto internazionale privato, ${ }^{a}$ ed., Giuffrè, Milano, 1950; G. Balladore Pallieri, Diritto internazionale privato, en "Trattato di diritto civile e commerciale", Giuffrè, Milano, 1974, pp. 173-174; E. Bетті, Problematica del diritto internazionale, Milano, A. Giuffrè, 1956, pp. 420-421; S. GEMmA, Appunti di diritto internazionale, diritto pubblico, Bologna, N. Zanichelli, 1923, p. 123; D. Anzillotт, Corso di lezioni di diritto internazionale privato, Athenaeum, 1918, p. 219; G. Bosco, Corso di diritto internazionale privato, Castellani, 1939, p. 222; G. MorelLi, Elementi di diritto internazionale privato italiano, Jovene, 1962, p. 96; M. Miele, Scritti di diritto matrimoniale, Cedam, 1964, p. 25; R. MonAco, L'efficacia della legge nello spazio, Utet, 1964, pp. 153-157; P. Fedozzi, Il diritto internazionale privato: Teorie generali e diritto civile, Cedam, Padova, 1939, pp. 402-495; M. Miele, "Sulla legge applicabile alla rottura degli sponsali", Giurisprudenza comparata di diritto internazionale privato, 1942, pp. 77-89; G. MorelLI, "Legge regolatrice del contratto di matrimonio e volontá delle parti", Giurisprudenza comparata di diritto internazionale privato, 1942, pp. 219-129; R. DE NovA, "Gli sponsali in diritto internazionale privato", Il Foro Italiano, 1955, vol. 78, N. 2, pp. 25-38; R. DE NovA, “voce Matrimonio (promessa di), diritto internazionale privato", Novissismo Digesto italiano, X, Utet, 1964, pp. 426-429; M. Udina, Elementi di diritto internazionale privato italiano, Roma, A.R.E., Anonima romana editoriale, 1933, pp. 176; E. VITTA, Diritto internazionale privato, vol. II, UTET, Torino, 1973, pp. 167-171; E. VITTA, Diritto internazionale privato e processuale, $3^{\mathrm{a}}$ ed., Torino, UTET, 1989, p. 216. Con posterioridad a la legge 218/1995, cuyo art. 26 regula la cuestión por primera vez en el Derecho internacional privado italiano, destacan B. BAREL / St. ARMELLINI, Manuale breve Diritto internazionale privato: tutto il programma d'esame con domande e risposte commentate, Milano, Giuffrè, 2006, p. 136: F. Mosconi / C. CAmpiglio, Diritto internazionale privato e processuale. Vol. 2: Statuto personale e diritti reali, 4aed., Utet, Torino, 2016, pp. 85-86; G. ОвеRто, "La promessa di matrimonio", en VV.AA. Trattato di diritto di famiglia, diretto da I. ZAтTI, Famiglia e matrimonio, $2^{\mathrm{a}}$ ed., Milano, 2011, pp. 325-330; G. ОвеRTo, La promessa di matrimonio tra passato e presente, Cedam, Padova, 1996; A. SARAVALLE, “Articolo 26”, en Riforma del sistema italiano di dirit- 
frecuentes los casos en los que los sujetos implicados en una promesa de matrimonio residen habitualmente en países diferentes y pertenecen a culturas distintas en las que dicha promesa posee un valor social y jurídico también muy distinto. El amor es el motivo de la mayor parte de esas promesas, pero pasado el dulce momento de la efervescencia romántica, algunas personas incumplen tales promesas de matrimonio, se olvidan de las mismas o, simplemente, nunca más dan señales de vida. En otras ocasiones, el amor no ha estado nunca presente. Una persona ha engañado a otra. Le ha hecho creer que había amor verdadero e intención auténtica de formar una familia basada en el matrimonio, cuando, en realidad, ha habido sólo un artificio, un ardid, una pura y vil añagaza. El engaño, instrumentado en la ruptura de la promesa de matrimonio, ha servido para que alguien pueda viajar desde un país a otro, y/o para obtener regalos, dinero y otras ventajas económicas. Regalos que no se devuelven y dinero que se evapora. Ejemplos no faltan. Así, la STS 3 diciembre 2020 abordó el siguiente caso ${ }^{9}$. Una mujer española con residencia habitual en Madrid se enamoró de un joven armenio. Le regaló un coche, cantidades elevadas de dinero y diversas joyas de valor. Las hijas de la señora solicitaron al juez que su madre fuera sometida a tutela y/o el nombramiento de un curador al estimar que no disponía del juicio ni de la capacidad precisa para realizar tales disposiciones patrimoniales. El joven armenio regresó a su país. La pregunta surge espontánea: si hubiera mediado una promesa de matrimonio del joven armenio a la señora española, $\mathrm{y}$ aquél la hubiera roto ¿puede la señora española reclamar las cantidades gastadas por la mujer en bienes y servicios en consideración de un futuro matrimonio que ya no va a celebrarse? Desde Armenia con amor, pero la señora española ha gastado importantes cantidades de dinero que ahora carecen de sentido.

5. Todo lo anterior adquiere una tonalidad especial en un contexto transfronterizo, pues éste hace que las cuestiones jurídicas surjan espontáneamente como las setas en primavera y se vuelvan complejas como la mente de un adolescente. Piénsese, por ejemplo, en una promesa de matrimonio formulada vía WhatsApp, por varón marroquí y dirigida a ciudadana española: el varón reside en Marruecos y ella reside en Argelia, pero tienen pensado fijar su primer domicilio conyugal en España inmediatamente después de la celebración del enlace. En ese escenario, la mujer adquiere una vivienda en España así como

to internazionale privato legge 31 maggio 1995 n. 218, Rivista di Diritto internazionale privato e processuale, 1995, pp. 10431046 y los muy sobresalientes trabajos de N. Boschiero, "Sulla disciplina internazionalprivatistica della promessa di matrimonio e delle donazioni", en GAJA (a cura di), La riforma del diritto internazionale privato e processuale, Raccolta in ricordo di E. Vitta, Milano, 1994, pp. 277-287; N. Boschiero, “Art. 26”, en S. Bariatti (a cura di), Legge 31 maggio 1995 n. 218 , Riforma del sistema italiano di diritto internazionale privato. Commentario, en Nuove leggi civili commentate, 1996, pp. 1149-1156. La doctrina anglosajona sobre el tema puede analizarse en la citada aportación, admirable, de E. RABEL, The conflict of laws: A comparative study. Vol. 1: Introduction: Family Law, $2^{\mathrm{a}}$ ed., Ann Arbor, The University of Michigan press, Chicago, Callaghan \& company, 1958, pp. 215-221, así como en E. Sprro, "Breach of Promise (Based on Guggenheim v. Rosenbaum", The International and Comparative Law Quarterly, 1962, vol. 11, n.1 (January 1962), pp. 260-266 y P.R.H. WeBB / D.J. LATHAM Brown, "Engagements to Marry and the Conflict of Laws", The International and Comparative Law Quarterly, vol. 15, n. 4, 1966, pp. 947-995. La doctrina alemana más temprana puede encontrarse en A. Nussbaum, Deutsches Internationales Privatrecht, Tübingen, 1932, pp. 98-100; G. MelCHIOR, Die Grundlagen des deutschen internationalen Privatrechts, Institut für Ausländisches und Internationales Privatrecht, Berlin, 1932 (reprint 2016), De Gruyter (Verlag), n. 255; D. Fudickar, "Ansprüche des Brautvaters bei Auflösung des Verlöbnisses türkischer Verlobter", IPRax, 1985, pp. 253-262; F. GAMILLSCHEG, "Das Verlöbnis im deutschen internationalen privatrecht", RabelsZ, 1968, pp. 473-487; M. WoLfF, Derecho internacional privado, Ed. Labor. Barcelona 1936, traducción de José Rovira y Ermengol, pp. 286-287; R. RAAPE, Internationales Privatrecht, 5th ed., Berlin Frankfurt a.M., Verlag Franz Vahlen GmbH, 1961. pp. 266-274. En la doctrina suiza puede verse A.F. SCHNITZER, Handbuch des internationalen Privatrechts: einschliesslich Prozessrecht, unter besonderer Berücksichtigung der schweizerischen Gesetzgebung und Rechtsprechung, T.I , $3^{\mathrm{a}}$ ed., Verlag für Recht und Gesellschaft, 1957, pp. 308-311. Las aportaciones de la doctrina española sobre este tema son, generalmente, antiguas. Destaca el muy lúcido análisis de J.D. GonzÁLEz CAmpos, "El matrimonio en el Derecho civil internacional", en M. Agullar Navarro, Derecho civil internacional, Facultad de Derecho, Universidad Complutense, Madrid, $4^{\mathrm{a}}$ ed,. 1975 (reimpresión 1979), pp. 243-371, esp. pp. 258-262, así como las reflexiones contenidas en manuales de Derecho internacional privado como los de W. GoldschmidT, Sistema y filosofia del Derecho internacional privado, t.I, Ed.Bosch, Barcelona, 1948, pp. 227-229: J.A. TOMÁs OrTiz DE LA TORRE, "Formación del matrimonio y estados del vínculo en el Derecho civil internacional español”, en M. Aguilar Navarro y otros, Lecciones de Derecho civil internacional, Serv.publ. Facultad Derecho, Univ.Complutense. Madrid, 1982, pp. 121-129; M. DE Lasala Llanas, Sistema español de Derecho civil internacional e interregional, Ed.Rev.Derecho privado, Madrid, 1933, pp. 5-56; J.R. DE OrúE Y ARREGU, Manual de Derecho internacional privado, $3^{\mathrm{a}}$ ed., Madrid, Ed.Reus, 1952, p. 642, así como en J.M. EsPinAR VICENTE, El matrimonio y las familias en el sistema español de DIPr., Madrid, Tecnos, 1996, pp. 111-114.

${ }^{9}$ [ECLI: ES:TS:2020:4050]. 
numerosos elementos para amueblar el hogar que compra por Internet en negocios españoles e italianos y regala al varón un automóvil de lujo que ha comprado en Francia. Una semana antes del matrimonio, la mujer, que se halla en Francia, recibe un e-mail de su prometido, que se encuentra en Marruecos en ese momento y en el que le indica que no va a contraer matrimonio. Como se observa, en este caso, la promesa de matrimonio se formula en Marruecos y se recibe a Argelia; se rompe también en Marruecos y dicha ruptura se recibe en Francia; la mujer reside en Argelia y ostenta nacionalidad española y ha realizado gastos en España, Francia e Italia en consideración del futuro matrimonio; el lugar del futuro primer domicilio conyugal se fijó en España. Ante esta intensa dispersión de elementos en el espacio, la duda surge: ¿qué tribunales pueden conocer de las reclamaciones por daños que la mujer puede dirigir contra el varón? Y, naturalmente, ¿qué Ley debe regir dichas reclamaciones, la Ley española, la argelina, la marroquí, la francesa o la italiana, o todas a la vez? Bienvenidos todos al fascinante mundo del Derecho internacional privado.

6. Tras el fracaso de la promesa de matrimonio, una persona queda frustrada desde el punto de vista emocional y también desde el punto de vista económico, pues muchas veces dicha persona ha realizado compras, obsequios e inversiones con vistas a un enlace matrimonial que ya nunca tendrá lugar. En el horizonte aparece, servido en bandeja de plata, un litigio internacional. En los casos transfronterizos, en efecto, el incumplimiento de estas promesas hace surgir las dos cuestiones típicas del Derecho internacional privado: (i) la determinación de los tribunales competentes para conocer de las reclamaciones que plantea la víctima de la ruptura de la promesa de matrimonio y (ii) la precisión de la ley aplicable al fondo de tales reclamaciones.

7. Por otro lado, la regulación jurídica los distintos Estados sobre la promesa de matrimonio es variada, por lo que surgen auténticos conflictos de leyes en este sector, Cuatro grandes posiciones pueden distinguirse, como ilustra J.D. GonZÁLEZ CAMPOS ${ }^{10}$.

En primer lugar, ciertos ordenamientos jurídicos, como el Derecho argentino y el holandés, niegan toda acción de reparación por los daños patrimoniales y morales que puedan haberse generado tras la ruptura de una promesa de matrimonio. Tratan, con ello, estos ordenamientos, de salvaguardar la libertad nupcial de los contrayentes, escribe W. Goldschmidi ${ }^{11}$. También el Derecho de Nueva York niega toda reclamación por daños morales o económicos tras la ruptura de un "contract to marry". Así, en el caso Guggenheim v. Rosenbaum, fallado por un tribunal de Sudáfrica, explica E. Siro, quedó claro que el Derecho de Nueva York no permitía reclamar daños en un supuesto en el que un sujeto había prometido, en Nueva York, que contraería matrimonio en Sudáfrica con una mujer y que en dicho país instalarían el domicilio conyugal ${ }^{12}$.

\footnotetext{
${ }^{10}$ En general, los distintos tipos de enfoques que siguen los Derechos materiales de los diferentes Estados aparecen muy bien explicados en J.D. GonZÁlez CAmpos, "El matrimonio en el Derecho civil internacional", en M. Aguilar NaVArRo, Derecho civil internacional, Facultad de Derecho, Universidad Complutense, Madrid, 4 ed,. 1975 (reimpresión 1979), pp. 243-371, esp. pp. 258-262: “Ciertas legislaciones, como la de la República Argentina, excluyen cualquier reparación, precisamente como medio de eliminar toda presión legal sobre la libertad de los contrayentes; por él contrario, en los sistemas jurídicos anglosajones se admite ampliamente el deber por ruptura de la promesa matrimonial, que alcanza incluso a los posibles «taños morales» de la víctima. En una posición intermedia se sitúan muchos otros sistemas (como el español) que sancionan la ruptura del pacto de esponsales por los daños «efectivamente sufridos»". También con descripción de las varias tendencias en Derecho material comparado resulta útil la exposición de W. GolDSchmidt, Sistema y filosofía del Derecho internacional privado, t.I, Ed.Bosch, Barcelona, 1948, pp. 227-229. Un panorama bastante completo de la regulación material de la promesa de matrimonio y las acciones a las que da lugar, -si bien ya desfasado por el paso del tiempo en algunos casos, como se puede apreciar en la información relativa a Alemania y en particular en lo relativo al muy llamativo art. 1300 BGB (acción de reclamación pecuniaria por desfloración de la mujer)-, puede verse en: https://www.lawreform.ie/_fileupload/consultation\%20papers/wpBreachofPromise.htm\#: :text=A\%20THE\%20PRESENT\%20LAW,to\%20marry\%20has\%20been\%20made.\&text=A\%20promise $\% 20$ by $\% 20$ one $\% 20$ person,the $\% 20$ conduct $\% 20$ of $\% 20$ the $\% 20$ parties.

${ }^{11}$ W. Goldschmidt, Sistema y filosofia del Derecho internacional privado, t.I, Ed.Bosch, Barcelona, 1948, pp. 227-229: “El derecho a pedir indemnización por injustificada resolución de los esponsales de futuro pertenece al orden público alemán, su denegación al orden público holandés".

${ }^{12}$ E. SPIRo, "Breach of Promise (Based on Guggenheim v. Rosenbaum", The International and Comparative Law Quarterly, 1962, vol. 11, n.1 (January 1962), pp. 260-266.
} 
En segundo término, otros sistemas legales, más liberales, admiten acciones de resarcimiento por los daños que causa la ruptura de la promesa matrimonial, incluido los posibles daños morales que sufre la víctima. Es el caso, notorio, del Derecho inglés.

En tercer lugar, en un lugar intermedio, ciertos Derechos estatales, como el español y el francés, admiten solamente acciones para recuperar los gastos realizados por la víctima de la ruptura de la promesa de matrimonio en consideración del matrimonio y otros daños puramente patrimoniales.

En cuarto lugar, algunos Derechos estatales admitían, en el pasado, la actio matrimonialis, esto es, una acción que podía ejercitar la víctima de la ruptura para obligar a la otra parte a contraer matrimonio. Así, como recuerdan H. CoRnejo ChÁvez y W. Goldschmidt, una ley noruega de 31 mayo 1918 recogía el derecho de la novia embarazada a solicitar la celebración del matrimonio, esto es, la actio matrimonialis $^{13}$. De modo similar, el Derecho de Estonia también admitía que la obligación de contraer matrimonio derivada de una promesa de matrimonio podía ser sustituida por pena pecuniaria ${ }^{14}$. Estos ordenamientos han eliminado progresivamente la actio matrimonialis y hoy día no consta la existencia de Estados con una regulación jurídica que permita a una parte obligar a la otra a contraer matrimonio en ejecución de una promesa de matrimonio.

8. Sin embargo, el primer paso, siempre previo, a las dos clásicas cuestiones de Derecho internacional privado, -competencia judicial internacional y Derecho aplicable-, consiste en vencer una batalla, muy bien descrita por el clásico y deslumbrante texto de E. RABEL: la batalla de las calificaciones, una batalla en al que sólo un dominio sólido, acabado, cuidadoso y creativo de la mejor dogmática jurídica permitirá alcanzar la victoria al buen jurista ${ }^{15}$.

\section{Calificación jurídica de la promesa de matrimonio}

\section{Bienvenidos a la batalla de calificaciones}

9. El Derecho internacional privado europeo y el Derecho internacional privado español carecen de una norma que señale expresamente cuáles son los tribunales competentes y cuál es la Ley aplicable a la promesa de matrimonio y a sus consecuencias jurídicas.

10. No son muchos los sistemas nacionales de Derecho internacional privado que se ocupan de señalar la Ley aplicable a la promesa de matirmonio. Destacan el Derecho internacional privado belga (art. 45 de la Ley belga que contiene el Código de Derecho internacional privado de 16 julio 2004), el italiano (art. 26 legge 218/1995) y el turco (art. 12 de la Ley sobre el Derecho internacional privado y procesal n. 5718 de 27 noviembre 2007). Estos tres sistemas cuentan con una norma que fija la Ley

${ }^{13}$ W. GolDSchmidt, Sistema y filosofía del Derecho internacional privado, t.I, Ed.Bosch, Barcelona, 1948, pp. 227-229: “El derecho de la novia embarazada a pedir el matrimonio, que, p. ej., concede la Ley noruega de 1918, infringe el orden público español (art. 11, pár. 3", y art. 43)". H. CoRneJo CHÁvez, "Los esponsales", Revista Derecho PUCP, Pontificia Universidad Católica del Perú, 1949, n.9, pp. 11-25.

${ }^{14}$ H. Cornejo Chávez, "Los esponsales", Revista Derecho PUCP, Pontificia Universidad Católica del Perú, 1949, n.9, pp. $11-25$.

${ }^{15}$ E. RabeL, The conflict of laws: A comparative study. Vol. 1: Introduction: Family Law, $2^{\mathrm{a}}$ ed., Ann Arbor, The University of Michigan press, Chicago, Callaghan \& company, 1958, pp. 215-221, esp. p. 215: "Insofar as they have been dealt with at all, their treatment has suffered from divergency of classification in the various municipal laws". También J.D. GonZÁLEZ CAMPOS, "El matrimonio en el Derecho civil internacional", en M. Agullar Navarro, Derecho civil internacional, Facultad de Derecho, Universidad Complutense, Madrid, 4 a ed, 1975 (reimpresión 1979), pp. 243-371, esp. pp. 258-262: "Para un sector doctrinal, se considera que el problema del incumplimiento posee autonomía, independientemente de la promesa matrimonial que ha sido el origen del acto de ruptura; y la consecuencia de esta posición es reclamar una regulación especial del incumplimiento dentro del Derecho internacional privado. Posición esta difícilmente aceptable, pues los efectos de la promesa (en caso de ruptura) no pueden separarse de forma radical del negocio jurídico que ha sido su causa. De este modo, el problema se desplaza hacia la calificación del negocio jurídico, de la promesa matrimonial'. Sobre la necesidad de argumentación dogmática en Derecho internacional privado, vid. J. CARRASCOSA GonzÁLEZ, Derecho internacional privado y dogmática jurídica, Comares, Granada, 2021. 
reguladora de la promesa de matrimonio en casos internacionales ${ }^{16}$. Como explica A. SARAVALLE, aunque puede sorprender que la promesa de matrimonio, institución que se creía olvidada, cuente con una regulación propia de Derecho internacional privado en estas leyes de finales del siglo XX y principios del siglo XXI, ello tiene su explicación en dos motivos. En primer lugar, estos tres legisladores estatales han querido, con ello, zanjar las controversias doctrinales sobre la calificación de la promesa de matrimonio, germen de debates doctrinales interminables y motivo de una fuerte inseguridad jurídica. En segundo lugar, estos tres legisladores han querido elaborar una disciplina completa de las situaciones privadas internacionales, con las menores lagunas legales. Por ello, estas leyes especiales de Derecho internacional privado han recogido normas de conflicto de leyes, hasta hoy poco frecuentes, que señalan la ley aplicable a las reclamaciones derivadas de la ruptura de la promesa de matrimonio ${ }^{17}$.

11. Este silencio legal casi completo en Europa y total en el Derecho internacional privado europeo y español sobre la competencia judicial internacional y la ley aplicable a la promesa de matrimonio ha generado una dura "batalla de calificaciones" desde hace más de cien años. En efecto, visto que el Derecho internacional privado europeo y español cuentan tan sólo con normas de competencia internacional judicial y con normas de conflicto que fijan la Ley aplicable a categorías jurídicas generales, -como "matrimonio", a las "relaciones de familia", a los "contratos", a la "responsabilidad extracontractual" y a otros supuestos jurídicos configurados de forma muy amplia-, resulta necesario "calificar" la promesa de matrimonio. Sólo una vez averiguada y definida su naturaleza jurídica, la cuestión de la promesa de matrimonio podrá ser encajada en una de las anteriores categorías jurídicas generales. Como escribe G. BALladore Pallieri, en realidad, los problemas jurídicos más graves suscitados en Derecho internacional privado por la promesa de matrimonio vienen, precisamente, de las dificultades para calificar jurídicamente, de un modo correcto, dicha promesa de matrimonio ${ }^{18}$.

12. En este escenario, la doctrina ha entendido que la promesa de matrimonio puede ser calificada de maneras extraordinariamente diversas en los diferentes sistemas estatales de Derecho internacional privado, como muy bien exponen Y. Loussouarn / P. Bourel / P. DE VAREILLES-SOMMiEkers ${ }^{19}$. De la ca-

${ }^{16}$ Vid. art. 26 Legge 31 maggio 1995, n. 218, di riforma del sistema italiano di Diritto internazionale privato (Suppl. ord. GU Serie gen. 128 del 3 giugno 1995): "Promessa di matrimonio. 1. La promessa di matrimonio e le conseguenze della sua violazione sono regolate dalla legge nazionale comune dei nubendi o, in mancanza, dalla legge italiana”. El precepto se encuentra ubicado en el Titolo III («Diritto applicabile») y en el Capo IV («Rapporti di famiglia») de la Ley 218/1995. Vid. art. 45 de la Ley belga que contiene el Código de Derecho internacional privado de 16 julio 2004: «La promesse de mariage est régie: $1^{\circ}$ par le droit de l'Etat sur le territoire duquel l'un et l'autre des futurs époux ont leur résidence habituelle au moment de la promesse de mariage; $2^{\circ}$ à défaut de résidence habituelle sur le territoire d'un même Etat, par le droit de l'Etat dont l'un et l'autre des futurs époux ont la nationalité au moment de la promesse de mariage; $3^{\circ}$ dans les autres cas, par le droit belge». Este precepto se halla encuadrado en el Chapitre III de dicha Ley, titulado «Relations matrimoniales» y en la «Section 2. - Droit applicable à la promesse de mariage». Vid. Ley (Turquía) sobre el Derecho internacional privado y procesal (n. 5718) de 27 noviembre 2007, que entró en vigor el 12 de diciembre de 2007. Su art. 12 se ocupa de la promesa de matrimonio y afirma: "(1) The legal capacity to become engaged and the conditions thereof shall be governed by the respective national laws of the parties which are in force at the moment of engagement. (2) The provisions and consequences of the engagement are governed by the common national law or by Turkish law if the parties are of different nationalities". El texto puede verse en: https://www. ispramed.com/wp-content/uploads/2018/07/IPPL-Turkey.pdf.

${ }^{17}$ A. SARAVAlLe, "Articolo 26", en Riforma del sistema italiano di diritto internazionale privato legge 31 maggio 1995 n. 218 , Rivista di Diritto internazionale privato e processuale, 1995, pp. 1043-1046: "Ciò nonostante, le recenti leggi di riforma del diritto intemazionale privato italiana e turca hanno dedicato un'apposita norma alla promessa di matrimonio. La ragione della previsione di questa norma dev'essere allora ricercata, più in generale, nella volontà di predisporre una disciplina di conflitto completa ed analitica e in grado di por fine ad un 'antica querelle dottrina circa la piu corretta qualificazione dell'istituto".

${ }^{18}$ G. Balladore Pallieri, Diritto internazionale privato, en "Trattato di diritto civile e commerciale", Giuffrè, Milano, 1974, pp. 173-174: "vi è primo un istituto assai discusso: la promessa di matrimonio. Le maggiori discussioni al riguardo si appuntano sulla qualifica dell'atto: appartiene al diritto delle obbligazioni o al diritto di famiglia? Si sono messe in luce le incongruità dell'una e dell'altra soluzione".

${ }^{19}$ Y. Loussouarn / P. Bourel / P. De Vareilles-Sommières, Droit international privé, $10^{\mathrm{a}}$ ed., Paris, Dalloz, 2013, p. 391, n. 288: «La grande variété de conceptions qui règnent dans les différents systèmes juridiques a conduit aux rattachements les plus divers. Assimilée tantôt à un contrat ordinaire, tantôt à une convention d'ordre familial préparatoire au mariage ou à un élément du statut familial en raison des obligations qu'elle fait naître, tantôt enfin à un cas de responsabilité civile, la promesse de mariage est régie, suivant l'analyse que l'on en donne, soit par la loi contractuelle, soit par la loi personnel, soit par la loi 
lificación que se otorgue a la promesa de matrimonio dependerá la norma de conflicto aplicable y de ella y de su punto de conexión, depende, a su vez, cuál es la Ley sustantiva que regirá el fondo de la asunto. La ruptura de la promesa de matrimonio ha sido calificada, así, como un contrato, como una cuestión de régimen económico de los prometidos, como una cuestión familiar y para-matrimonial, como una cuestión familiar autónoma, como una cuestión relativa a la persona individual, como un hecho que da lugar a responsabilidad civil extracontractual y también, incluso, como una institución jurídica propia, que no encaja en ninguna de las categorías legales anteriores. El menú ofrece platos para todos los gustos.

13. Hasta hace pocos años, esto es, en un escenario en el que el Derecho internacional privado era una disciplina jurídica propia de cada Estado, los tribunales arrancaban de la tesis de la calificación lege fori. Ello significaba que los tribunales de un Estado calificaban la promesa de matrimonio con arreglo a su propio Derecho sustantivo. Así, por ejemplo, si en Derecho francés la promesa de matrimonio se considera un acto ilícito que produce responsabilidad civil extracontractual, entonces los tribunales franceses aplicaban las normas francesas de competencia internacional y la norma francesa de conflicto de leyes que fija la Ley estatal reguladora de las obligaciones extracontractuales. Del mismo modo, si en Derecho alemán la promesa de matrimonio se consideraba un acto propio del Derecho de familia, los tribunales alemanes aplicaban las normas alemanas de competencia internacional y la norma alemana de conflicto de leyes que fija la Ley estatal reguladora de las relaciones de familia. Y así, sucesivamente.

14. Ahora bien, en la actualidad, este enfoque que arrancaba de una calificación lege fori ha cambiado. Siempre con carácter previo y preferente, los tribunales de los Estados miembros de la UE deben tener presente la calificación que el Derecho europeo otorga a la promesa de matrimonio. Si el Derecho europeo considera que ésta, por ejemplo, genera obligaciones extracontractuales, se aplicarán las normas europeas que regulan la competencia judicial internacional y la norma europea de conflicto de leyes que fija la Ley estatal reguladora de las obligaciones extracontractuales.

15. Si el Derecho europeo no resulta aplicable, la cuestión debe enfocarse desde un punto de vista multi-jurisdiccional. En efecto, cada Derecho nacional puede calificar de modo distinto la promesa de matrimonio. El Derecho francés puede considerar que se trata de una cuestión de responsabilidad civil extracontractual, mientras que el Derecho alemán puede estimar que se trata de una cuestión de Derecho de familia. Esta situación puede conducir a paradojas, pues aunque dos Estados distintos dispongan de normas de conflicto idénticas, al calificar la cuestión de modo diferente, resultará que la Ley aplicable al fondo del asunto será distinta según se accione ante tribunales de un Estado o de otro. Así lo explica con claridad H. BATIFFOL sobre el previo ejemplo proporcionado por M. WoLFF ${ }^{20}$.

délictuelle». También B. Audit, Droit international privé, $5^{\mathrm{a}}$ ed., Issy-les-Moulineaux, LGDJ, 2006, p. 514: «Il est vrai que la localisation du délit peut faire difficultés en particulier lorsque les fiancés ne résident pas dans le même pays. Si l'on se prononce pour la loi du dommage, celui-ci, principalement d'ordre moral, pourra être considéré comme localisé au domicile de la victime». En ese mismo sentido, E. RABEL, The conflict of laws: A comparative study. Vol. 1: Introduction: Family Law, $2^{\mathrm{a}}$ ed., Ann Arbor, The university of Michigan press, Chicago, Callaghan \& company, 1958, pp. 215-221, esp. pp. 215-216.

${ }^{20} \mathrm{H}$. Batiffol, Aspects philosphiques du droit international privé, Paris, Dalloz, 1956, pp. 35-36: «Considérons par exemple avec Wolff le cas d'un Allemand rompant à Pans ses fiançailles avec une Allemande; l'action en dommages-intérêts de la fiancée est regardée par la règle allemande de conflit comme relevant de l'état des personnes, donc en l'espèce de la loi allemande; la règle française y voit (ou y verrait semble-t-il si la question se posait, étant donné la position du droit civil interne) une matière délictuelle, donc régie par la loi du lieu du délit, en l'espèce la loi française. Wolff estime que même devant un tribunal français la loi allemande peut être invoquée aussi bien que la loi française, car la règle de conflit française donnant compétence à la loi allemande pour le statut personnel des Allemands, doit accepter comme appartenant à ce statut tout ce que la loi allemande y englobe, et en particulier la mesure de la force obligatoire des fiançailles. Bien entendu la loi française pourra aussi être invoquée puisque la règle française de conflit donnant compétence à la loi du lieu du délit en matière délictuelle, la loi française du lieu de délit sanctionne la rupture de fiançailles sur le terrain délictuel. Le même raisonnement sur les règles de conflit allemandes montre que la même alternative existerait devant un tribunal allemand. Wolff en conclut très logiquement que la demanderesse s'appuiera à son choix sur l'une ou l'autre des deux lois qui admettent sa prétention. La logique de cette conclusion suffít à rendre suspectes les prémisses du raisonnement car elles se trouvent conduire ainsi obligatoirement à un résultat dont on peut apprécier la valeur: la demanderesse ayant le choix entre les deux lois, française et allemande, s'arrêtera évidemment à celle qui lui sera le plus favorable, en l'espèce probablement la loi allemande faisant écho 
16. En suma, bienvenidos todos a la batalla de calificaciones, una de las más fascinantes e intensas experiencias dogmáticas en Derecho internacional privado. Es el momento de averiguar cuál es la calificación correcta de la ruptura de la promesa de matrimonio en el Derecho internacional privado de la Unión Europea.

\section{Calificación de la promesa de matrimonio y de los esponsales en Derecho internacional privado europeo}

\section{A) Primacía de Derecho internacional privado europeo y calificación de la promesa de matrimonio}

17. Los tribunales españoles deben realizar la calificación de la promesa de matrimonio, a efectos del Derecho internacional privado, a partir del Derecho europeo. Ello es consecuencia de la primacía del mismo sobre los sistemas legales nacionales de Derecho internacional privado de los Estados miembros. En este punto del discurso, dos elementos previos son importantes.

En primer lugar, si el Derecho internacional privado europeo considera que la promesa de matrimonio debe ser calificada como una cuestión que pertenece a una determinación categoría jurídica, -»obligaciones contractuales», «obligaciones extracontractuales», «régimen económico matrimonial», etc.-, y que tal categoría jurídica está regulada por normas del Derecho internacional privado europeo, tales normas serán aplicables. En dicho supuesto, las normas españolas de Derecho internacional privado quedan totalmente desplazadas y no resultan aplicables.

En segundo lugar, en el supuesto de que, por el contrario, una vez que la promesa de matrimonio haya sido calificada con arreglo al Derecho europeo como pertenecientes a una categoría jurídica no regulada por el mismo, entonces la cuestión debe ser tratada desde una perspectiva nacional. En tal caso, los tribunales españoles deben calificar la promesa de matrimonio desde la óptica del Derecho sustantivo español (art. 12.1 CC). Una vez calificada con arreglo a los criterios del Derecho español, la promesa de matrimonio se regirá por la Ley designada por la norma de conflicto española correspondiente.

\section{B) El método unilateral europeo de calificación "reglamento por reglamento".}

18. El Derecho internacional privado europeo carece de una norma general que indique cómo resolver la cuestión de la calificación para determinar la norma de conflicto aplicable. Ahora bien, a pesar de ello, el legislador europeo proporciona una solución adecuada al siempre difícil e intrincado tema de la calificación. Como explica de modo muy sugestivo T. Vignal, cada reglamento europeo determina, de modo propio e independiente, la materia a la que es aplicable, esto, es, las concretas situaciones jurídicas internacionales cubiertas por el mismo ${ }^{21}$. El operador jurídico debe sólo comprobar que la situación jurídica concreta debatida aparece cubierta por un específico Reglamento europeo y si es así, el Reglamento en cuestión se aplicará y sus normas de conflicto fijarán la Ley estatal aplicable a la situación jurídica debatida.

19. Este método, como recuerdan A.-L. Calvo Caravaca / J. Carrascosa González, presenta tres ventajas indudables ${ }^{22}$. En primer lugar, es un método sencillo para el operador jurídico, que debe

à la tradition canonique qui raisons connues les fiançailles comme un premier élément du mariage, tandis que la qualification délictuelle française, avant tout soucieuse de la liberté des consentements le jour du mariage, rend plus lourde au demandeur la charge de la preuve qui porte à la fois sur la faute et le préjudice. C'est dire qu'on donne d'avance raisons au demandeur, ou plus précisément que le problème du conflit de lois est tranché d'office en sa faveur puisque c'est lui qui choisira, au mieux de ses intérêts, la loi applicable. Or, il n'y a aucune raison plausible de favoriser a priori le demandeur plutôt que le défendeur, et ce pour éviter de demandeur plutôt que le défendeur, et ce pour éviter de trancher le problème de conflit de lois».

${ }^{21}$ T. Vignal, Droit international privé, $4^{\mathrm{a}}$ ed., Paris, Sirey, 2017, pp. 44-49.

${ }^{22}$ A.-L. Calvo Caravaca / J. Carrascosa González, "Derecho aplicable (I). Técnicas de reglamentación. La norma de conflicto", en A.-L. Calvo Caravaca / J. Carrascosa GonzÁlez (directores), Tratado de Derecho internacional privado, primera edición, editorial Tirant Lo Blanch, València, vol. I, 2020, pp. 567-571. 
solamente tener presentes conceptos jurídicos europeos. En segundo lugar, es un método uniforme, pues todos los tribunales de todos los Estados miembros determinan del mismo modo el ámbito de aplicación de los reglamentos europeos y utilizan un catálogo único de calificaciones de las cuestiones jurídicas. En tercer lugar, es un método que, en teoría, no puede caer jamás en contradicciones. En efecto, al ser elaborados todos los reglamentos por el mismo legislador, -el legislador europeo-, toda cuestión litigiosa recibe una sola calificación y sólo un reglamento europeo es aplicable a cada cuestión litigiosa.

20. Este método unilateral europeo hace completamente inútiles las clásicas y decimonónicas teorías de la calificación lege fori y lege causae. Es irrelevante la calificación jurídica que la cuestión debatida reciba en la Lex Fori, esto es, en la Ley nacional del Estado miembro cuyos tribunales conocen del asunto. Es también irrelevante la calificación jurídica que la cuestión debatida reciba en la Lex Causae, esto es, en la Ley que rige el fondo de la promesa de matrimonio, sea ésta la que sea. Es indiferente, pues, la naturaleza jurídica de la cuestión en los Derechos nacionales. Lo único que es relevante es la calificación de este acto jurídico a la luz del Derecho de la UE. Puede afirmarse, así, que la calificación debe realizarse lege europae. El operador jurídico debe limitarse a atribuir a la promesa de matrimonio una "calificación europea". Así, podrá afirmar que la promesa de matrimonio hecha en Londres, por ejemplo, entre ciudadano suizo y ciudadano español, es, para el Derecho de la UE, "materia contractual", "materia extracontractual", "materia perteneciente a los regímenes económicos matrimoniales", "materia relativa a las relaciones familiares" o la que corresponda.

21. En esta perspectiva, cada Reglamento europeo precisa de modo propio e independiente, su ámbito de aplicación material, opera a través de dos elementos hermenéuticos fundamentales.

22. En primer lugar, se utiliza un elemento positivo: la definición europea de las materias reguladas. Para precisar las materias reguladas, las materias cubiertas por el Reglamento en cuestión, cada Reglamento europeo emplea, a su vez, dos técnicas precisas y distintas pero complementarias.

Según la primera técnica, la técnica del concepto general europeo, se define en abstracto, mediante conceptos generales, la materia regulada por cada reglamento de Derecho internacional privado: obligaciones extracontractuales, obligaciones contractuales, divorcio, sucesión por causa de muerte, etc. Estos "conceptos generales" se definen mos europeus, esto es, son conceptos autónomos, conceptos propios del Derecho de la UE que no se extraen de ninguna Ley nacional concreta. Así, existe un concepto europeo de "obligaciones contractuales", un concepto europeo de "obligaciones extracontractuales", un concepto europeo de "sucesión mortis causa", etc. Ahora bien, con frecuencia, los Reglamentos europeos no recogen estos "conceptos generales". En tales supuestos, recuerda S. BARIATTI, es el TJUE el que interpreta y define el concepto europeo de la materia objeto de regulación por un Reglamento de la UE (SAP Asturias 7 febrero 2018 [lesiones sufridas en hotel sito en Francia]) 23. Así, el Reglamento Roma I se aplica a las "obligaciones contractuales", pero no define tal concepto. Pues bien, el TJUE entiende que la noción "materia contractual" u "obligaciones contractuales" es autónoma y propia del Derecho de la UE y no debe definirse con arreglo al Derecho nacional de ningún Estado en concreto. El TJUE, en esta línea, por ejemplo, ha entendido que la "materia contractual" comprende los litigios derivados de un "compromiso libremente asumido por una parte frente a otra". Así, por ejemplo, una donación de inmueble está cubierta por el concepto "obligaciones contractuales" empleado por el citado Reglamento Roma I y también por el Reglamento Bruselas I-bis (art. 7.1 RB I-bis).

A tenor de la segunda técnica, la técnica de las cuestiones reguladas «en particular», cada reglamento europeo contiene, además, bajo la rúbrica "ámbito de la Ley aplicable”, una detallada lista de cuestiones que deben considerarse reguladas, en particular, por dicho texto legal. Se trata de una lista de cuestiones concretas, normalmente complicadas y de calificación discutida y discutible, que el le-

\footnotetext{
${ }^{23}$ S. BARIATTI, "Qualificazione e interpretazione nel diritto internazionale privato comunitario: prime riflessioni”, en S. BARIATtI (Coord.), La famiglia nel diritto internazionale privato comunitario, Milano, Dott. A. Giuffrè Editore, S.p.A., 2007, pp. 153-173. Vid. la muy interesante SAP Asturias 7 febrero 2018 [ECLI: ES:APO:2018:293], que aborda el caso de la calificación de ciertos daños producidos en un hotel situado en Francia como "contractuales" o "extracontractuales".
} 
gislador europeo califica como cuestiones cubiertas por el ámbito material del Reglamento en cuestión. Como explica con perspicacia M. FALLON, de ese modo directo se solventa el problema suscitado por ciertas cuestiones cuya calificación ha sido, tradicionalmente, objeto de disputa ${ }^{24}$. Así se puede apreciar en numerosas disposiciones legales europeas: art. 12 RR-I [obligaciones contractuales], art. 15 RRII [obligaciones extracontractuales], Cons. [10] RR-III [Ley aplicable al divorcio], art. 11 PLH 2007 [alimentos], etc. Por ejemplo, el art. 12.1 RR-I establece que la prescripción de la acción para reclamar la entrega de la cosa en la compraventa es una cuestión cubierta por la noción «materia contractual». Para el legislador europeo, ésta es una cuestión que debe calificarse como cuestión «contractual» y no como cuestión «procesal».

23. En segundo lugar, se utiliza un elemento negativo: las cuestiones expresamente excluidas del ámbito material de cada reglamento. Cada reglamento europeo excluye de su ámbito de aplicación material ciertas cuestiones que pueden suscitar dudas calificatorias. Ejemplo: el art. 1.2.c) RR-I indica que están excluidas del ámbito espacial de aplicación del Reglamento Roma I las «obligaciones que se deriven (...) de testamentos y sucesiones». Por ello, para el Derecho internacional privado europeo, un contrato sucesorio no puede ser calificado como «materia contractual» regulada por el Reglamento Roma I.

24. En conclusión, puede afirmarse que mediante el método unilateral europeo «Reglamento por Reglamento», el operador jurídico debe: (a) calificar, con arreglo a los elementos hermenéuticos que proporciona cada reglamento europeo y la jurisprudencia del TJUE, la cuestión de fondo debatida, la situación jurídica concreta de la que se trate; (b) aplicar, en consecuencia, el concreto Reglamento europeo que se auto-declara aplicable al caso concreto ya calificado, después sus normas de conflicto y por último la Ley estatal a la que éstas conducen.

25. Una vez calificada la cuestión debatida con arreglo a los criterios que proporciona el Derecho internacional privado europeo, dos resultados son posibles.

En primer lugar, puede que la cuestión quede cubierta y regulada por los reglamentos europeos de Derecho internacional privado. En dicho caso, las normas europeas de competencia internacional señalarán cuál es el tribunal competente para conocer de las reclamaciones derivadas de una promesa de matrimonio. Del mismo modo, las normas europeas de conflicto de leyes concretarán qué Ley estatal debe regular la promesa de matrimonio así como las consecuencias jurídicas del eventual incumplimiento de la misma.

En segundo lugar, puede suceder que la cuestión jurídica no quede cubierta por ningún concreto reglamento europeo. En tal supuesto, la competencia judicial internacional y la ley aplicable a la misma son cuestiones que deberán ser decididas con arreglo al Derecho internacional privado del Estado miembro cuyos tribunales conocen del asunto.

\section{La concreta calificación de la promesa de matrimonio en Derecho internacional privado europeo}

\section{A) Posibles calificaciones jurídicas de la cuestión}

26. En línea de principio, cuatro son las calificaciones posibles de la promesa de matrimonio y de los esponsales en Derecho internacional privado europeo.

En primer lugar, podría pensarse que la ruptura de la promesa de matrimonio y de los esponsales es una cuestión relativa al "régimen económico matrimonial" o al "régimen económico de las parejas registradas". Se aplicaría, entonces, el Reglamento (UE) 2016/1103 del Consejo de 24 de junio de 2016 por el que se establece una cooperación reforzada en el ámbito de la competencia, la ley aplicable, el reconocimiento y la ejecución de resoluciones en materia de regímenes económicos matrimoniales o bien el Reglamento (UE) 2016/1104 del Consejo de 24 de junio de 2016 por el que se establece una coo-

\footnotetext{
${ }^{24}$ M. FALlon, "La nueva Ley belga conteniendo el Código de Derecho internacional privado", REDI, 2004, pp, 821-836, con extrema claridad.
} 
peración reforzada en el ámbito de la competencia, la ley aplicable, el reconocimiento y la ejecución de resoluciones en materia de efectos patrimoniales de las uniones registradas ${ }^{25}$. Tales instrumentos legales fijarán, en ese caso, los tribunales estatales competentes para conocer de las reclamaciones por ruptura de una promesa de matrimonio y la Ley estatal reguladora del fondo de dicha cuestión.

En segundo lugar, podría también conjeturarse que la ruptura de la promesa de matrimonio y de los esponsales debe ser calificada como una cuestión relativa a la "materia contractual", porque se trata de un incumplimiento de obligaciones contractuales. En dicho supuesto, se aplicaría, para fijar los tribunales estatales competentes para conocer de las reclamaciones por ruptura de una promesa de matrimonio, el Reglamento Bruselas I-bis y en particular, su art. 7.126. Para determinar la Ley estatal aplicable a las consecuencias de la ruptura de una promesa de matrimonio, sería aplicable el Reglamento Roma ${ }^{27}$.

En tercer lugar, puede pensarse que la ruptura de la promesa de matrimonio y de los esponsales deben calificarse como una cuestión cubierta por la materia extracontractual. En dicho supuesto, para fijar los tribunales estatales competentes para conocer de las reclamaciones por ruptura de una promesa de matrimonio, sería aplicable el citado Reglamento Bruselas I-bis y en particular, su art. 7.2. Para concretar determinar la Ley estatal aplicable a las consecuencias de la ruptura de una promesa de matrimonio, sería aplicable el Reglamento Roma I y en particular su art. $4^{28}$.

En cuarto lugar, también puede aventurarse que la promesa de matrimonio y los esponsales deben calificarse como un supuesto específico de "relaciones familiares". Si éste fuera el caso, ello significaría que el Derecho internacional privado europeo carece de normas aplicables a dichas cuestiones y que se trata de una cuestión no regulada por el mismo. En tal caso, el Derecho internacional privado europeo no es aplicable y la determinación de los tribunales competentes y de la Ley aplicable la ruptura de una promesa de matrimonio se debe fijar con arreglo al Derecho internacional privado nacional del Estado miembro ante cuyos tribunales haya presentado la demanda. En este supuesto, la ruptura de una promesa de matrimonio debe ser calificada por el Derecho nacional de dicho Estado a fin de determinar la norma de competencia judicial internacional y la norma de conflicto de dicho Estado miembro que resultan aplicables a la cuestión.

27. Debe también subrayarse que, además, las disposiciones de los reglamentos europeos de Derecho internacional privado deben interpretarse las unas en relación con las otras, para evitar contradicciones y dotar de un sentido lógico y valorativo a dichos reglamentos. Todos los reglamentos europeos de Derecho internacional privado deben interpretarse y explicarse en sintonía y en armonía con los demás reglamentos europeos de Derecho internacional privado, como ha precisado la STJUE 11 junio 2015, C-649/13, Nortel, FD $26^{29}$. Ello evita solapamientos entre tales reglamentos, de modo que una cuestión jurídica no resulte regulada por varios reglamentos, sino por uno solo. En general,

\footnotetext{
${ }^{25}$ Reglamento (UE) 2016/1103 del Consejo de 24 de junio de 2016 por el que se establece una cooperación reforzada en el ámbito de la competencia, la ley aplicable, el reconocimiento y la ejecución de resoluciones en materia de regímenes económicos matrimoniales (DOUE L 183 de 8 julio 2016). Reglamento (UE) 2016/1104 del Consejo de 24 de junio de 2016 por el que se establece una cooperación reforzada en el ámbito de la competencia, la ley aplicable, el reconocimiento y la ejecución de resoluciones en materia de efectos patrimoniales de las uniones registradas (DOUE L 183 de 8 julio 2016).

${ }^{26}$ Reglamento (UE) n. 1215/2012 del Parlamento Europeo y del Consejo de 12 de diciembre de 2012 relativo a la competencia judicial, el reconocimiento y la ejecución de resoluciones judiciales en materia civil y mercantil (refundición) (DOUE L 351 de 20 diciembre 2012), conocido como Reglamento Bruselas I-bis.

${ }^{27}$ Reglamento (CE) 593/2008 del Parlamento Europeo y del Consejo de 17 de junio de 2008 sobre la ley aplicable a las obligaciones contractuales (Roma I) (DOUE L 177 de 4 julio 2008).

${ }^{28}$ Reglamento (CE) No 864/2007 del Parlamento Europeo y del Consejo de 11 de julio de 2007 relativo a la ley aplicable a las obligaciones extracontractuales («Roma II») (DOUE L 199 de 31 julio 2007).

${ }^{29}$ STJUE 11 junio 2015, C-649/13, Comité d'entreprise de Nortel Networks y otros [ECLI:EU:C:2015:384], FD 26: "En ese sentido el Tribunal de Justicia ya ha juzgado que los Reglamentos 44/2001 y 1346/2000 deben interpretarse de tal manera que se evite todo solapamiento entre las normas jurídicas que ambos instrumentos establecen, así como todo vacio jurídico. De este modo, las acciones que, en virtud del artículo 1, apartado 2, letra b), del Reglamento $n^{\circ} 44 / 2001$, estén excluidas del ámbito de aplicación de este último Reglamento, por relacionarse con «la quiebra, los convenios entre quebrado y acreedores y demás procedimientos análogos», entrarán en el ámbito de aplicación del Reglamento $n^{\circ} 1346 / 2000$. De modo simétrico, las acciones que no estén incluidas en el ámbito de aplicación del artículo 3, apartado 1, del Reglamento $n^{\circ}$ 1346/2000 entrarán en el ámbito de aplicación del Reglamento $n^{\circ} 44 / 2001 . . . ”$.
} 
los conceptos jurídicos de Derecho internacional privado empleados por varios reglamentos europeos deben ser interpretados del mismo modo, con el mismo significado. Es ésta la llamada "coherencia conceptual del Derecho internacional privado europeo", en palabras de J. BASEDOw y que se puede apreciar en el texto de los Cons. 7 y 17 RR-I y Cons. 7 RR-II y en la jurisprudencia del TJUE (STJUE 28 julio 2016, C-191/15, Amazon, FD 37; STJUE 21 enero 2016, C-359/14 y C-475/14, ERGO, FD 43) $)^{30}$. Como indica F. GARCIMARTín AlfÉrez, ésta es la regla general de interpretación ${ }^{31}$. A lo anterior conviene añadir que los términos empleados por los reglamentos europeos de Derecho internacional privado deben ser interpretados en modo propio. En especial, debe indicarse que el Derecho internacional privado no está condicionado ni tiene por qué seguir las definiciones del Derecho material europeo ni del Derecho material de los Estados miembros. La independencia conceptual del Derecho internacional privado, apunta L. DE Lima PinheIro, permite que este sector del Derecho cumpla su misión de manera más satisfactoria ${ }^{32}$.

\section{B) Calificación contractual}

28. Algunos tribunales, algunos autores y algunos sistemas jurídicos nacionales han considerado que la promesa de matrimonio debe considerarse un "contrato" o una obligación contractual unilateral. La consideración de la promesa de matrimonio como "contrato" es característica del tradicional Derecho internacional privado inglés, explica E. VITTA ${ }^{33}$. Es el contrato para contraer matrimonio: contract to marry, engagement to marry". También aceptan la naturaleza contractual de la promesa de matrimonio los Derechos de Estados que siguen, con más o menos convicción y sistema, la tradición del Common Law inglés. Es el caso de Sudáfrica, expone E. Spiro, tal y como se aprecia en el famoso caso "Guggenheim v. Rosenbaum", fallado por un tribunal sudadricano ${ }^{34}$. En Derecho sueco la promesa de matrimonio también ha sido considerada, tradicionalmente, un contrato, subraya A. WeILL ${ }^{35}$.

29. Esta calificación contractual es la lógica consecuencia de considerar que, en realidad, para el Derecho internacional privado inglés, el matrimonio es un contrato. Como explica J.D. GonzÁLEZ CAMPOS, si esa calificación contractual se acepta, deben aplicarse a la promesa de matrimonio, por analogía, las normas de Derecho internacional privado previstas para los contratos ${ }^{36}$.

${ }^{30}$ Vid. Cons. 7 RR-II: “(7) El ámbito de aplicación material y las disposiciones del presente Reglamento deben garantizar la coherencia con el Reglamento (CE) no 44/2001 del Consejo, de 22 de diciembre de 2000, relativo a la competencia judicial, el reconocimiento y la ejecución de resoluciones judiciales en materia civil y mercantil (5) (Bruselas I), y con los instrumentos que tratan sobre la ley aplicable a las obligaciones contractuales". Vid. Cons 7 RR-I: “(7) El ámbito de aplicación material y las disposiciones del presente Reglamento deben garantizar la coherencia con el Reglamento (CE) no 44/2001 del Consejo, de 22 de diciembre de 2000, relativo a la competencia judicial, el reconocimiento y la ejecución de resoluciones judiciales en materia civil y mercantil (Bruselas I), y el Reglamento (CE) no 864/2007 del Parlamento Europeo y del Consejo, de 11 de julio de 2007, sobre la ley aplicable a las obligaciones extracontractuales (Roma II)". Vid. STJUE 28 julio 2016, C-191/15, Verein für Konsumenteninformation vs. Amazon EU Sàrl [ECLI:EU:C:2016:612]; STJUE 21 enero 2016, C-359/14 y C-475/14, ERGO Insurance [ECLI:EU:C:2016:40].

${ }^{31}$ F.J. Garcimartín Alférez, “El Reglamento 'Roma I' sobre ley aplicable a las obligaciones contractuales: ¿Cuánto ha cambiado el Convenio de Roma de 1980?”, Diario La Ley, núm. 6957, Sección Doctrina, 30 mayo 2008, versión on line.

${ }^{32}$ L. DE Lima Pinheiro, “A interpretação no direito internacional privado", $C D T, 2020$, n.2, vol. 11, pp. 496-509.

${ }^{33}$ E. VITTA, Diritto internazionale privato vol. II, UTET, Torino, 1973, pp. 167-171, esp. p. 167: "Quanto alla legge regolatrice degli sponsali, $i$ vari sistemi positivi divergono tra loro. Il diritto inglese (ed il diritto svedese) considerano gli sponsali alla stregua di un contratto, la cui non esecuzione importa la responsabilità contrattuale del fidanzato recalcitrante; con la conseguenza che i giudici britannici sottoporranno la questione alla proper law of the contract".

${ }^{34}$ Caso «Guggenheim v. Rosenbaum», 1961 (4) S.A. 21 (W). Vid. E. SpIro, "Breach of Promise (Based on Guggenheim v. Rosenbaum", The International and Comparative Law Quarterly, 1962, vol. 11, n.1 (January 1962), pp. 260-266: “The view, held not only by the learned judge, that for the purposes of the conflict of laws the contract to marry should be treated like an ordinary contract is referred to by Professor Rabel as an "old" one. Indeed, if the view were correct, then the parties could, just as in ordinary contracts, choose in a direct way the law which should govern their contract to marry".

${ }^{35}$ A. Weill, "Fiançailles", Encyclopedie Dalloz droit international, París, 1968-69 (dir. Ph. Franceskakis), vol.II, 1969, pp. 22-24: «On conçoit l'application de la loi du contrat dans les pays qui considèrent les fiançailles comme un contrat. C'est le cas notamment du droit suédois».

${ }^{36}$ J.D. GonzÁlez Campos, "El matrimonio en el Derecho civil internacional", en M. Aguilar Navarro, Derecho civil in- 
30. El carácter contractual del matrimonio, y en consecuencia, de la promesa de matrimonio, deriva del Derecho canónico, que estuvo en vigor para toda Europa occidental durante más de quinientos años, explica P. FEDOzzi ${ }^{37}$. La visión canónica del matrimonio influyó, tras la Revolución francesa, en la regulación del matrimonio civil acogida en múltiples países europeos. Según muestra el clásico estudio de E. ENGDAHL, la concepción del matrimonio como contrato en Derecho internacional privado es consecuencia del impacto, en toda Europa, de las tesis de TomÁs SÁNCHEZ dE ÁvILA, insigne jesuita español nacido en Córdoba y fallecido en Granada. ToMÁs SÁNCHEZ DE ÁvILA gozó de gran autoridad y prestigio en todo lo concerniente a la configuración jurídica y sacramental del matrimonio. Expuso sus tesis en su obra Disputationum De Sancto Matrimonio Sacramento, fechada en 1602, obra de tal repercusión que los seminaristas de la época solían decir "si quieres saber más que el demonio, lee a Sánchez en De matrimonio" 38 . Este autor partió del carácter estrictamente territorial del Derecho Canónico y formuló la regla Lex Loci Celebrationis para el matrimonio: éste se rige, tanto en lo relativo a las condiciones de forma como en las condiciones de fondo, -consentimiento matrimonial, capacidad nupcial-, por la Ley del país donde el matrimonio se hubiera celebrado. Ya en la Edad Media los canonistas y los juristas buscaban un "modelo estable de matrimonio" para la Iglesia Católica frente al matrimonio romano, que rea una relación de puro hecho, desprovisto de solemnidades, basado en un consentimiento continuo y en la mera cohabitación (honor matrimonii). Para ello, nada mejor que recurrir a la figura del contrato. El Papa Nicolás I había aludido a la máxima consensus facit nuptias, -tomada del gran jurisconsulto romano UlPIANO-, en el año 866. Por eso, desde el siglo XI, se exalta el carácter contractual del matrimonio. Tanto fue así, que canonistas y teólogos aceptaban pacíficamente que la "naturaleza jurídica del matrimonio" era la de un contrato ${ }^{39}$. Lo que se discutía era el carácter de tal contrato: ¿contrato consensual o contrato real?. No obstante, es muy probable que, a su vez, Tomás SÁnchez se apoyara en las soluciones que unas decenas de años antes había desarrollado D. DE Covarrubias y Leyva. En efecto, durante el período de aplicación exclusiva en Europa del Derecho canónico a la formación del matrimonio, existían ciertas variantes entre Estados y Provincias sobre la "forma" de prestar el consentimiento solemne al matrimonio. Hay que recordar, con P. MAYER, que en la Edad Media, cada obispo gozaba de un cierto poder legislativo, -sin perjuicio del Derecho canónico, único en todo el mundo-, por lo que surgen problemas de determinación de la Ley aplicable. Los canonistas realizan "glosas" a las Decretales, como las hechas a la Decretal A Nobis (Clemente III), en 1193, y Ut animarum (Bonifacio VIII), en 1298. Ello explica que fueran los canonistas los primeros que se ocuparan del tema de la "Ley aplicable" a la formación del matrimonio. D. CovarRuBias y Leyva se preocupó por la cuestión y apuntó también la solución de la aplicación de

ternacional, Facultad de Derecho, Universidad Complutense, Madrid, $4^{\text {a }}$ ed,. 1975 (reimpresión 1979), pp. 243-371, esp. pp. 2598-290: "En tercer lugar, se admite una calificación contractual de la promesa; y la ruptura se considera como un incumplimiento contractual. Posición que ha sido mantenida por la jurisprudencia inglesa desde el caso «Hansen c. Dixon» hasta las últimas decisiones en el tema; y su justificación radica en una analogía con la propia concepción contractual del matrimonio".

${ }^{37}$ P. Fedozzi, Il diritto internazionale privato: Teorie generali e diritto civile, Cedam, Padova, 1939, pp. 402-455: "Se la questione si presenta davanti al giudice italiano questi potrà essere in dubbio se gli sponsali debbano, secondo la prevalente dottrina canonistica accolta in alcune legislazioni, considerarsi come un contratto preliminare...".

${ }^{38}$ E. EnGDAHL, "Proposal for a Benign Revolution in Marriage Law and Marriage Conflicts Law”, Iowa Law Review, 1969, pp. 56-68; ID., "The Canonical and Metaphysical Background of the Classic Dutch Marriage Conflicts Rule, NILR, 1968, pp. 42-67.

${ }^{39}$ La construcción del matrimonio como un contrato y su repercusión para el Derecho internacional privado se puede seguir en el clásico y admirable trabajo de E. EnGDAHL, "Proposal for a Benign Revolution in Marriage Law and Marriage Conflicts Law", Iowa Law Review, 1969, pp. 56-68; ID., "The Canonical and Metaphysical Background of the Classic Dutch Marriage Conflicts Rule, NILR, 1968, pp. 42-67; J.D. GonzÁlez CAMPos, "El matrimonio en el Derecho civil internacional", en M. Aguilar Navarro, Derecho civil internacional, Facultad de Derecho, Universidad Complutense, Madrid, $4^{\mathrm{a}}$ ed,. 1975 (reimpresión 1979), pp. 243-371; J. CARrascosa GonZÁlez, Matrimonio y elección de Ley (estudio de Derecho internacional privado), Ed. Comares, Granada, 2000, pp. 45-49; S. Adroher Biosca, Forma del matrimonio y Derecho internacional privado, Ed.Bosch, Barcelona, 1993, pp. 45-49, E. CORECCO, "Die Lehre der Untrennbarkeit des Ehevertrages vom Sacrament im Lichte des scholastischen Prinzips 'Gratia perficit, non destruit naturam'”, Archiv für Katholisches Kirchenrecht, n.143, 1974, p. 435; A. Bernárdez Cantón, Curso de Derecho matrimonial Canónico, Tecnos, Madrid, 5ª ed., 1986, pp. 25-26 y 44-48; J. GAUDEMEt, "El vínculo matrimonial. Incertidumbre el la Alta Edad Media", en AA.Vv., Matrimonio y Divorcio, Salamanca, 1974, pp. 8790; J. Fornés, Derecho matrimonial canónico, Tecnos, Madrid, 1990, pp. 91-97; A. Molina Melí / M. Elena Olmos Ortega, Derecho matrimonial canónico, sustantivo y procesal, Civitas, Madrid, 1985, pp. 88-91; S. CARrión, Historia y futuro del matrimonio civil en España, Ed.RDP, Edersa, Jaén, 1977, pp. 3-8; DE SMET, De sponsalibus et Matrimonio, Brujas, 1927, 4ª ed., pp. 387-390; M. REQUeJo IsIDRo, Ley local y forma de los actos en el DIPr. español, Eurolex, Madrid, 1998, pp. 284-316. 
la Ley del país de celebración del matrimonio (Lex Loci Celebrationis), en clara imitación de las reglas estatutarias relativas a los contratos. Legistas y canonistas, que enseñaban en las misma Universidades, solían coincidir en las soluciones de DIPr., expone brillantemente el citado P. MAYER ${ }^{40}$.

31. El carácter contractual de la promesa de matrimonio en Derecho internacional privado inglés fue defendido por J. WestlaKe en su clásico tratado ${ }^{41}$. En este sentido, la famosa sentencia Kremezi vs. Ridgeway (1949) consideró que la promesa de matrimonio tenía naturaleza de "contrato" ${ }^{42}$. La sentencia abordó el caso de una doble promesa de matrimonio, -la segunda sustituyó a la primera-, en cuya virtud un oficial inglés, Tom Ridgeway, prometió matrimonio a una joven griega con residencia en Atenas, Liana Kremezi, conocida como "la dama de Atenas", "the maid of Athens". La primera promesa tuvo lugar en Grecia y la segunda en Londres. Los acuerdos carecían de una elección de ley aplicable a la misma. El tribunal inglés estimó que ambas promesas de matrimonio constituían un contrato (= "agreement to marry") y buscó la Ley estatal apropiada a la misma (= the proper Law). Según los tribunales ingleses, dicha Ley, la Ley del país más conectado con el caso (the proper law of the contract) era, a falta de indicación al respecto de las partes, la Ley del país donde los sujetos habían pensado establecer su primer domicilio conyugal, Inglaterra, como ha explicado N. BosChIERo ${ }^{43}$. Se trata del país de ejecución de la promesa de matrimonio. El tribunal aplicó el Derecho inglés y la dama de Atenas obtuvo una indemnización de 10.000 libras esterlinas, una suma muy considerable. El hecho causó un fuerte impacto social, tanto que se publicó en la prensa de la época ${ }^{44}$. El mismo criterio, -ley del país del domicilio conyugal proyectado-, fue aplicado en el precedente caso Hansen vs. Dixon (1906) ${ }^{45}$. En el caso "Guggenheim v. Rosenbaum", fallado por un tribunal de Sudáfrica, quedó claro que the proper law of the contract suele ser, en efecto, en los sistemas legales anglosajones, el país donde el contrato debe ejecutarse. Ello se concreta, en los casos de ruptura de promesa matrimonial, en el país donde los prometidos tenían intención de instalar el domicilio conyugal ${ }^{46}$.

${ }^{40}$ P. MAYER / V. Heuzé, Droit international privé, 11ª ed., Issy-les-Moulineaux, LGDJ, 2014, pp. 48 y 359.

${ }^{41}$ J. Westlake, A Treatise on Private International Law, Or The Conflict of Laws, with Principal Reference to Its Practice in the English and Other Cognate Systems of Jurisprudence, Editor W. Maxwell, 1858, pp. 315-333 y J. WestLake, Traité de droit international privé, traducción de la $5^{\text {a }}$ edición (1912), por Paul Goulé, Paris, Librairie de la société du Recueil Sirey, 1914, n. 212 y 224

${ }^{42}$ Kremezi v. Ridgway [1949] 1 All E. R. 662. Vid. P.R.H. Webb / D.J. Latham Brown, "Engagements to Marry and the Conflict of Laws", The International and Comparative Law Quarterly, vol. 15, n. 4, 1966, pp. 947-995, así como P.M. NORTH, "Varying the proper law", Multum Non Multa. Festschrift für Kurt Lipstein aus Anlass seines 70. Geburtstages, Heidelberg, Karlsruhe, 1980, pp. 205-220. También E. RABEL, The conflict of laws: A comparative study. Vol. 1: Introduction: Family Law, $2^{\mathrm{a}}$ ed., Ann Arbor, The university of Michigan press, Chicago, Callaghan \& company, 1958, pp. 215-221, esp. p. 216.

${ }^{43}$ N. Boschiero, “Art. 26”, en S. Bariatti (a cura di), Legge 31 maggio 1995 n. 218, Riforma del sistema italiano di diritto internazionale privato. Commentario, en Nuove leggi civili commentate, 1996, pp. 1149-1156. En este sentido se orienta cierta antigua jurisprudencia inglesa. En el caso Hansen vs. Dixon, (1906) 96 L.T. 32, (1906) 23 T.L.R. 56, el tribunal señaló que era indiferente el lugar donde la promesa de matrimonio se hubiera hecho o formalizado, puesto que lo relevante era, a falta de elección hecha por las partes sobre la Ley aplicable a la promesa de matrimonio, el lugar donde las partes tenían la intención de situar el hogar matrimonial. E. RABEL, The conflict of laws: A comparative study. Vol. 1: Introduction: Family Law, $2^{\mathrm{a}}$ ed., Ann Arbor, The university of Michigan press, Chicago, Callaghan \& company, 1958, pp. 215-221, esp. p. 216.

${ }^{44}$ La solución judicial del caso vio la luz en numerosos periódicos el día 25 febrero 1949, por ejemplo, en The Camberra Times. Se trataba de una suma muy elevada. La dama de Atenas afirmó que si el oficial Graeme le pagaba 2200 libras de modo inmediato, no exigiría el resto de la suma. De se modo, con su magnánimo gesto, ella evitó la total bancarrota de Thomas Graeme: “ $£ 10,500$ AWARDED GREEK GIRL FOR BREACH OF PROMISE LONDON, Thursday. Liana Maria Kremezi, 23, of Greece, known as "The Maid of Athens" for her work in the war-time resistance movement, was yesterday awarded $£ 10,500$ damages and costs against Lieutenant-Commander Thomas Graeme ... The £10,500 awarded to the plaintiff is one of the heviest amounts warded in Britain in a brech of promise case (...). Miss Kramezi's s claim included special damages of $£ 17,446$ which, she said, she has spent on her trousseau. Commenting on her action, Miss Kremezi said: "England has returned to me my great love for her. As for Tom Ridgeway, I am very sorry indeed. But I had to bring the action to clear my father's name. "In spite of his actions, such a great love as mine has been, cannot be wholly washed away in a moment". Reuter quotes her as adding, "In a small corner of my heart, I feel a maternal affection for him, like a mother feels for a child who has behaved badly". El texto de la noticia tal y como fue publicada por The Camberra Times puede verse en: https://trove.nla.gov.au/newspaper/article/2791757.

${ }^{45}$ Hansen vs. Dixon, (1906) 96 L.T. 32, (1906) 23 T.L.R. 56.

${ }^{46}$ E. SPIRo, "Breach of Promise (Based on Guggenheim v. Rosenbaum", The International and Comparative Law Quarterly, 1962, vol. 11, n.1 (January 1962), pp. 260-266: “According to both English and South African law the proper law of the con- 
32. En otros países también ha sido defendida la naturaleza contractual de la promesa de matrimonio. Así, un sector minoritario de la doctrina italiana consideró, en su momento, que los esponsales constituían un contrato, como recuerda E. VITTA ${ }^{47}$. Del mismo modo, cierta jurisprudencia suiza también se inclinó por esta calificación contractual de la promesa de matrimonio, según indica E. RABEL ${ }^{48}$. Del mismo modo, incluso en la doctrina española antigua y no tan antigua se encuentran autores partidarios de la calificación de los esponsales y de la promesa de matrimonio como un "contrato". Antes del Código civil español de 1889, dicha calificación contractual conducía a la aplicación, a la promesa matrimonial, de la Ley del país de celebración del contrato. Era ésta la solución conflictual recogida en la Ley 15, título 14, Partida III de las Partidas alfonsinas, texto legal aplicable antes del Código civil español de 1889 e incluso tras el mismo, pues dicho código carecía de una norma de conflicto que precisara cuál era la ley aplicable a los contratos internacionales. Esta calificación contractual fue sostenida, por ejemplo, por J.R. DE OrúE y ARREgui ${ }^{49}$. También J.A. TomÁs Ortiz dE la Torre consideró que los esponsales debían regirse por la Ley determinada con arreglo a la norma de conflicto que rige las obligaciones contractuales ${ }^{50}$. Del mismo modo, aunque sin verdadera convicción ni sistema, afirma M. DE LASALA LLANAS que los esponsales y la promesa de matrimonio constituyen un contrato y se rigen por la Ley española si tales declaraciones se han realizado en España (lex loci contractus) y se rigen por la ley nacional común de los prometidos en el caso de que ambos ostenten la misma nacionalidad, ya que ésa es la "regla en materia de obligaciones convencionales, por presunción de su voluntad" el siglo XIX debía decidir si las reclamaciones derivadas de ruptura de los esponsales eran competencia de la jurisprudencia civil o eclesiástica, también apostaba, en aquellos tiempos, por el carácter de los mismos como un «contrato» ${ }^{52}$. Por si fuera poco, y para introducir todavía más variedad y caos en medio

tract is the law of the country which the parties have agreed or intended or are presumed to have intended shall govern it; and in the case of a contract concluded in one country to be performed in another, it can be presumed, in the absence of an express term or any other indication to the contrary, that the proper law is the law of the latter (lex loci solutionis). Applying these principles, the learned judge found on the proved facts that the proper law of the contract to marry was the law of South Africa. The irresistible inference from all the facts appeared to the learned judge to be that both parties intended that the law of South Africa, where they were to rejoin one another as soon as possible and arrange to get married, should govern their contract, and that they could not possibly have intended that the New York law should apply to their relationship, for which conclusion the learned judge found strong support in the decision in Hansen Dixon".

${ }^{47}$ E. VITTA, Dirito internazionale privato e processuale, $3^{\mathrm{a}}$ ed., Torino, UTET, 1989, pp. 215-216: “Cominciando dal matrimonio, conviene soffermarsi dapprima sulla promessa di matrimonio, o sponsali. Un'opinione minoritaria ritiene che la promessa di matrimonio costituisca un contratto e cada pertanto sotto le leggi di cui all'art. $25,1^{\circ}$ comma, oppure, volta a volta, che dia luogo ad obbligazioni 'ex lege', essendo quindi regolata dal $2^{\circ}$ comma dello stesso articolo (le due soluzioni sono state successivamente proposte dal Balladore Pallieri)". En sentido favorable a la calificación de la promesa como "contrato" a efectos de precisar la Ley aplicable a la forma de la misma, vid. T. BALlarino, Diritto internazionale privato, Cedam, Padova, 1982, pp. 706-707: "Poiché la promessa di matrimonio ha un carattere indiscutibilmente contrattuale, verrà in considerazione anche per essa la legge regolatrice della forma. Ciò, tuttavia, sempre e soltanto nei limiti in cui la forma costituisca una condizione di validità della fattispecie negoziale e non per effetti ulteriori, come avviene nell'art. 81 del nostro codice civile".

${ }^{48}$ E. RABel, The conflict of laws: A comparative study. Vol. 1: Introduction: Family Law, $2^{\mathrm{a}}$ ed., Ann Arbor, The university of Michigan press, Chicago, Callaghan \& company, 1958, pp. 215-221, esp. p. 216, nota [4].

49 J.R. De Orúe y Arregui, Manual de Derecho internacional privado, $3^{\mathrm{a}}$ ed., Madrid, Ed.Reus, 1952, p. 642: “respecto a la ley aplicable, dado el carácter contractual de los esponsales, se regirán por la 'lex loci contracti' propia del pais en que se celebraron, ley que determinara la concesión y forma de solicitarse las indemnizaciones».

${ }^{50}$ J.A. Tomás Ortiz de la Torre, "Celebración del matrimonio", en M. Aguilar Benítez de Lugo y otros, Lecciones de Derecho civil internacional, Ed. Tecnos, Madrid, 1996, pp. 88-116, esp. p. 94: “... pensamos que habrian de calificarse los esponsales como obligación convencional y por tanto, la norma de colisión correspondiente debe ser la aplicable".

${ }^{51}$ M. De Lasala Llanas, Sistema español de Derecho civil internacional e interregional, Ed. Rev. Derecho privado, Madrid, 1933, pp. 110-111: "Para los extranjeros, no tendrá aplicación la mencionada regla, si son de distinta nacionalidad, pues en este caso la obligación se rige por la lex loci contractus, que, en la hipótesis, es la ley española. Cuando los prometidos sean del mismo país, regirá la ley de su nacionalidad, como es regla en materia de obligaciones convencionales, por presunción de su voluntad".

${ }^{52}$ STS 13 enero 1879, Jurisprudencia Civil, vol. 41, caso Pérez vs. Rodríguez, pp. 23-24 y J. Puente EgIDo, Derecho internacional privado español, doctrina legal del Tribunal Supremo, Ed. RDP, Madrid, 1981, pp. 748-449: "Considerando que las cuestiones que surgen acerca del cumplimiento de un contrato celebrado conforme á las leyes y á las buenas costumbres deben resolverse con arreglo á lo pactado, porque es la ley principal para las partes; Considerando que si D. José Rodríguez López prometió casarse con Doña Josefa Pérez Salgueiro, obligándose en otro caso á entregarla 5.000 pesetas por razón de perjuicios, claro y evidente es que no habiendo cumplido el primer extremo del contrato se halla obligado á cumplir el segundo...". 
de esta confusión calificatoria, algunos autores, como W. GolDSChMiDT, estimaron que los esponsales eran, para el Derecho español, "contratos de Derecho de familia", y debían regirse por las normas de Derecho internacional privado que rigen estos contratos propios del Derecho de familia ${ }^{53}$. En tal sentido el autor citado defendió la aplicación de las normas que fijan la ley aplicable a las capitulaciones matrimoniales para los efectos económicos de los esponsales y la promesa de matrimonio y las normas que rigen los efectos personales del matrimonio, por analogía, para los efectos personales derivados de la promesa matrimonial y los esponsales ${ }^{54}$.

33. Todas las consideraciones anteriores sobre la posible calificación contractual de la ruptura de la promesa de matrimonio sólo son válidas en, sin embargo, en el marco de concretos sistemas jurídicos nacionales. En Derecho internacional privado europeo debe razonarse de modo diferente, esto es, en un modo europeo, liberado de conceptos, definiciones y naturalezas jurídicas nacionales de la promesa de matrimonio.

34. Podría pensarse que los esponsales y la promesa de matrimonio son instituciones jurídicas cubiertas por la "materia contractual" definida en sentido europeo. Para analizar la cuestión es preciso arrancar de dos previos.

Primero: la noción "materia contractual" debe definirse en términos autónomos, propios del Reglamento Bruselas I-bis y del Reglamento Roma I, propios, en definitiva, del Derecho internacional privado europeo. Así lo ha indicado el TJUE en copiosa jurisprudencia ${ }^{55}$. En consecuencia, para determinar si el objeto del litigio constituye una "materia contractual" no debe recurrirse al concepto que sobre tal noción se tenga en los Derechos nacionales de los Estados miembros, - el concepto de "contrato" y de "obligaciones contractuales" en Derecho inglés, español o francés-, sino al concepto europeo de materia contractual.

Segundo: el TJUE ha señalado que la "materia contractual", definida en sentido europeo, comprende los litigios derivados de un "compromiso libremente asumido por una parte frente a otra". Una inmensa masa de constante jurisprudencia del TJUE así lo indica ${ }^{56}$. Basta, pues, con que se pueda iden-

${ }^{53}$ W. Goldschmidt, Sistema y filosofia del Derecho internacional privado, t.I, Ed.Bosch, Barcelona, 1948, pp. 227-229: "Si en el problema de calificación procediera, por ende, la aplicación de la doctrina de la "lex civilis fori", habríamos de acudir a las normas de colisión sobre contratos del Derecho de familia".

${ }^{54}$ W. Goldschmidt, Sistema y filosofia del Derecho internacional privado, t.I, Ed.Bosch, Barcelona, 1948, pp. 227-229: “A los efectos patrimoniales de los esponsales de futuro, sobre todo al deber de devolver los regalos, así como a la obligación de la parte culpable de indemnizar a la parte abandonada, debe aplicarse el Derecho al que las partes se han sometido mediante posibles capitulaciones prenupciales. Si no hubiese tales capitulaciones, debe aplicarse el Derecho nacional del futuro marido en el momento de la celebración de los esponsales de futuro, en analogía la reglamentación patrimonial del matrimonio (...). A los efectos personales de los esponsales de futuro debe aplicarse el Derecho mudadizo del futuro marido, igualmente en analogía a la regulación de similares problemas en el Derecho matrimonial".

${ }^{55}$ STJCE 22 marzo 1983, 34/82, Peters vs. Zuid Nederlandse Aannemers Vereniging, Recueil, 1983, pp. 987-1012 [ECLI:EU:C:1983:87];STJCE 8 marzo 1988,9/87,Arcadovs. Haviland,Recopilación, 1988,pp.1539-1556[ECLI:EU:C:1988:127]; STJCE 27 septiembre 1988, 189/87, Kalfelis vs. Schröder, Recopilación, 1988, pp. 5565-5588 [ECLI:EU:C:1988:459]; STJCE 17 junio 1992, C-26/91, Jakob Handte vs. Mecano-Chimoques, Recopilación, 1992, pp. 3967-3996. [ECLI:EU:C:1992:268]; STJCE 19 mayo 1998, C-351/96, Drouot assurances SA vs. Consolidated metallurgical industries (CMI industrial sites), Protea assurance, Groupement d'intérêt économique (GIE) Réunion européenne, Recopilación, 1998, p. I-3075. [ECLI:EU:C:1998:509]; STJCE 17 septiembre 2002, C-334/00, Fonderie Officine Meccaniche Tacconi SpA vs. Heinrich Wagner Sinto Maschinenfabrik GmbH (HWS), Recopilación, 2002, p. I-07357, [ECLI:EU:C:2002:499]; STJCE 1 octubre 2002, C-167/00, Verein für Konsumenteninformation vs. Karl Heinz Henkel, Recopilación, 2002, p. I-8111. [ECLI:EU:C:2002:555]; STJCE 5 febrero 2004, C-265/02, Frahuil SA vs. Assitalia SpA., Recopilación, 2004, p. I-1543 [ECLI:EU:C:2004:77]; STJUE STJUE 14 marzo 2013, C-419/11, Česká spořitelna, a.s. vs. Gerald Feichter. [ECLI:EU:C:2013:165]; STJUE 20 abril 2016, C-366/13, Profit Investment SIM SpA [ECLI:EU:C:2016:282], FD 53; STJUE 15 junio 2017, C-249/16, Saale Kareda vs. Stefan Benkö, [ECLI:EU:C:2017:472], FD 28; STJUE 7 marzo 2018, C-274/16, C-447/16 y C-448/16, Air Nostrum [ECLI:EU:C:2018:160]; FD 58; STJUE 4 octubre 2018, C-337/17, Feniks sp. z o.o. vs. Azteca Products \& Services, S.L., [ECLI:EU:C:2018:805], FD 38.

${ }^{56} \mathrm{Vid}$. como pronunciamientos más destacados en torno al concepto de "materia contractual" en el Derecho internacional privado europeo, STJCE 22 marzo 1983, 34/82, Peters vs. Zuid Nederlandse Aannemers Vereniging, Recueil, 1983, pp. 9871012 [ECLI:EU:C:1983:87]; STJCE 17 junio 1992, C-26/91, Jakob Handte vs. Mecano-Chimoques, Recopilación, 1992, pp. 3967-3996. [ECLI:EU:C:1992:268]; STJCE 17 septiembre 2002, C-334/00, Fonderie Officine Meccaniche Tacconi SpA vs. Heinrich Wagner Sinto Maschinenfabrik GmbH (HWS), Recopilación, 2002, p. I-07357, [ECLI:EU:C:2002:499]; STJCE 
tificar una obligación jurídica libremente asumida por una parte frente a otra, aunque esa otra parte sea indeterminada o no haya intervenido en un acuerdo o pacto con la persona que libremente se obliga o no exista "contrato" entre ellas (auto TJUE 13 febrero 2020, C-606/19, Iberia, FD 33; STJUE 26 marzo

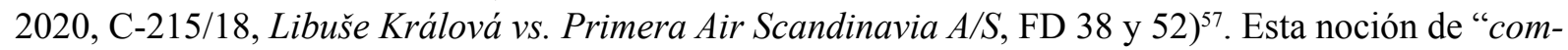
promiso libremente asumido por una parte frente a otra" es amplia (AAP Zaragoza 11 octubre 2007 [transporte de pasajeros] $)^{58}$. Para el Derecho europeo, en realidad, no es el contrato lo que crea las obligaciones contractuales. Éstas nacen de la voluntad unilateral y libre de cada parte. La voluntad unilateral y libre de una persona, dirigida a otra persona, es la que crea la "materia contractual".

35. Así las cosas, podría pensarse que los esponsales y la promesa de matrimonio son instituciones jurídicas cubiertas por la "materia contractual" tal y como ha sido definida en sentido europeo. Podría aducirse, en dicho sentido, que la obligación asumida por una persona que se compromete libremente a contraer matrimonio (= "promesa de matrimonio") y que las obligaciones de los sujetos que se comprometen a celebrar matrimonio entre ellos (= "esponsales") son compromisos voluntariamente aceptados por tales personas. Como tales, deberían constituir, desde el punto de vista del Derecho internacional privado europeo, un caso típico de "obligaciones contractuales". Esta posición conduciría a aplicar las normas de Derecho internacional privado europeo que regulan las obligaciones contractuales y no las que rigen las relaciones familiares y matrimoniales. El Reglamento Bruselas I-bis y el Reglamento Roma I serían aplicables, por tanto, a las reclamaciones por ruptura de una promesa de matrimonio con carácter internacional. Sin embargo no es así. Existen poderosas razones que permiten afirmar que las reclamaciones derivadas de la ruptura de la promesa de matrimonio no están incluidas en la materia contractual propia del Derecho europeo.

36. En primer lugar, aunque pueda parecer lo contrario, la promesa de matrimonio es un compromiso libremente asumido pero no tiene carácter jurídico, sino moral y/o emocional. La palabra "compromiso", empleada por la jurisprudencia del TJUE, hace referencia a una obligación de contenido legal, a una obligación que es exigible porque la ley así lo indica. Para negar el carácter jurídico del compromiso asumido en una promesa de matrimonio basta hacer referencia a los siguientes argumentos.

En primer lugar, el art. 9 de la Carta de los derechos fundamentales de la Unión Europea hecha en Niza el 7 de diciembre de 2000 (2007/C 303/01), bajo el rótulo de "Derecho a contraer matrimonio y derecho a fundar una familia", afirma que "se garantizan el derecho a contraer matrimonio y el derecho a fundar una familia según las leyes nacionales que regulen su ejercicio" ${ }^{59}$. Ese derecho subjetivo de

\footnotetext{
5 febrero 2004, C-265/02, Frahuil SA vs. Assitalia SpA., Recopilación, 2004, p. I-1543 [ECLI:EU:C:2004:77]; STJCE 19 mayo 1998, C-351/96, Drouot assurances SA vs. Consolidated metallurgical industries (CMI industrial sites), Protea assurance, Groupement d'intérêt économique (GIE) Réunion européenne, Recopilación, 1998, p. I-3075. [ECLI:EU:C:1998:509]; STJCE 20 enero 2005, C-27/02, Petra Engler vs. Janus Versand GmbH, Recopilación, 2005, p. I-499 [ECLI:EU:C:2005:33], FD 51; STJUE 14 marzo 2013, C-419/11, Česká spořitelna, a.s. vs. Gerald Feichter. [ECLI:EU:C:2013:165], FD 47; STJUE 10 septiembre 2015, C-47/14, Holterman Ferho Exploitatie BV, Ferho Bewehrungsstahl GmbH, Ferho Vechta GmbH, Ferho Frankfurt GmbH vs. Friedrich Leopold Freiherr Spies von Büllesheim, [ECLI:EU:C:2015:574], FD 52; STJUE 21 enero 2016, C-359/14 y C-475/14, ERGO Insurance [ECLI:EU:C:2016:40], ERGO, FD 44; STJUE 21 abril 2016, C-572/14, AustroMechana Gesellschaft zur Wahrnehmung mechanisch-musikalischer Urheberrechte GmbH vs. Amazon, FD 35; STJUE 15 junio 2017, C-249/16, Saale Kareda vs. Stefan Benkö, [ECLI:EU:C:2017:472], FD 28; STJUE 7 marzo 2018, C-274/16, C-447/16 y C-448/16, Air Nostrum [ECLI:EU:C:2018:160], FD 60; STJUE 8 mayo 2019, C-25/18, Brian Andrew Kerr vs. Pavlo Postnov, Natalia Postnova, [ECLI:EU:C:2019:376], FD 24; STJUE 4 octubre 2018, C-337/17, Feniks sp. z o.o. vs. Azteca Products \& Services, S.L., [ECLI:EU:C:2018:805] FD 39; STJUE 5 diciembre 2019, C-421/18, Ordre des Avocats du barreau de Dînant vs. $J N$, [ECLI:EU:C:2019:1053], FD 26; Auto TJUE 19 novembre 2019, C-200/19, INA-Industrija nafte d.d. y otros vs. Ljubljanska banka d.d., [ECLI:EU:C:2019:985], FD 30; STJUE 11 noviembre 2020, C-433/19, Ellmes Property Services Limited vs. SP, [ECLI:EU:C:2020:900], FD 37; Auto TJUE 13 febrero 2020, C-606/19, flightright GmbH vs. Iberia, [ECLI:EU:C:2020:101], FD 33; STJUE 26 marzo 2020, C-215/18, Libuše Králová vs. Primera Air Scandinavia A/S, [ECLI:EU:C:2020:235], FD 38 y 52.

${ }^{57}$ Auto TJUE 13 febrero 2020, C-606/19, flightright GmbH vs. Iberia, [ECLI:EU:C:2020:101]; STJUE 26 marzo 2020 , C-215/18, Libuše Králová vs. Primera Air Scaandinavia A/S, [ECLI:EU:C:2020:235].

${ }^{58}$ AAP Zaragoza 11 octubre 2007 [ECLI:ES:APZ:2007:1004A].

${ }^{59}$ DOUE C 326 de 26 octubre 2012 (versión consolidada 2012) y texto en http://eur-lex.europa.eu/legal-content/ES/ TXT/?uri=CELEX:12012P/TXT.
} 
toda persona cubre el derecho a contraer matrimonio significa que un ser humano no puede ser obligado a contraer matrimonio en virtud de un acuerdo previo o de una promesa unilateral de contraer matrimonio. Por tanto, para el Derecho europeo, la promesa de matrimonio presenta un contenido puramente moral y emocional y no jurídico. No es un compromiso jurídicamente exigible. Al igual que afirmaciones como "te querré siempre", "quiero fundar una familia contigo", "quiero tener hijos contigo", la promesa de matrimonio, -"te prometo que me casaré contigo"-, no tiene contenido jurídico y por eso su contenido, la celebración del matrimonio, no puede ser exigido ante un tribunal, pues el Derecho no concede acción para ello.

En segundo lugar, la inmensa mayoría de las legislaciones del mundo consideran que estas promesas de matrimonio no producen efectos jurídicamente obligatorios. No obligan a las personas a contraer matrimonio ni a indemnizar a la otra parte en el caso de no celebrase el matrimonio. La promesa de matrimonio es un acuerdo, un pacto, un compromiso unilateral o bilateral, si se quiere, pero que no produce efectos obligatorios. Es un compromiso no obligatorio, es un acuerdo sin contenido negocial. Y un acuerdo sin contenido, sin obligaciones, no puede calificarse como "contrato", como muy bien han destacado G. Balladore Pallieri y N. Boschiero ${ }^{60}$.

En tercer lugar, cabe apuntar que, en estos casos, y salvo prueba en contrario, las personas se comprometen a contraer matrimonio en unos ciertos términos y no a indemnizar a la otra persona por los gastos y daños que les puede haber causado el incumplimiento de la promesa de matrimonio. Por tanto, no puede sostenerse que los daños causados de ruptura de la promesa de matrimonio sean consecuencia de un compromiso libre y voluntariamente asumido por una persona. Esta obligación, si es que existe, no es una obligación contractual. En efecto, en estos esponsales y promesas, las personas se obligan a contraer matrimonio, pero no suelen obligarse a pagar los gastos producidos en casos de no celebración del matrimonio. En consecuencia, si se reclama una indemnización derivada del incumplimiento de la promesa de matrimonio, se reclama el cumplimiento de una obligación establecida, en su caso, por la ley y no derivada de la voluntad de una persona. Tal obligación no presenta naturaleza contractual.

37. En conclusión, se debe afirmar que la promesa de matrimonio no puede calificarse como un "contrato" y las obligaciones que surgen de la misma no son obligaciones en materia contractual. El art. 7.1 del Reglamento Bruselas I-bis no es aplicable a las reclamaciones por ruptura de estas promesas. El Reglamento Roma I es inaplicable para fijar la Ley aplicable a la promesa de matrimonio.

\section{C) Calificación como cuestión de régimen económico}

38. El Reglamento (UE) 2016/1103 del Consejo de 24 de junio de 2016 por el que se establece una cooperación reforzada en el ámbito de la competencia, la ley aplicable, el reconocimiento y la ejecución de resoluciones en materia de regímenes económicos matrimoniales (DOUE L 183 de 8 julio 2016) indica, con toda claridad que es aplicable "a los regímenes económicos matrimoniales" (art. 1.1 R.2016/1103). Con arreglo al art. 3.1.a) del mismo, se entenderá por "régimen económico matrimonial" el "conjunto de normas relativas a las relaciones patrimoniales entre los cónyuges y con terceros, como resultado del matrimonio o de su disolución". Es evidente que la promesa de matrimonio y los esponsales no regulan las relaciones patrimoniales entre los cónyuges, pues en estos casos, los prometidos

${ }^{60}$ G. Balladore Pallieri, Diritto internazionale privato, en "Trattato di diritto civile e commerciale", Giuffrè, Milano, 1974, pp. 173-174: “A considerarla come una obbligazione convenzionale ne deriverebbe tra l'altro la inammissibile conseguenza della possibilità per le parti di scegliere la legge regolatrice (cosidetto principio della autonomia delle parti) (...) la promessa di matrimonio, se è atto giuridico, non è però negozio giuridico. Si noti infatti che per il nostro diritto la promessa di matrimonio non produce alcun obbligo giuridico di contrarre quest'ultimo, e nemmeno produce inadempimento. Gli effetti no sono dunque quelli conformi alla volontà delle parti, ma solo quelli fissati per legge, e questi effetti, anche quando rivestono il carattere di risarcimento non costituiscono risarcimento per inadempimento di una obbligazione contrattuale, poiché la obbligazione di questo tipo, come si è detto testé, non vi è". También N. Boschiero, “Art. 26”, en S. Bariatti (a cura di), Legge 31 maggio 1995 n. 218, Riforma del sistema italiano di diritto internazionale privato. Commentario, en Nuove leggi civili commentate, 1996, pp. 1149-1156. 
nunca llegan a ser cónyuges. Por otro lado, el art. 3.1.b) R.2016/1103 precisa que se entiende por "capitulaciones matrimoniales", el "acuerdo en virtud del cual los cónyuges o futuros cónyuges organizan su régimen económico matrimonial". Es también obvio que la promesa de matrimonio y los esponsales no son instituciones que organizan el régimen económico matrimonial de los prometidos. En consecuencia, parece sencillo concluir que la promesa de matrimonio y los esponsales no pueden calificarse como una institución cubierta por la categoría jurídica "régimen económico matrimonial" y que también por tanto, que el Reglamento (UE) 2016/1103 del Consejo de 24 de junio de 2016 por el que se establece una cooperación reforzada en el ámbito de la competencia, la ley aplicable, el reconocimiento y la ejecución de resoluciones en materia de regímenes económicos matrimoniales no es aplicable a tales cuestiones.

39. Por otra parte, el Reglamento (UE) 2016/1104 del Consejo de 24 de junio de 2016 por el que se establece una cooperación reforzada en el ámbito de la competencia, la ley aplicable, el reconocimiento y la ejecución de resoluciones en materia de efectos patrimoniales de las uniones registradas precisa que regula "los efectos patrimoniales de las uniones registradas" (art. 1.1 R.2016/1104). El art. 3.1.a) R.2016/1104 precisa que se entiende por "unión registrada" el "régimen de vida en común de dos personas regulado por ley, cuyo registro es obligatorio conforme a dicha ley y que cumple las formalidades jurídicas exigidas por dicha ley para su creación”. El art. 3.1.b) R.2016/1104 indica que se entiende por "efectos patrimoniales de la unión registrada", el conjunto de normas relativas a las relaciones patrimoniales de los miembros de la unión registrada entre sí y con terceros, como resultado de la relación jurídica creada por el registro de la unión o su disolución". Finalmente, el art. 3.1.c) R.2016/1104 indica que se entiende por "capitulaciones de la unión registrada" el "acuerdo en virtud del cual los miembros o futuros miembros organizan los efectos patrimoniales de su unión registrada". El objetivo del reglamento citado es fijar la Ley aplicable a las relaciones económicas entre convivientes de una pareja registrada que se refieren a "la administración cotidiana del patrimonio de los miembros de la unión registrada" y a la "liquidación, en particular como consecuencia de la separación de la pareja o del fallecimiento de uno de sus miembros" ${ }^{\prime}$. Es evidente que las consecuencias económicas de la ruptura de una promesa de matrimonio o de unos esponsales no tiene nada que ver con estos aspectos. Incluso en el caso de existir una pareja de hecho, la ruptura de una promesa de matrimonio realizada entre los convivientes no constituye una infracción de las reglas jurídicas que rigen las relaciones entre los convivientes de hecho. Por ello, la promesa de matrimonio y los esponsales no pueden calificarse como una institución incluida en la materia "efectos patrimoniales de las uniones registradas" y también por ello, el Reglamento (UE) 2016/1104 del Consejo de 24 de junio de 2016 por el que se establece una cooperación reforzada en el ámbito de la competencia, la ley aplicable, el reconocimiento y la ejecución de resoluciones en materia de efectos patrimoniales de las uniones registradas no es aplicable a estas cuestiones.

40. Como indicara hace años años J.D. GonzÁlez CAMPos, debe recordarse que la regulación jurídica de la promesa de matrimonio no comporta ninguno de los efectos propios del régimen jurídico de la familia ${ }^{62}$. Ninguno de los reglamentos europeos citados es aplicable a las reclamaciones que surgen tras la ruptura de una promesa de matrimonio.

\section{D) Calificación de tipo familiar, matrimonial y personal}

41. Ciertos expertos, como A. Schnitzer, R. de Nova, M. Miele, R. Monaco, E. Vitta y T. BALLARINO, han estimado que la promesa de matrimonio podría ser calificada como una "relación de

${ }^{61}$ Cons. (18) R.2016/114: “El ámbito de aplicación del presente Reglamento debe incluir todos los aspectos de Derecho civil de los efectos patrimoniales de las uniones registradas, relacionados tanto con la administración cotidiana del patrimonio de los miembros de la unión registrada como con su liquidación, en particular como consecuencia de la separación de la pareja o del fallecimiento de uno de sus miembros".

${ }^{62}$ J.D. González Campos, "El matrimonio en el Derecho civil internacional", en M. Aguilar Navarro, Derecho civil internacional, Facultad de Derecho, Universidad Complutense, Madrid, 4ª ed,. 1975 (reimpresión 1979), pp. 243-371, esp. pp. 261-262. 
familia" ${ }^{93}$. Algunos autores, como es el caso de E. VITTA, enfatizan, también, que ésta es la calificación más difundida en los sistemas de Derecho internacional privado de los distintos países europeos y razón no le falta ${ }^{64}$. Dentro de esta calificación genérica de la promesa de matrimonio como una cuestión de "relaciones familiares" existen variantes curiosas y sugestivas, gozo máximo y sublime de los expertos legales en Derecho internacional privado más entregados a los placeres más exquisitos de la dogmática jurídica.

\section{a) La calificación matrimonial}

42. En el caso de que el Derecho europeo considerase que las reclamaciones derivadas de promesas de matrimonio incumplidas constituyen una cuestión de "relaciones familiares" o de "estado civil" estaría excluido de la aplicación de todos los reglamentos europeos de Derecho internacional privado. Así se establece en el art. 1.2.b) RR-I, art. 1.2.a) RR-II y art 1.2.a) RB I-bis.

43. Determinados autores consideran que la promesa de matrimonio debe ser calificada como una "cuestión matrimonial", o bien como una cuestión de "Derecho de familia", explica E. RABEL ${ }^{65}$. En efecto, en países como Italia, Alemania, -en este caso con ciertos pero leves matices-, y España, la doctrina mayoritaria era favorable a una calificación de la promesa de matrimonio como una cuestión familiar o "para-matrimonial" ${ }^{\text {. }}$. Esa calificación familiar, como cuestión perteneciente al "estatuto per-

${ }^{63}$ M. Miele, Scritti di diritto matrimoniale, Cedam, 1964, p. 25; R. Monaco, L'efficacia della legge nello spazio, Utet, 1964, p. 154: "la promessa di matrimonio può infatti essere considerata come un rapporto obbligatorio, da sottoporsi quindi alia legge regolatrice delle obbligazioni, oppure come un fatto che, posto in relazione ad altre circostanze, è suscettivo di certe conseguenze giuridiche, oppure ancora come attinente al diritto di famiglia. Secondo l'ordinamento italiano quest'ultima è la soluzione da darsi al problema di qualificazione"; R. DE Nova, "voce Matrimonio (promessa di), diritto internazionale privato", Novissismo Digesto italiano, X, Utet, 1964, pp. 426-429; R. DE NovA, "Gli sponsali in diritto internazionale privato", Il Foro Italiano, 1955, vol. 78, N. 2, pp. 25-38; R. DE NovA, “Obbligazioni (Diritto internazionale privato)", en AA.VV., Enciclopedia del diritto, Giuffrè, Milano, 1979, pp. 456-500; A.F. SCHNITZER, Handbuch des internationalen Privatrechts: einschliesslich Prozessrecht, unter besonderer Berücksichtigung der schweizerischen Gesetzgebung und Rechtsprechung, T.I , $3^{\mathrm{a}}$ ed., Verlag für Recht und Gesellschaft, 1957, pp. 308-311; E. VITTA, Diritto internazionale privato, vol.II, UTET, Torino, 1973, p. 167; T. Ballarino, Diritto internazionale privato, Cedam, Padova, 1982, p. 707.

${ }^{64}$ E. VITTA, Diritto internazionale privato, vol. II, UTET, Torino, 1973, pp. 167-171, esp. pp. 167-168: “La maggior parte dei sistemi continentali europei fanno invece rientrare la promessa di matrimonio nell'ambito del diritto di famiglia, sottoponendo la rottura della promessa alla legge regolatrice del matrimonio, al quale gli sponsali sono strettamente collegati, oppure li considerano una convenzione di tipo familiare facendoli cadere sotto la legge regolatrice delle convenzioni tra coniugi. Si noti però, che la questione della legge applicabile si pone solo relativamente alle obbligazioni di carattere finanziario a carico del colpevole della rottura ed a favore della parte che abbia subito un danno in conseguenza della rottura stessa. Infatti non si riscontra, nelle varie legislazioni, un obbligo di esecuzione specifica, nel senso che il fidanzato recalcitrante possa esser costretto a sposarsi, vi sono anzi sistemi, come il francese, nei quali gli sponsali non costituiscono un contratto giuridicamente obbligatorio, ma solo una promessa d'inole puramente morate, il cui adempimento è solo una questione di cosienza; cosicchè i danni non saranno dovuti per la rottura della promessa in sé considerata, ma solo in quanto possano essere specificamente dimostrati nelle circostanze del caso".

${ }^{65}$. Rabel, The conflict of laws: A comparative study. Vol. 1: Introduction: Family Law, $2^{\mathrm{a}}$ ed., Ann Arbor, The university of Michigan press, Chicago, Callaghan \& company, 1958, pp. 215-221, esp. p. 216.

${ }^{66}$ Para Italia, vid. inter alia, R. Monaco, L'efficacia della legge nello spazio, Utet, 1964, pp. 153-157: "la promessa di matrimonio può infatti essere considerata come un rapporto obbligatorio, da sottoporsi quindi alia legge regolatrice delle obbligazioni, oppure come un fatto che, posto in relazione ad altre circostanze, è suscettivo di certe conseguenze giuridiche, oppure ancora come attinente al diritto di famiglia. Secondo l'ordinamento italiano quest'ultima è la soluzione da darsi al problema di qualificazione", así como P. Fedozzi, Il diritto internazionale privato: Teorie generali e diritto civile, Cedam, Padova, 1939, pp. 402-455: "La determinazione della legge applicabile agli sponsali promessa bilaterale di matrimonio è dominata dalla qualificazione che la legge del giudice dà all'atto. Se la questione si presenta davanti al giudice italiano questi potrà essere in dubbio se gli sponsali debbano, secondo la prevalente dottrina canonistica accolta in alcune legislazioni, considerarsi come un contratto preliminare e debba quindi ad essi applicarsi la disposizione del nostro titolo preliminare relativa alle obbligazioni convenzionali (art. 9) oppure se essi appartengono al diritto di famiglia e quindi debba applicarsi ad essi il principio generale dell'art. 6. Quest'ultima tesi sarà indubbiamente seguita dal nostro giudice". También A. SARAVALLE, "Articolo 26", en Riforma del sistema italiano di diritto internazionale privato legge 31 maggio 1995 n. 218, Rivista di Diritto internazionale privato e processuale, 1995, pp. 1043-1046: "Secondo la tesi prevalente, l'attinenza con il matrimonio faceva ricadere I'istituto nel diritto di famiglia". Para España, vid. J.D. GonzÁlez CAMPos, "El matrimonio en el Derecho civil internacional", en M. Aguilar Navarro, Derecho civil internacional, Facultad de Derecho, Universidad Complutense, Madrid, $4^{\mathrm{a}}$ ed,. 1975 (reimpresión 1979), pp. 243-371, esp. pp. 261-262: “En el sistema español, según se ha indicado, prima una calificación 
sonal" fue también mayoritaria en Suiza, escribe A.F. SCHNITZER ${ }^{67}$. En consecuencia, en este caso, si la promesa de matrimonio merece una calificación como una cuestión de "Derecho de familia" o como una "cuestión matrimonial", entonces deberían aplicarse, por analogía, las normas de Derecho internacional privado nacionales de cada Estado relativas a la celebración del matrimonio ${ }^{68}$.

44. En particular, en Derecho internacional privado italiano, se ha citado a favor de la calificación familiar de la promesa de matrimonio una sentencia dictada por la Corte d'Apello della Libia de 12 mayo $1932^{69}$. Se trataba de una promesa de matrimonio realizada entre dos ciudadanos libios de religión hebraica y que residían en Bengasi, promesa que aparecía acompañada, en el mismo documento, de una cláusula penal para el caso de incumplimiento de la promesa y de la no celebración del matrimonio. El tribunal tuvo que decidir sobre la discutida validez de dicha cláusula, que era válida según el derecho judío, pero inválida según el Derecho común italiano. Era, pues, necesario, calificar la promesa de matrimonio y la cláusula penal como cuestiones bien de "Derecho de familia" o bien de "Derecho de obligaciones". Si se optaba por una calificación familiar, era aplicable la ley nacional común, esto es, la ley judía, y la promesa era válida y la cláusula penal también. Si se optaba por la calificación contractual, entonces era aplicable la Ley italiana, ya que la promesa se formalizó en territorio italiano y la cláusula penal no era exigible. Pues bien, el tribunal tomó una tercera vía. Dividió la controversia en dos cuestiones distintas. Afirmó que el acuerdo de matrimonio, la promesa de matrimonio debía ser calificada como cuestión relativa a la familia y que, por tanto, se regía por la Ley judía: la promesa era válida, pues. Por otro lado, indicó que la cláusula penal debía considerarse como perteneciente una cuestión relativa al Derecho de obligaciones, por tanto, debía regirse por la Ley del lugar donde se había acordado tal cláusula, Ley italiana, y dado que según dicha Ley italiana esta cláusula era nula y sin valor, declaró la nulidad de la misma ${ }^{70}$.

\section{(a) Aplicación de la Ley personal / Ley nacional común de los prometidos}

45. De ese modo, en Alemania, Italia y España, al menos, la promesa de matrimonio ha sido considerada una cuestión de Drcho de Familia y se ha sujetado a la Ley personal común de los prome-

familiar por parte de la doctrina, de manera que la consecuencia sería someter el régimen de la ruptura de los esponsales a la ley rectora de los efectos de la promesa, esto es, la ley nacional del varón en el momento de la celebración de los esponsales".

${ }^{67}$ A.F. SCHNITZER, Handbuch des internationalen Privatrechts: einschliesslich Prozessrecht, unter besonderer Berücksichtigung der schweizerischen Gesetzgebung und Rechtsprechung, T.I , $3^{\mathrm{a}}$ ed., Verlag für Recht und Gesellschaft, 1957, pp. 308-311.

${ }^{68}$ De todos modos, no existe "una" Ley aplicable al matrimonio en Derecho internacional privado español, sino que existe una Ley que regula la capacidad, otra el consentimiento y otra la forma del matrimonio, por lo que habría que precisar a cuál de tales leyes es aplicable, por analogía, a la promesa de matrimonio, como indica T. BALLARINo, Diritto internazionale privato, Cedam, Padova, 1982, pp. 706-707: "Neppure si può parlare, come subito diremo, di una legge regolattice del matrimonio alla quale la promessa possa essere ricondotta per attrazione".

${ }^{69}$ Sentencia de la Corte d'Apello della Libia de 12 mayo 1932, en Rivista di Diritto internazionale privato e processuale, 1932, p. 432.

${ }^{70}$ P. Fedozzi, Il diritto internazionale privato: Teorie generali e diritto civile, Cedam, Padova, 1939, pp. 146-147: "Una sentenza del 12 marzo 1932 della Corte d'appello di Libia mi sembra che, senza dirlo, abbia fatto applicazione di questo concetto della preminenza della legge metropolitana all'interessante materia delle qualificazioni. Si trattava di una promessa di matrimonio scambiata fra due cittadini libici israeliti di Bengasi accompagnata da una clausola penale per il caso di inadempienza. La Corte doveva decidere del valore contestato di questa clausola, che sarebbe stata valida secondo il diritto giudaico, invalida secondo il diritto comune italiano. L'applicazione dell'uno o dell'altro diritto derivava dal modo in cui la clausola penale doveva essere qualificata: se si riteneva che essa appartenesse al diritto di famiglia, si doveva applicare il diritto giudaico mantenuto in vigore per gli israeliti appunto per i rapporti di famiglia, se si riteneva invece che essa facesse parte del diritto delle obbligazioni, si doveva applicare il codice civile italiano introdotto in colonia con vigore territoriale assoluto per tutti i rapporti obbligatori. La Corte ha correttamente condotto il processo della qualificazione in base alla legge metropolitana, ma limitandosi ad osservare che «il concetto del diritto di famiglia, quale si è voluto mantenere ai cittadini italiani libici, va necessariamente preso dal nostro diritto». Quindi aggiunse: «Tuttavolta che in un unico documento si regolano istituti di diritto che, per la nostra legge e per la nostra concezione giuridica vanno riportati a branche diverse di diritto, sembra corretto alla Corte, anche perchè l'analogia non è consentita in leggi eccezionali, come nella specie, mantenere autonome le figure dei diversi istituti e regolarli secondo la rispettiva legge». Da ciò la Corte trasse la conseguenza che la convenzione doveva essere regolata dal diritto ebraico per quanto riguardava la promessa di matrimonio, giacché per questa parte essa atteneva al diritto di famiglia, e dal diritto italiano rispetto alla clausola penale, dovendo quest'ultima ritenersi appartenente al diritto delle obbligazioni e siccome in base al diritto italiano tale clausola è nulla, cosi doveva sancirsene la nullità". 
tidos, que suele ser la Ley nacional de ambos. Como subrayan T. BALLARINo / A. Bonomi, la conexión entre "libertad matrimonial" y "promesa de matrimonio" apunta a considerar que ésta debe ser calificada como una cuestión matrimonial a regular por la Ley nacional común de los prometidos ${ }^{71}$. Para el legislador italiano de 1995 la cuestión sigue siendo de naturaleza matrimonial o para-matrimonial, puesto que, explica A. SARAVALLE, el art. 26 legge 218, que regula la cuestión, está colocado en la parte de la ley que se ocupa de las relaciones de familia y además, emplea conexiones de tipo personal, esto es la nacionalidad común de los prometidos ${ }^{72}$. El art. 39 del Código Bustamante (La Habana, 20 Febrero 1928) también consideró que esta cuestión debía quedar sujeta a la Ley personal común de las partes, y en su defecto, a la Lex Fori ${ }^{73}$.

46. Esta visión de la promesa de matrimonio destaca que ésta nace y se desarrolla en un contexto familiar, en un ambiente cultural específico que suele ser el correspondiente al país cuya nacionalidad ostentan ambos sujetos. Es por eso que la ley nacional común debe aplicarse. Es la ley que ambos esperan ver aplicada a dicha promesa de matrimonio, la ley que se corresponde con sus vínculos culturales, religiosos y morales comunes. El art. 9.1 CC, en el caso español, apuntaría, en efecto, a la aplicación de la Ley nacional común de los prometidos.

(b) Ley aplicable en defecto de nacionalidad común de los prometidos

47. En defecto de tal nacionalidad común se abren diferentes posibilidades que han sido defendidas tanto por insignes autores como por cierta jurisprudencia en los distintos sistemas nacionales de Derecho internacional privado.

48. En primer lugar, un nutrido grupo de expertos ha defendido la famosa "teoría del cúmulo". Sostienen que debería aplicarse cumulativamente las Leyes nacionales de ambos sujetos. Así lo sostuvo G. BALladore Pallieri y también T. BALlarino ${ }^{74}$. Ello conduciría, en la práctica, y a los efectos de poder exigir responsabilidad civil por ruptura de la promesa, a requerir que la promesa se ajuste a los términos de la ley nacional más restrictiva. Así, en el caso de que un ciudadano francés prometiera matrimonio a un sujeto español y dicha promesa resultara incumplida, el sujeto español sólo podría reclamar responsabi-

${ }^{71}$ T. Ballarino / A. Bonomi, Diritto internazionale privato, 3a ed., Cedam, 1999, pp. 373-374: "La seconda soluzione è stata accolta nella legge di riforma che rende applicabile, in prima battuta, la legge nazionale comune dei nubendi. Tale scelta è da approvare dato lo stretto legame esistente tra ai sensi sponsali ed il principio della libertà matrimoniale".

${ }^{72}$ A. Saravalle, "Articolo 26", en Riforma del sistema italiano di diritto internazionale privato legge 31 maggio $1995 \mathrm{n}$. 218, Rivista di Diritto internazionale privato e processuale, 1995, pp. 1043-1046: "la norma, infatti, aderisce chiaramente alla tesi prevalente com'è possibile evincere dalla sua collocazione all'interno del capo quarto della legge, dedicato appunto ai rapporti di famiglia, e soprattutto, dal ricorso ad un criterio di collegamento di tipo personale".

${ }^{73}$ Artículo 39 Código Bustamante: "Se rige por la ley personal común de las partes y, en su defecto, por el derecho local, la obligación o no de indemnización por la promesa de matrimonio incumplida o por la publicación de proclamas en igual caso". El texto puede verse en: https://www.oas.org/juridico/spanish/mesicic3_ven_anexo3.pdf.

${ }^{74}$ G. Balladore Pallieri, Diritto internazionale privato, en "Trattato di diritto civile e commerciale", Giuffrè, Milano, 1974, pp. 173-174: "La materia è dunque regolata dal secondo comma dell'art. 25 (obbligazioni extracontrattuali); ma vedremo, esaminando quella disposizione, che le obbligazioni 'ex lege'sono normalmente disciplinate in conformità alla legge applicabile al rapporto a cui ineriscono, nel caso nostro essendo sancito in considerazioni di possibili rapporti familiari, la obbligazione di cui si tratta è regolata dalla legge competente per i rapporti di famiglia e cioè dalla legge nazionale" y con mayor claridad: "Nel caso poi che si tratti di promessa fra due persone di diversa nazionalità, io non vedo alcun inconveniente a riconoscere che ciascuno è sottoposto agli obblighi derivantigli dalla sua legge nazionale, dato che è il suo diritto nazionale quello che gli va applicato, anche se tali obblighi riescono diversi da quelli che incomberebbero all'altro promittente qualora si trovasse egli nella stessa situazione. Il caso non è diverso da quello in cui ciascun coniuge può trovarsi per la sussistenza o la inesistenza nella legge nazionale dell'altro di impedimenti al matrimonio che non esistono o che esistono nella propria legislazione nazionale"; T. BALlarino, Diritto internazionale privato, Cedam, Padova, 1982, pp. 706-707: "Ne segue che si dovranno applicare le due leggi in concorso cumulativo, e prevarrà la più restrittiva, quella cioè che stabilisce requisiti più severi". También a favor del cúmulo, con mayor o menor simpatía, como solución de lege lata, se muestran R. DE NovA, "Gli sponsali in diritto internazionale privato", Il Foro Italiano, 1955, vol. 78, N. 2, pp. 25-38; R. DE Nova, "voce Matrimonio (promessa di), diritto internazionale privato", Novissismo Digesto italiano, X, Utet, 1964, pp. 426-429; G. MorelLI, "Legge regolatrice del contratto di matrimonio e volontá delle parti”, Giurisprudenza comparata di diritto internazionale privato, 1942, pp. 219-129. 
lidad al francés si se verifican los requisitos al efectos exigidos tanto por el Derecho francés como por el Derecho español. Lo que significa que el Derecho más exigente para poder reclamar responsabilidad civil derivada de la ruptura de la promesa de matrimonio, sea el francés o el español, debe observarse, como muy bien explica C. FoCARELLI ${ }^{75}$. Buena parte de la doctrina italiana y algún autor alemán ha defendido esta tesis del "cúmulo de las Leyes nacionales", una tesis farragosa, es cierto, y complicada, es verdad, como expone A. SARAVALLE ${ }^{76}$. Favorable a esta tesis del cúmulo se mostró la sentencia del tribunal regional superior de Munich de 13 marzo 1929, citada por H. LEWALD, que afrontó el siguiente caso: una mujer checoslovaca reclamó daños e intereses en reparación del daño moral resultante de la ruptura de una promesa de matrimonio por parte de un ciudadano alemán. Pues bien, el tribunal falló a favor de la acumulación de los dos estatutos personales y como la legislación checoslovaca no admitía la reparación del daño moral tras la ruptura de la promesa matrimonial en cuestión, rechazó la reclamación de la mujer ${ }^{77}$.

49. En segundo lugar, otros autores, en casos de nacionalidad diferente de las partes, apuntaban a una solución diferente: la teoría de la aplicación distributiva de las respectivas nacionales. En este sentido, la víctima de la ruptura debe poder solicitar una indemnización máxima con arreglo a su Ley nacional y el presunto responsable sólo responderá, al máximo en sintonía con su propia ley nacional, ex-

${ }^{75}$ C. Focarelli, Lezioni di diritto internazionale privato, Morlacchi Ed., Perugia, 2006, pp. 93-94: "l'opinione prevalente era peraltro nel senso che si sarebbe trattato di un istituto del diritto di famiglia (benché posto in essere prima che la "famiglia» si formi con il matrimonio), con conseguente applicazione della legge nazionale comune ex art. 17 o, in caso di cittadinanza diversa, delle due leggi nazionali applicate cumulativamente. Il «cumulo» conduceva a riconoscere, in caso di rottura della promessa, alla parte lesa non più di quanto previsto da entrambe le leggi nazionali, e quindi in pratica dalla più restrittiva... (...) Si noterà inoltre che, a differenza dei diritti della personalità, per la promessa di matrimonio le conseguenze della violazione non sono sottoposte alla legge regolatrice dell'illecito ....".

${ }^{76}$ E. VITTA, Diritto internazionale privato vol. II, UTET, Torino, 1973, pp. 167-171, esp. p. 168; R. Monaco, L'efficacia della legge nello spazio, Utet, 1964, p. 155; R. DE NovA, "voce Matrimonio (promessa di), diritto internazionale privato", Novissismo Digesto italiano, X, Utet, 1964, pp. 426-429; R. DE NovA, "Gli sponsali in diritto internazionale privato", Il Foro Italiano, 1955 , vol. 78, N. 2, pp. 25-38; M. MieLE, "Sulla legge applicabile alla rottura degli sponsali", Giurisprudenza comparata di diritto internazionale privato, 1942, pp. 77-89; G. MoRelli, "Legge regolatrice del contratto di matrimonio e volontá delle parti", Giurisprudenza comparata di diritto internazionale privato, 1942, pp. 219-129; D. AnZILLotTI, Corso di lezioni di diritto internazionale privato, Athenaeum, 1918, pp. 219-221; D. ANZILlotTI, Corso di diritto internazionale privato, 1912-13, pp. 484-490; G. Bosco, Corso di diritto internazionale privato, Castellani, 1939, p. 222; G. Bosco, Corso di diritto internazionale privato, Firenze, 1936, p. 139; M. Udina, Elementi di diritto internazionale privato italiano, Roma, A. R. E., Anonima romana editoriale, 1933, p. 176; E. BetтI, Problematica del diritto internazionale, Milano, A. Giuffrè, 1956, pp. 420-421; S. GemmA, Appunti di diritto internazionale, diritto pubblico, Bologna, N. Zanichelli, 1923, p. 123; P. Fedozzi, Il diritto internazionale privato: Teorie generali e diritto civile, Cedam, 1935, p. 400, también partidario de la "teoría del cúmulo" pero sólo en el caso en el que, tras el matrimonio la mujer no adquiriese la nacionalidad del marido, pues en caso contrario, consideraba aplicable "la legge nazionale del fidanzato", esto es, la "Ley nacional del novio". P. Fedozzi, Il diritto internazionale privato: Teorie generali e diritto civile, Cedam, Padova, 1939, pp. 402-405: “... rimanendo così in ogni singolo caso le obbligazioni commisurate alla legge più favorevole all'obbligato". Un análisis crítico y muy fundado de estas posiciones puede verse en E. VITTA, Diritto internazionale privato e processuale, $3^{\mathrm{a}}$ ed., Torino, UTET, 1989, p. 216. Para el Derecho internacional privado alemán, favorable a la teoría del cúmulo, antes de la sentencia del BGH (Alemania) de 21 noviembre 1958, vid. M. WolfF, Derecho internacional privado, Ed. Labor. Barcelona 1936, traducción de José Rovira y Ermengol, pp. 286-287: «Para saber si se ha estipulado válidamente un " "contrato de esponsales" hay que acudir al Derecho nacional de los dos contrayentes. Si éstos son de distinta nacionalidad, los esponsales serán solamente válidos cuando cada uno de los contrayentes observe los requisitos exigidos por su Derecho nacional (...) Siendo válidos las esponsales, tendrán sólo los efectos jurídicos comunes a los Derechos nacionales de ambos contrayentes: sería contrario a la idea de comunidad que para uno de los contrayentes produjeran efectos más intensos que para el otro». Vid. A. SARAVAlLE, "Articolo 26", en Riforma del sistema italiano di diritto internazionale privato legge 31 maggio 1995 n. 218, Rivista di Diritto internazionale privato e processuale, 1995, pp. 1043-1046: "Nel vigore delle preleggi, qualora $i$ nubendi avessero nazionalità diverse, si riteneva comunemente necessario procedere all'applicazione cumulativa delle due leggi nazionali, cosicché risultavano ammissibili solo le conseguenze previste da entrambe le leggi. Soluzione questa guanto farraginosa, di poco semplificata dal suggerimento di un autorevole dottrina di procedere, invece, ad un'applicazione disgiuntiva delle due leggi". Bien explicada también la tesis del cúmulo, con fuertes críticas, por A. Weill, "Fiançailles", Encyclopedie Dalloz droit international, París, 1968-69 (dir. Ph. Franceskakis), vol.II, 1969, pp. 22-24.

${ }^{77}$ Sentencia citada por H. Lewald apud P. Fedozzi, Il diritto internazionale privato: Teorie generali e diritto civile, Cedam, Padova, 1939, p. 404, nota [2]: "Si trattava di sapere se una donna cecoslovacca può pretendere danni interessi in riparazione del danno morale risultante dalla rottura di una promessa di matrimonio, di cui essa fu vittima da parte di un cittadino tedesco: il Tribunale si pronunciò per il cumulo dei due statuti personali e siccome il diritto cecoslovacco non ammette la pretesa in questione cosii respinse la domanda". 
pone E. VitTA ${ }^{78}$. Es decir: la ley nacional de la víctima de la ruptura de la promesa de matrimonio rige su derecho a solicitar una indemnización por tal ruptura, mientras que la ley nacional del sujeto que rompe su promesa de matrimonio rige su obligación de satisfacer una indemnización. Esta postura fue adoptada por la famosa sentencia del BGH (Alemania) de 21 noviembre 1958. El Tribunal Supremo alemán aplicó a la responsabilidad civil derivada de la ruptura de una promesa de matrimonio hecha por sujeto austriaco a mujer alemana, la Ley nacional de la persona que había roto la promesa de matrimonio, esto es, la Ley austríaca. Al mismo tiempo, la víctima, alemana en este caso, según dicha sentencia, podía hacer valer la protección jurídica que le otorgaba su propia Ley nacional ${ }^{79}$. El tribunal optó por esta solución porque, explica J.A. TOMÁs ORTIZ DE LA TORRE, el Derecho alemán admitía una indemnización especial por desfloración (art. 1300 BGB Alemania), algo no contemplado por el Derecho austríaco. Por tanto, es natural y comprensible pensar que el tribunal favoreció a la víctima alemana para que pudiera solicitar dicha indemnización por desfloración, de modo que la Ley nacional del responsable de la ruptura de la promesa no se aplicó en toda su extensión ${ }^{80}$. Esta solución edificada sobre la aplicación distributiva de las Leyes nacionales fue seguida en Alemania durante años, indica M. SchwimanN ${ }^{81}$. Por tanto, en la práctica se optó por la ley nacional de la persona demandada, -presunto responsable de la ruptura de la promesa matrimonial-, pero con dicha excepción nacionalista. Así, en el caso de Alemania, explica A. NusSBAUM, debe distinguirse entre indemnización por gastos hechos con motivo del matrimonio, -sometidos a la Ley nacional de la persona responsable de la ruptura-, e "indemnización por desfloración", -sujeta a la Ley personal de la víctima- ${ }^{82}$.

\section{b) Calificación como cuestión familiar autónoma}

50. Ciertos legisladores nacionales consideran que los esponsales y la promesa de matrimonio deben calificarse como unas "relaciones matrimoniales autónomas", esto es, conectadas con el matrimonio, pero distintas a éste.

Este enfoque es el seguido por el art. 26 legge 218/1995 en Italia, que contempla expresamente el supuesto y que ha seguido la tesis dominante en la doctrina italiana antes de la ley 218/1995, favorable a la aplicación de la Ley nacional común de los prometidos $\left(\right.$ fidanzati $^{83}$. Este precepto se encuentra

${ }^{78}$ E. VITTA, Diritto internazionale privato e processuale, $3^{\mathrm{a}}$ ed., Torino, UTET, 1989, p. 216: "Per parte nostra concordiamo che la promessa di matrimonio attenga al diritto di famiglia e che la rottura della promessa cada pertanto sotto la legge nazionale, in base all'art. 17. In caso di diversa cittadinanza delle parti, tuttavia, riteniamo, a differenza della dottrina dominante, che si debba ricorrere disgiuntamente alle due leggi nazionali. Ciò nel senso che colui il quale è vittima della rottura di promessa non potrà richiedere più di quanto la sua legge nazionale gli concede. Mentre colui contro il quale la domanda è rivolta potrà, a sua volta, esser condannato solo nei limiti ammessi dalla di lui legge nazionale". También en E. ViTTA, Diritto internazionale privato vol. II, UTET, Torino, 1973, pp. 167-171, esp. p. 169. Con matices, parece ser también la opinión de E. Betтi, Problematica del diritto internazionale, Milano, A. Giuffrè, 1956, p. 421: "si può dire, in generale, che ciascuna parte ha gli obblighi che le impone il suo statuto personale, ed anche i diritti che il suo statuto personale le conferisce".

${ }^{79}$ Sentencia del BGH alemán de 21 noviembre 1958, Revue critique de droit international privé, 1959, p. 680, con nota de E. Mezger. Vid. también H. Batiffol / P. Lagarde, Droit international privé, t.II, 7 ed., LGDJ, Paris, 1983, n. 415 nota 4 bis, pp. 39-40. J.A. TomÁs Ortiz de la Torre, “Celebración del matrimonio”, en M. Aguilar Benítez de Lugo y otros, Lecciones de Derecho civil internacional, Ed. Tecnos, Madrid, 1996, pp. 88-116, esp. pp. 91-95, que cita la opinión de M. HABICHT en favor de la Ley nacional del responsable de la ruptura.

${ }^{80}$ J.A. Tomás Ortiz de la Torre, "Celebración del matrimonio", en M. Aguilar Benítez de Lugo y otros, Lecciones de Derecho civil internacional, Ed. Tecnos, Madrid, 1996, pp. 88-116, esp. pp. 91-95.

${ }^{81}$ Citado por T. Ballarino / A. Bonomi, Diritto internazionale privato, $3^{\mathrm{a}}$ ed., Cedam, 1999, p. 374.

${ }^{82}$ A. Nussbaum, Deutsches Internationales Privatrecht, Tübingen, 1932, pp. 98-100, opinión analizada por J.A. TOMÁS ORTIZ DE LA TORRE, "Formación del matrimonio y estados del vínculo en el Derecho civil internacional español", en M. AgUILAR Navarro y otros, Lecciones de Derecho civil internacional, Serv.publ. Facultad Derecho, Universidad Complutense, Madrid, 1982, pp. 121-129, esp. p. 127.

${ }^{83}$ E. VITTA, Diritto internazionale privato e processuale, $3^{\mathrm{a}}$ ed., Torino, UTET, 1989, p. 216: "L'opinione di gran lunga prevalente è tuttavia nel senso che trattisi di istituto del diritto di famiglia, sottoposto pertanto alla legge nazionale comune delle parti, in base al $1^{\circ}$ comma dell'art. 17'; C. Focarelli, Lezioni di diritto internazionale privato, Morlacchi Ed., Perugia, 2006, p. 94: "Si noterà inoltre che, a differenza dei diritti della personalità, per la promessa di matrimonio le conseguenze della violazione non sono sottoposte alla legge regolatrice dell 'illecito ...."; T. BALlaRIno, Diritto internazionale privato, Cedam, Padova, 
englobado en el Titolo III («Diritto applicabile») y en el Capo IV («Rapporti di famiglia») de la Ley 218/1995 e indica que la promesa de matrimonio es una «relación de familia» autónoma, distinta al matrimonio y que se somete a la ley nacional de ambas personas y, en defecto de nacionalidad común, al Derecho sustantivo italiano ${ }^{84}$. Un buen ejemplo de su aplicación puede verse en el Decreto de la Corte di Apello di Torino de 23 diciembre 2010 [sentencia siria que procede a la ruptura del compromiso matrimonial «ktab ktab» propio del Derecho sirio] ${ }^{85}$.

Es ésta la línea también acogida por el art. 45 de la Ley belga que contiene el Código de Derecho internacional privado de 16 julio 2004, encuadrado en el Chapitre III de dicha Ley, titulado «Relations matrimoniales» y en la «Section 2. - Droit applicable à la promesse de mariage» ${ }^{86}$. El precepto somete la promesse de mariage al Derecho de la residencia habitual común y en su defecto a la Ley nacional común y a falta de esta conexión, a la Ley belga.

Ambos legisladores nacionales, el italiano y el belga, en efecto, han regulado de manera diferenciada la cuestión de la Ley aplicable a la promesa de matrimonio en casos internacionales, pero se han inspirado en la regulación del matrimonio. De ese modo, explican B. BARel / St. Armeluini, las conexiones recogidas al efecto son las mismas o muy similares que las expresamente previstas para fijar la Ley aplicable al matrimonio ${ }^{87}$.

\section{c) Calificación como cuestión relativa a la persona individual.}

51. Otra variante de la calificación familiar de la promesa de matrimonio considera que, en realidad, esta promesa afecta primordialmente a la libertad de contraer matrimonio de la persona que efectúa la promesa. En consecuencia, constituye una cuestión relativa a la "persona" más que relativa a la "familia" o al "matrimonio".

En tal caso, la validez de la promesa, su fuerza obligatoria y su sanción en caso de ruptura son cuestiones que deberían sujetarse a la Ley nacional de dicha persona, de la persona que promete matrimonio y falta a su promesa, como han apuntado P. MAYER / V. HeUzé y anteriormente, M. HABICHT ${ }^{88}$.

En el mismo sentido se pronunció una sentencia del Kammergericht (Alemania) de 11 enero 1939, citada por E. RABEL, en el caso de un ciudadano estadounidense domiciliado en Nueva York que disponía de una residencia temporal en Alemania y que sedujo a una joven alemana y le prometió matrimonio. El ciudadano norteamericano rompió su promesa, pero el tribunal alemán negó la acción de

1982, pp. 706-707: "Benché l'unica sentenza italiana, di cui siamo a conoscenza, si sia espressa per la qualificazione come obbligazione ex lege ed abbia applicato la legge del luogo in cui la promessa era stata prestata, riteniamo che l'appartenenza degli sponsali al diritto delle persone, nella generale accezione dell 'art. 17, non possa venir posta in dubbi".

${ }^{84}$ Art. 26 Legge 31 maggio 1995, n. 218, di riforma del sistema italiano di Diritto internazionale privato (Suppl. ord. GU Serie gen. 128 del 3 giugno 1995): "Promessa di matrimonio. 1. La promessa di matrimonio e le conseguenze della sua violazione sono regolate dalla legge nazionale comune dei nubendi o, in mancanza, dalla legge italiana".

${ }^{85}$ Decreto Corte Apello Torino 23 diciembre 2010, Rivista di Diritto internazionale privato e processuale, 2011, p. 478 [sentencia siria que procede a la ruptura del compromiso matrimonial "ktab ktab" propio del Derecho sirio]).

${ }^{86}$ Art. 45 de la Ley belga que contiene el Código de Derecho internacional privado de 16 julio 2004: «La promesse de mariage est régie: $1^{\circ}$ par le droit de l'Etat sur le territoire duquel l'un et l'autre des futurs époux ont leur résidence habituelle au moment de la promesse de mariage; $2^{\circ}$ à défaut de résidence habituelle sur le territoire d'un même Etat, par le droit de l'Etat dont l'un et l'autre des futurs époux ont la nationalité au moment de la promesse de mariage; $3^{\circ}$ dans les autres cas, par le droit belge».

${ }^{87}$ B. Barel / St. Armellini, Manuale breve Diritto internazionale privato: tutto il programma d'esame con domande e risposte commentate, Milano, Giuffrè, 2006, p. 136: "Come per il matrimonio, il criterio di collegamento è quello della cittadinanza comune, in mancanza della quale si applica la legge italiana".

${ }^{88}$ P. MAYer / V. Heuzé, Droit international privé, $11^{\mathrm{a}}$ ed., Issy-les-Moulineaux, LGDJ, 2014, n. 548: “.... Pourtant, le problème est au fond celui de la liberté du mariage, et il pourrait être rattaché au statut personnel, donc soumis à la loi nationale; au cas où les deux fiancés n'auraient pas la même nationalité, on retiendrait la nationalité de fauteur de la rupture, puisque c'est sa liberté qui est en cause". También explicado por Y. Loussouarn / P. Bourel / P. DE VAReILles-Sommières, Droit international privé, $10^{\mathrm{a}}$ ed., Paris, Dalloz, 2013, p. 391, n. 288. La opinión de M. HaBicht puede leerse apud J.A. TomÁs Ortiz DE LA TORRE, „Formación del matrimonio y estados del vínculo en el Derecho civil internacional español“, en M. AGUILAR Navarro y otros, Lecciones de Derecho civil internacional, Serv.publ. Facultad Derecho, Univ.Complutense. Madrid, 1982, pp. 121-129, esp. p. 126-127. 
la mujer, y sostuvo que las normas de conflicto alemanas remitían la regulación de la cuestión a la Ley de Nueva York como Ley personal del sujeto que rompe la promesa. En efecto, con arreglo a la Ley de Nueva York, el incumplimiento de la promesa de matrimonio no da acción de ningún tipo a la otra parte ${ }^{89}$.

También en este sentido se manifiesta E. SirRo, para el que la Ley personal del presunto responsable de la ruptura de la promesa matrimonial se corresponde con la Ley del país de más previsible aplicación para las partes y con la naturaleza del "contract to marry": una persona se obliga con arreglo a su propia Ley personal y ambas partes saben perfectamente cuál es la Ley personal del prometido incumplidor ${ }^{90}$.

52. En España, esta calificación llevaría a aplicar el art. 9.1 CC y, en consecuencia, la Ley nacional del prometido que realiza la promesa de matrimonio, pues como afirmara sagazmente M.A. AMORES CONRADI, el art. 9.1 CC no sólo establece la Ley aplicable a las materias expresamente señaladas en el precepto. Además de ello, el articulo citado recoge un principio general de reglamentación que sirve para interpretar el sistema español de Derecho internacional privado en las materias relativas al Derecho de la persona y familia, el tradicional "estatuto personal", así como para integrar las lagunas legales que puedan surgir en la materia ${ }^{91}$.

\section{d) Perspectiva europea: rechazo de la calificación familiar}

53. Las argumentaciones anteriores en favor de una calificación familiar, matrimonial o personal se basan en análisis de la naturaleza jurídica de la promesa llevados a a cabo en el seno de Derechos nacionales concretos. Desde la perspectiva del Derecho europeo, este análisis resulta ser muy diferente. Preciso resulta arrancar de datos positivos propios del Derecho europeo y no de las concepciones propias del Derecho nacional de los Estados miembros. Como se ha indicado anteriormente: el Derecho internacional privado europeo excluye de todos sus reglamentos ciertas materias que denomina "relaciones familiares" y "estado civil". Así se aprecia en el art. 1.2.b) RR-I, art. 1.2.a) RR-II y art. 1.2.a) RB I-bis. Un análisis de estas disposiciones así lo demuestra.

52. En primer lugar, el art. 1.2.a) RR-II excluye del ámbito de aplicación del Reglamento Roma II "las obligaciones extracontractuales que se deriven de relaciones familiares". En segundo lugar, el art. 1.2.a) RR-I excluye de su ámbito de aplicación material "el estado civil y la capacidad de las personas físicas", y el art. 1.2.) RR-I excluye del ámbito de aplicación del Reglamento Roma I "las obligaciones que se deriven de relaciones familiares y de relaciones que la legislación aplicable a las mismas considere que tienen efectos comparables, incluida la obligación de alimentos". En tercer lugar, el art. 1.2.a) RB I-bis excluye del ámbito de aplicación del Reglamento Bruselas I-bis "el estado y la capacidad de las personas físicas, los regímenes matrimoniales o los que regulen relaciones con efectos comparables al matrimonio según la ley aplicable". Pues bien, puede afirmarse que estas exclusiones no cubren las reclamaciones derivadas del incumplimiento de una promesa de matrimonio y ello por varias razones.

En primer lugar, el Considerando (10) del Reglamento Roma II indica que "[l]as relaciones familiares deben abarcar parentesco, matrimonio, afinidad y familia colateral". Deja pues, claro este texto, que el art. 1.2.a) RR-II no se aplica a la promesa de matrimonio y ésta no está excluida del Reglamento Roma II. El art. 1.2.a) RR-II alude al matrimonio y a figuras jurídicas con rasgos similares,

${ }^{89}$ E. Rabel, The conflict of laws: A comparative study. Vol. 1: Introduction: Family Law, $2^{\mathrm{a}}$ ed., Ann Arbor, The university of Michigan press, Chicago, Callaghan \& company, 1958, pp. 215-221, esp. p. 219.

${ }^{90}$ E. SPIRo, "Breach of Promise (Based on Guggenheim v. Rosenbaum", The International and Comparative Law Quarterly, 1962, vol. 11, n.1 (January 1962), pp. 260-266: "It seems to me that, subject to paragraph 4, infra, the personal law of the defendant is the most appropriate solution. It has regard to the nature of the contract to marry and satisfies the requirements of certainty (...) The learned judge applied the proper law of the contract to marry which, in his view, was the law of South Africa. The law of South Africa happened also to be the lex fori. It is probably for this reason that the learned judge did not deal with the question whether the claim before him was not in the nature of a remedy subject to the lex fori on that ground".

${ }_{91}$ M.A. Amores Conradi, “Art. 9.1 CC”, en AA.VV., Comentario del Código civil, publicado por el Ministerio de Justicia, Madrid, 1991, pp. 76-79. 
como las parejas registradas, así como a relaciones de parentesco, como la filiación. Dicho esto, debe recordarse que la promesa de matrimonio no hace surgir ninguna relación de parentesco ni relación familiar alguna entre los prometidos, como ya observó G. BALLADORE PALLIERI en dos diferentes ediciones de su magnífico Diritto internazionale privato $(1950 \text { y } 1974)^{92}$. La promesa de matrimonio no convierte a los prometidos en familia ni hace surgir ningún vínculo de familia entre los mismos, recuerda J.A. TOMÁs ORTIZ DE LA TORRE ${ }^{33}$. Tampoco obliga a instaurar entre los prometidos una relación de familia ni de matrimonio. Como indicara J.D. GonZÁlez CAMPos, en realidad, la calificación familiar de la promesa de matrimonio resulta forzada: dicha promesa no da lugar a ninguna relación de familia, pues sólo existe un pacto de futuro respecto a la unión matrimonial ${ }^{94}$.

En segundo lugar, la promesa de matrionio tampoco es un matrimonio ni un contrato o pacto previo al matrimonio. De hecho, la familia no se ha creado todavía, el matrimonio no se ha celebrado y por eso los legisladores nacionales regulan la promesa de matrimonio de manera separada a los derechos y deberes de los cónyuges una vez celebrado el matrimonio.

En tercer lugar, ningún Derecho nacional establece un régimen económico particular y específico para los "prometidos", recuerda P. MANKowski, régimen que pueda aplicarse a las obligaciones, extracontractuales o contractuales, que pudieran surgir entre los prometidos ${ }^{95}$.

${ }^{92}$ G. Balladore Pallieri, Diritto internazionale privato, en "Trattato di diritto civile e commerciale", Giuffrè, Milano, 1974, pp. 173-174: "A considerarla appartenente al diritto di famiglia, a parte che una famiglia non c'è, ne deriverebbe la difficoltà di trovare una legge regolatrice nel caso di promessa tra persone di diversa cittadinanza...”. Más claramente puede explorarse este argumento en la edición anterior de la misma obra, i.e., G. BALLADORE PALLIERI, Diritto internazionale privato, $2^{\mathrm{a}}$ ed., Giuffrè, Milano, 1950: "Il fatto che il nostro codice includa la promessa di matrimonio nel libro dedicato ai rapporti familiari non è un elemento rilevante o almeno decisivo, come del resto riconosce, e già lo abbiamo visto, anche la corrente dottrina. D'altra parte è ben certo che la promessa di matrimonio non fa sorgere, tra coloro che la Il fatto che il nostro che la prestano, alcun vincolo o alcun rapporto familiare e che, quindi non appartiene di per sè ai diritti di famiglia. È anche certo che giuridicamente essa non fa sorgere alcun obbligo di costituire un rapporto familiare, poiché la sua inadempienza può dar luogo solo a risarcimento di danni o ad altre conseguenze patrimoniali, ma non certo alla pretesa che il matrimonio venga celebrato. Tutto ciò che si può dire è che, se la promessa, viene adempiuta, sorge un rapporto familiare; ma dedurre da questo solo fatto che anche la promessa, di matrimonio appartiene al diritto familiare, sarebbe come sostenere che la promessa di vendita appartiene ai diritti reali perchè, se adempiuta, dà luogo al trasferimento di un diritto reale. Come la promessa di vendita appartiene, per comune consenso, al diritto delle obbligazioni ed è regolata dalla legge competente per queste, e non da quella applicabile ai diritti reali, così la promessa di matrimonio appartiene al diritto delle obbligazioni, e non è nemmeno, come le convenzioni matrimoniali, in tal modo connessa con certi rapporti familiari e regolata in vista delle peculiarità di questi, da potersi considerare una loro parte integrante".

${ }^{93}$ J.A. Tomás Ortiz de la Torre, "Celebración del matrimonio", en M. Aguilar Benítez de Lugo y otros, Lecciones de Derecho civil internacional, Ed. Tecnos, Madrid, 1996, pp. 088-116, esp. p. 94: “... las normas de colisión y sus reglas interpretativas suponen unas actitudes prematrimoniales, pero que en modo alguno constituyen de por sí relaciones jurídicas familiares. La promesa de matrimonio y los gastos que se inician con vistas a éste (compra de vivienda para futuro domicilio conyugal, utillaje, ajuar, etc.) no crean la relación jurídica matrimonial base de la familia; desde la perspectiva de la Ley, claro está, no afectan ni al domicilio de los novios, ni a su residencia habitual, ni a la nacionalidad (que ya no queda afectada ni con la celebración del matrimonio), ni producen efectos jurídicos personales (fidelidad, cohabitación, mandato doméstico, etc.) ni patrimoniales como régimen económico del matrimonio. Los actos jurídicos que se llevan a cabo con anterioridad a la celebración del matrimonio se enmarcan en una situación prefamiliar, pero no pasan las fronteras del de familia aun cuando tales actos tengan como fin la constitución de la familia e incluso algunos sólo tengan razón de ser con relación a ese fin (por ejemplo, otorgamiento de capitulaciones prematrimoniales, no llegando a celebrarse después del matrimonio)".

${ }^{94}$ J.D. GonZÁlez CAmpos, "El matrimonio en el Derecho civil internacional", en M. AguILAR Navarro, Derecho civil internacional, Facultad de Derecho, Universidad Complutense, Madrid, 4a ed,. 1975 (reimpresión 1979), pp. 243-371, esp. pp. 261-262: "En función de estos elementos, podría sostenerse que el objetivo de política legislativa de las normas materiales del Derecho español es el de proteger a la parte por el hecho de esa ruptura sin justa causa, tras haber iniciado los actos preparatorios del matrimonio. Y la protección se concreta en la posibilidad de un resarcimiento del daño patrimonial ocasionado por el incumplimiento de la promesa. Los intereses de Ia parte lesionada, de este modo, aparecen como dominantes. Por ello, en la perspectiva del Derecho internacional privado debe descartarse una construcción analógica con el régimen matrimonial, que responde a objetivos e intereses distintos. La solución adecuada desde este planteamiento sería estar a la ley de la residencia habitual de la parte perjudicada por la ruptura. La sustitución de la ley nacional (conexión de base en nuestro sistema) por la residencia habitual se justifica en atención que ésta expresa la conexión directa de la víctima con su medio social, que es donde se han manifestado los efectos de la ruptura injustificada y donde, de ordinario, se han sufrido los daños cuyo resarcimiento cabe exigir".

${ }^{95}$ P. Mankowski, “Art. 1 Rome II Regulation”, en U. Magnus / P. Mankowski (Eds.), Rome II Regulation, European Commentaries on Private International Law, Köln, Verlag Dr. Otto Schmidt, 2019, pp. 56-129, esp. p. 95: “Mere engagements intended to lead to future marriage between the now 'fiancées' are sometimes regarded as being covered by [Article 1] (2) (a). 
En cuarto término, el hecho de que la promesa de matrimonio se regule en ciertos códigos civiles nacionales, como el italiano y el español, en la parte de dichos códigos dedicada al matrimonio, no dice nada en concreto ni definitivo sobre la naturaleza jurídica de la promesa de matrimonios, como han subrayado G. Balladore Pallieri y J.A. Tomás Ortiz de la Torre ${ }^{96}$.

En quinto lugar, debe destacarse con especial énfasis que las reclamaciones judiciales por ruptura de la promesa de matrimonio tiene como objeto la recuperación de los gastos hechos en vistas de un matrimonio que no se celebra. No es la ruptura de la promesa lo que hace surgir la responsabilidad civil, enfatiza A. WeILL, sino los gastos efectuados por razón de un matrimonio que no se celebró a pesar de que existía una previa promesa de matrimonio ${ }^{97}$.

En sexto lugar, las materias excluidas del Reglamento Roma I, Roma II y Bruselas I-bis II deben interpretarse de forma restrictiva. Con ello se potencia el efecto útil de estos reglamentos. De este modo, al no estar expresamente contemplada la exclusión de tales reglamentos de la promesa de matrimonio, debe afirmarse que los daños contractuales o extracontractuales sufridos tras una ruptura de la promesa de matrimonio están incluidos en los reglamentos europeos citados. Queda por ver, de todos modos, si las reclamaciones por gastos efectuados tras la ruptura de la promesa de matrimonio presentan carácter contractual o extracontractual. En el primer caso, sería aplicable el Reglamento Roma I. En el segundo, sería aplicable lo es el Reglamento Roma II.

55. Puede, pues afirmarse, que desde el punto de vista del Derecho europeo, las relaciones entre novios y prometidos formalizadas en una promesa de matrimonio no son "relaciones de familia". Por tanto, los reglamentos europeos Roma I y Roma II citados anteriormente no excluyen las reclamaciones entre los ex-prometidos. Por tanto, si surgen obligaciones extracontractuales entre tales sujetos, por ejemplo, por daños que uno causa a otro, el Reglamento Roma II es aplicable. Si se estima que la promesa de matrimonio es un contrato, entonces las reclamaciones entre los ex-prometidos se regularán por el Reglamento Roma I.

\section{e) Calificación propia: the proper law}

56. Por otro lado, ciertos autores, como es el caso, significativamente, del jurista alemán L. RAAPE, han considerado que la promesa de matrimonio no puede calificarse ni como contrato, ni como obligación extracontractual ni como relación de familia ni como cuestión relativa a la persona ${ }^{98}$. Existe, se dice, una laguna calificatoria. De ese modo, ante la ausencia de una norma de conflicto europea y nacional de los Estados miembros que pueda aplicarse para determinar la Ley aplicable a la promesa de matrimonio, se debe recurrir a los principios generales del Derecho internacional privado y en concreto al principio de los vínculos más estrechos. Si se acepta esta perspectiva, entonces la Ley aplicable a la promesa de matrimonio debe ser, indica con su habitual brillantez E. RABEL, la Ley del país más

Yet it appears hardly conceivable that engagements really carry a regime of common property between the fiancées. If and insofar as non-registered partnerships in general carry such regime under their respective applicable law it appears unnecessary to refer to the engagement as some kind of specific sub-type". En el mismo sentido, también, J.A. TOMÁs ORTIZ DE LA TORRE, "Celebración del matrimonio", en M. Aguilar Benitez de Lugo y otros, Lecciones de Derecho civil internacional, Ed. Tecnos, Madrid, 1996, pp. 088-116, esp. p. 94.

${ }^{96}$ G. Balladore Pallieri, Diritto internazionale privato, $2^{\mathrm{a}}$ ed., Giuffrè, Milano, 1950: "Avverto preliminarmente che non tratto a questo proposito degli sponsali, poiché, malgrado la collocazione di questi nel codice tra gli istituti familiari, malgrado l'assenso della pressoché unanime dottrina e giurisprudenza, non mi sembra che questa qualificazione si possa accogliere ai fini del diritto internazionale privato"; J.A. TomÁs Ortiz de la Torre, "Celebración del matrimonio", en M. Aguilar BeníteZ DE Lugo y otros, Lecciones de Derecho civil internacional, Ed. Tecnos, Madrid, 1996, pp. 088-116, esp. p. 94: “... los esponsales aun cuando ubicados en el Código Civil dentro del «matrimonio» y, por consiguiente, del Derecho de familia, se desplazan claramente del mismo. La «colocación» de una institución dentro del CC puede ser guía para lograr su calificación, pero no siempre resulta regla invariable".

${ }_{97}$ A. WeILl, "Fiançailles”, Encyclopedie Dalloz droit international, París, 1968-69 (dir. Ph. Franceskakis), vol.II, 1969, pp. $22-24$.

${ }_{98}^{9}$ R. RAAPE, Internationales Privatrecht, 5th ed., Berlin - Frankfurt a.M., Verlag Franz Vahlen GmbH, 1961. pp. 266-274. 
estrechamente conectado con la misma, que habría que concretar caso por caso, con atención a las circunstancias concretas de cada supuesto específico, sin que se puedan ofrecer puntos de conexión fijos $a$ priori para determinar cuál es el país más vinculado ${ }^{99}$.

57. Algunos autores, en este sentido, han defendido la aplicación de la Ley nacional de la persona víctima de la ruptura de la promesa, puesto que la reputación de dicha persona y sus expectativas razonables de matrimonio son los elementos en mayor medida dañados por la rotura de la promesa de matrimonio. Es ésta la solución propuesta por P.H. NeUHAus ${ }^{100}$. En la misma perspectiva, pero en favor de la Ley del lugar de residencia habitual de la víctima se manifestó F. VISCHER, que estimaba que el daño principal derivado de esta ruptura se producía en dicho país ${ }^{101}$. En igual sentido se pronuncia L. RAAPE ${ }^{102}$.

\section{f) Calificación extracontractual}

58. Queda, así, por dilucidar si la ruptura de la promesa de matrimonio y de los esponsales puede y/o debe calificarse como una cuestión en materia contractual o extracontractual. Para ello es preciso tener presente el concepto de "materia delictual o cuasidelictual" o "responsabilidad extracontractual" propio del Derecho europeo.

59. En Derecho internacional privado europeo, el concepto de "materia delictual o cuasidelictual" o "responsabilidad extracontractual" debe definirse de forma autónoma. Se trata de un concepto jurídico europeo que debe concretarse a los efectos del Reglamento Bruselas I-bis y Reglamento Roma II, y con arreglo a criterios hermenéuticos propios del DIPr. europeo, esto es, según el sistema y a los objetivos de dichos Reglamentos. No deben tenerse presentes las definiciones del concepto "materia delictual o cuasidelictual" contenidas en los Derechos nacionales de los Estados miembros. Así lo ha indicado el TJUE en constante, sólida y abundante jurisprudencia ${ }^{103}$.

60. En general, puede afirmarse que el TJUE ha indicado que el concepto de "materia delictual o cuasi delictual" es muy extenso. Comprende toda obligación que no surge de una relación jurídica li-

${ }^{99}$ E. Rabel, The conflict of laws: A comparative study. Vol. 1: Introduction: Family Law, $2^{\mathrm{a}}$ ed., Ann Arbor, The university of Michigan press, Chicago, Callaghan \& company, 1958, p. 221: "It would be preferable for the conflicts rule to be free from interfering substantive law; the rule should simply refer the rights and obligations flowing from an engagement to the law of the place regarded under the circumstances as the center of the social relation between the parties at the time of engagement".

${ }^{100}$ P.H. Neuhaus, Die Grundbegriffe des Internationalen Privatrechts, 2a ed., Tübingen, 1976, esp. p. 126.

${ }^{101}$ Apud E. VitTA, Diritto internazionale privato vol. II, UTET, Torino, 1973, pp. 167-171, esp. p. 169 nota [8] y apud J.A. Tomás Ortiz de la Torre, “Celebración del matrimonio”, en M. Aguilar Benítez de Lugo y otros, Lecciones de Derecho civil internacional, Ed. Tecnos, Madrid, 1996, pp. 88-116, esp. pp. 91-95.

${ }^{102}$ R. RAAPE, Internationales Privatrecht, 5th ed., Berlin - Frankfurt a.M., Verlag Franz Vahlen GmbH, 1961. pp. 266-274. La solución propuesta por L. RAAPE es comentada por J.A. TOMÁS ORTIZ DE LA TORRE, "Formación del matrimonio y estados del vínculo en el Derecho civil internacional español", en M. Aguilar NaVArro y otros, Lecciones de Derecho civil internacional, Serv.publ. Facultad Derecho, Univ.Complutense. Madrid, 1982, pp. 121-129, esp. p. 126. En el mismo sentido indica W. Goldschmidt, Sistema y filosofía del Derecho internacional privado, t.I, Ed.Bosch, Barcelona, 1948, pp. 227-229, que: "L. RAAPE, en Alemania, aplica la ley que se aplica a los efectos de un contrato (....) a favor de la ley domiciliaria de la víctima".

${ }^{103}$ STJUE 24 noviembre 2020, C-59/19, Wikingerhof GmbH \& Co. KG vs. Booking.com BV, [ECLI:EU:C:2020:950], FD 25; STJUE 12 septiembre 2018, C-304/17, Helga Löber vs. Barclays Bank plc [ECLI:EU:C:2018:701], FD 19; STJUE 21 diciembre 2016, C-618/15, Concurrence SARL vs. Samsung Electronics France SAS, Amazon Services Europe Sàrl [ECLI:EU:C:2016:976], FD 25; STJUE 14 julio 2016, C-196/15, Granarolo SpA vs. Ambrosi Emmi France SA. [ECLI:EU:C:2016:559], FD 19-20; STJUE 16 junio 2016, C-12/15, Universal Music International Holding BV vs. Michael Tétreault Schilling, [ECLI:EU:C:2016:449], FD 24; STJUE 21 abril 2016, C-572/14, Austro-Mechana Gesellschaft zur Wahrnehmung mechanisch-musikalischer Urheberrechte GmbH vs. Amazon [ECLI:EU:C:2016:286], FD 29; STJCE 19 septiembre 1995, C-364/93, Antonio Marinari vs. Lloyd's Bank plc, Recopilación, 1995, p. I-2719, [ECLI:EU:C:1995:289] STJUE 28 enero 2015, C-375/13, Harald Kolassa vs. Barclays Bank plc. [ECLI:EU:C:2015:37], FD 43; STJUE 25 octubre 2011, C-509/09 y C-161/10, eDate Advertising GmbH vs. Xy Olivier Martinez, Robert Martinez y MGN Limited, Recopilación, 2011, p. I-10269. [ECLI:EU:C:2011:685], FD 38; STJCE 22 marzo 1983, 34/82, Peters vs. Zuid Nederlandse Aannemers Vereniging, Recueil, 1983, pp. 987-1012. [ECLI:EU:C:1983:87], FD 17. 
bremente asumida por una parte, es decir, toda pretensión con la que se exija la responsabilidad jurídica de un demandado y que no esté cubierta por la "materia contractual" regulada en el art. 7.1 RB I-bis ${ }^{104}$

61. Importante resulta subrayar que la calificación de una relación jurídica como "contractual" o "extracontractual" es, según el TJUE, excluyente. Si se trata de materia contractual no puede ser al mismo tiempo materia extracontractual y viceversa (STJUE 24 noviembre 2020, C-59/19, Wikingerhof, FD 26 in fine). Si el demandante basa su demanda contra el demandado en las estipulaciones de un contrato que ambos han firmado, la acción será "contractual". Si se basa en disposiciones legales y no en un contrato, la acción será "delictual / extracontractual"105.

62. Para el Derecho de la UE, la diferencia entre la materia contractual y la materia delictual o cuasidelictual es clara: la materia debe ser calificada como "contractual" cuando la obligación surge de la voluntad de una persona que ha consentido libremente en obligarse a dar, hacer o no hacer algo frente a otra parte. Frente a ello, la materia es "delictual o cuasi-delictual" / "extracontractual" cuando la obligación nace de la Ley, que impone a un sujeto el deber legal de dar, hacer o no hacer alguna cosa, con independencia e incluso en contra de la voluntad del sujeto obligado, como ha declarado el TJUE ${ }^{106}$. En consecuencia, el concepto de "obligaciones extracontractuales" cubre todas las obligaciones que surgen directamente de la Ley y no de la voluntad de una persona ni tampoco de una relación jurídica previa entre dos sujetos, como la filiación, el matrimonio, la tutela, etc.

63. Las reclamaciones surgidas por la ruptura de una promesa de matrimonio deben ser calificadas como reclamaciones en materia extracontractual. Esta tesis parece ser la más solvente a la luz del Derecho europeo y ha sido sostenida desde hace ya años por numerosos especialistas.

Es una tesis francesa, pues la mayor parte de la doctrina y de la jurisprudencia de ese país, estimaron que estas reclamaciones debían ser calificadas como casos de responsabilidad extracontractual. Así puede verse en los escritos de A. Weill, P. Bourel, J.-P. Niboyet, H. Batiffol, entre otros muchos expertos jurídicos franceses ${ }^{107}$. En general, en Francia la jurisprudencia se manifestó en favor de una

${ }^{104}$ STJUE 24 noviembre 2020, C-59/19, Wikingerhof GmbH \& Co. KG vs. Booking.com BV, [ECLI:EU:C:2020:950], FD 23; STJUE 12 septiembre 2018, C-304/17, Helga Löber vs. Barclays Bank plc [ECLI:EU:C:2018:701], FD 19; STJUE 18 julio 2013, C-147/12, ÖFAB, Östergötlands Fastigheter AB vs. Frank Koot, Evergreen Investments BV. [ECLI:EU:C:2013:490], FD 32; STJUE 15 noviembre 2012, C-456/11, Gothaer Allgemeine Versicherung AG, ERGO Versicherung AG, Versicherungskammer Bayern-Versicherungsanstalt des öffentlichen Rechts, Nürnberger Allgemeine Versicherungs-AG, Krones AG vs. Samskip GmbH. [ECLI:EU:C:2012:719], FD 45; STJUE 28 julio 2016, C-191/15, Verein für Konsumenteninformation vs. Amazon EU Sàrl [ECLI:EU:C:2016:612], FD 37.

${ }^{105}$ STJUE 24 noviembre 2020, C-59/19, Wikingerhof GmbH \& Co. KG vs. Booking.com BV, [ECLI:EU:C:2020:950], FD 26: "Por lo que respecta, en primer lugar, a la sistemática del Reglamento n. 1215/2012, este se basa en la regla general de la competencia de los órganos jurisdiccionales del Estado miembro del domicilio del demandado, mientras que las reglas de competencia especial previstas en particular en su artículo 7 constituyen excepciones a esa regla general y, en cuanto tales, deben interpretarse en sentido estricto (...) y son mutuamente excluyentes en la aplicación de ese Reglamento".

${ }^{106}$ STJCE 22 marzo 1983, 34/82, Peters vs. Zuid Nederlandse Aannemers Vereniging, Recueil, 1983, pp. 987-1012. [ECLI:EU:C:1983:87]; STJCE 27 septiembre 1988, 189/87, Kalfelis vs. Schröder, Recopilación, 1988, pp. 5565-5588 [ECLI:EU:C:1988:459]; STJCE 10 enero 1990, C-115/88, Reichert vs. Dresdner Bank [I], Recopilación, 1990, pp. 27-44. [ECLI:EU:C:1990:3]; STJCE 26 marzo 1992, C-261/90, Reichert vs. Dresdner Bank [II], Recopilación, 1992, pp. 21492186. [ECLI:EU:C:1992:149]; STJCE 19 septiembre 1995, C-364/93, Antonio Marinari vs. Lloyd's Bank plc, Recopilación, 1995, p. I-2719. [ECLI:EU:C:1995:289]; STJCE 19 mayo 1998, C-351/96, Drouot assurances SA vs. Consolidated metallurgical industries (CMI industrial sites), Protea assurance, Groupement d'intérêt économique (GIE) Réunion européenne, Recopilación, 1998, p. I-3075. [ECLI:EU:C:1998:509]; STJCE 11 julio 2002, 96/00, Rudolf Gabriel, Recopilación, 2002, p. I-6367. [ECLI:EU:C:2002:436]; STJCE 17 septiembre 2002, C-334/00, Fonderie Officine Meccaniche Tacconi SpA vs. Heinrich Wagner Sinto Maschinenfabrik GmbH (HWS), Recopilación, 2002, p. I-07357. [ECLI:EU:C:2002:499]; STJUE 17 octubre 2013, C-519/12, OTP Bank Nyilvánosan Müködö Részvénytársaság vs. Hochtief Solution AG, [ECLI:EU:C:2013:674], FD 26; STJUE 28 enero 2015, C-375/13, Harald Kolassa vs. Barclays Bank plc. [ECLI:EU:C:2015:37], FD 40-41; STJUE 16 junio 2016, C-12/15, Universal Music International Holding BVvs. Michael Tétreault Schilling, [ECLI:EU:C:2016:449], FD 24.

${ }^{107}$ H. BatifFol, Aspects philosphiques du droit international privé, Paris, Dalloz, 1956, p. 135; A. Weill, "Fiançailles", Encyclopedie Dalloz droit international, París, 1968-69 (dir. Ph. Franceskakis), vol.II, 1969, pp. 22-24; P. Bourel, Les conflits de lois en matière d'obligations extracontractuelles, París, LGDJ, 1961, pp. 117-120; J. DeRruPÉ / J.-P. Laborde, Droit international privé, Dalloz, 16 a ed., 2008, pp. 138-139: «Les fiançailles, spécialement pour ce qui touche la réparation de leur rupture 
calificación extracontractual y, en consecuencia, defendió la aplicación de la Ley del lugar donde ha ocurrido el hecho ilícito, hecho del que deriva la obligación de reparar los daños causados ${ }^{108}$.

En la doctrina italiana apoyó esta calificación, solitariamente, G. BALLADORE-PALLIERI ${ }^{109}$. Es curioso señalar que en un caso aislado fallado por los tribunales italianos, -y ello a pesar de que casi toda la doctrina de dicho país defendiera una calificación familiar de estas reclamaciones y la aplicación de la Ley nacional de las partes-, una sentencia del tribunale di Sondrio (Italia) de 21 febrero 1953, Moser vs. Sironi optó por la tesis francesa, esto es, por la calificación extracontractual ${ }^{110}$. Se trataba de una promesa de matrimonio realizada por un ciudadano italiano a su novia suiza. Ante la ruptura de tal promesa, la ciudadana suiza reclamó una indemnización. El tribunale di Sondrio (Italia) aplicó el Derecho suizo, pues la ruptura de la promesa se calificó como un hecho ilícito que generaba responsabilidad civil extracontractual y el tribunal estimó que tal hecho ilícito había tenido lugar en Suiza: lex loci actus.

En la doctrina española fue J.D. GonzÁLEZ CAMPos el defensor de esta tesis extracontractual, al que siguió J.M. EsPinar Vicente ${ }^{11}$. De modo perspicaz y brillante, J.D. GonZÁlez CAmpos, aun sin

fautive, relèvent du statut des faits juridiques»; F. MéLın, Droit international privé: droit des conflits de juridictions, droit des conflits de lois, droit de la nationalité, condition des étrangers en France, $8^{\mathrm{a}}$ ed., Issy-les-Moulineaux, Gualino, 2018, p. 156: «Les quelques décisions qui sont intervenues en ce domaine penchent plutôt pour une extension de la qualification utilisée en matière interne. Les fiançailles sont dépourvues d'effet juridique autonome et ne sont appréhendées par le droit qu'en cas de rupture fautive. On peut donc estimer que les fiançailles doivent relever de la règle de conflit applicable en matière délictuel»; P. Courbé, Droit international privé, Colin-Dalloz, Paris, 2007, p. 225: «Il faut noter, au préalable, que les fiançailles ou le concubinage, qui n'ont pas généré encore de contentieux abondant dans les relations internationales, sont rattachés à la responsabilité délictuelle»; D. Bureau / H. Mur Watt, Droit international privé, Tome II Partie spéciale, $3^{\mathrm{a}}$ ed., Presses universitaires de France (PUF), Paris, 2014, p. 114: «On mettra de côté les fiançailles, que le droit français exclut de la catégorie du statut personnel au nome de la liberté du mariage pour en assortir la rupture d'un rattachement délictuel»; Y. LoussouARN / P. Bourel / P. de VAReIlles-Sommières, Droit international privé, 10ª ed., Paris, Dalloz, 2013, p. 391, n. 288: «S'appuyant sur les données du droit interne, la tendance de la doctrine française est d'intégrer la matière dans la catégorie des obligations délictuelles. La jurisprudence bien que rare, paraît également favorable à ce point de vue. Sans doute conviendrait-il, tout en maintenant le principe de la lex loci delicti commissi, d'aménager le rattachement proposé en tenant compte du caractère particulier relations entre fauteur de la rupture de fiançailles et sa victime»; B. AuDIT, Droit international privé, $5^{\mathrm{a}}$ ed., Issyles-Moulineaux, LGDJ, 2006, p. 514: «Mais la conception française interne n'attache aux fiançailles aucune obligation de contracter mariage et la promesse ne crée aucun embryon de famille de nature à justifier pleinement la qualification de statut personnel. Aussi peut-on également rapprocher la rupture des fiançailles du statut délictuel, la loi applicable étant alors celle du lieu de la rupture fautive»; E. RABEL, The conflict of laws: A comparative study. Vol. 1: Introduction: Family Law, $2^{\mathrm{a}}$ ed., Ann Arbor, The university of Michigan press, Chicago, Callaghan \& company, 1958, pp. 215-221, esp. p. 217: "The majority of the countries following the French system, consider liability for breach of promise to marry to pertain to tort law. Consequently, in conflicts cases the law of the place of the wrong is held to be applicable, but no clear rules exist for the determination of the place of the wrong in such instances". Aunque no comparten esta calificación extracontractual, admiten que se trata de la tendencia dominante en la doctrina francesa P. MAYER / V. HeuZÉ, Droit international privé, 11 $1^{\mathrm{a}}$ ed., Issy-les-Moulineaux, LGDJ, 2014, n. 548: «Un mot cependant doit d'abord être dit de la question des fiançailles: quelle loi détermine leur force obligatoire, la sanction de leur rupture? La tendance dominante, qui prend pot base les solutions du droit interne français, voit dans la rupture fautive des fiançailles la source d'une responsabilité quasi délictuelle, soumise à la loi du lieu de la rupture...».

${ }^{108}$ H. Batiffol / P. LAGARde, Droit international privé, t.II, 7 ed., LGDJ, Paris, 1983, n. 415 nota 4 bis, pp. 39-40: «La soumission du consentement à la loi personnelle inclut-elle la valeur juridique éventuelle des fiançailles? La réponse affirmative este naturelle dans les pays qui, avec la tradition canonique, admettent cette valeur; dans ceux qui comme la France, ne voient qu'une possibilité de dommages intérêts pour faute délictuelle dans la rupture, la tendance est d'applique la loi du lieu du délit». También J.A. Tomás OrTiz de la Torre, “Celebración del matrimonio”, en M. Aguilar Benítez de Lugo y otros, Lecciones de Derecho civil internacional, Ed. Tecnos, Madrid, 1996, pp. 088-116, esp. p. 94.

${ }^{109}$ Paladín único de esta calificación en la doctrina italiana fue el singular G. Balladore Pallieri, Diritto internazionale privato, en "Trattato di diritto civile e commerciale", Giuffrè, Milano, 1974, p. 174.

${ }^{110}$ Sentencia Tribunale di Sondrio (Italia) 21 febrero 1953, Moser vs. Sironi, Il Foro italiano, 1954, p. 408. También en Rivista di diritto internazionale, 1954, pp. 613-619 con nota de F. DuRANTE. Vid. C. Focarelli, Lezioni di diritto internazionale privato, Morlacchi Ed., Perugia, 2006, pp. 93-94. Muy bien comentada también por E. ViTTA, Diritto internazionale privato, vol. II, UTET, Torino, 1973, pp. 167-171, esp. p. 169.

${ }^{111}$ J.D. GonzÁlez Campos, "El matrimonio en el Derecho civil internacional”, en M. Aguilar Navarro, Derecho civil internacional, Facultad de Derecho, Universidad Complutense, Madrid, $4^{a}$ ed, 1975 (reimpresión 1979), pp. 243-371, esp. pp. 261-262: "En función de estos elementos, podría sostenerse que el objetivo de política legislativa de las normas materiales del Derecho español es el de proteger a la parte por el hecho de esa ruptura sin justa causa, tras haber iniciado los actos preparatorios del matrimonio. Y la protección se concreta en la posibilidad de un resarcimiento del daño patrimonial ocasionado por el incumplimiento de la promesa. Los intereses de Ia parte lesionada, de este modo, aparecen como dominantes. Por ello, en la perspectiva del Derecho internacional privado debe descartarse una construcción analógica con el régimen matrimonial, que 
afirmarlo de modo expreso, califica la promesa de matrimonio como un caso especial de responsabilidad civil extracontractual que debe sujetarse a la Ley del país donde la ruptura de la promesa de matrimonio produce el daño. Se puede considerar que dicho daño se produce en el país de la residencia habitual de la víctima de la ruptura de la promesa. Dicho país corresponde al medio social de la víctima, donde normalmente se han realizados los gastos a indemnizar. Es la Lex loci commissi delicti, la Ley del país donde ha ocurrido el hecho ilícito extracontractual ${ }^{112}$.

64. Desde el punto de vista del Derecho internacional privado europeo se impone, la tesis extracontractual y ello por varios motivos.

En primer lugar, cabe afirmar que la obligación de resarcir los gastos efectuados en vista del matrimonio que no se ha llegado a celebrar y en presencia de una promesa de matrimonio deriva directamente de la Ley y no de la voluntad libre de una persona. En estos casos, nadie se obliga previa y voluntariamente a indemnizar los gastos realizados propter nuptias. Es la Ley la que impone dicha obligación cuando: (a) se incumple la promesa de matrimonio (= que, en la inmensa mayoría de los ordenamientos jurídicos, no puede ser obligada a cumplirse en sí misma), (b) la parte que no ha incumplido su promesa de contraer matrimonio ha efectuado ciertos gastos en vistas a un matrimonio que no se celebró y (c) la no celebración del matrimonio se produce sin una causa. Por tanto, esta obligación de reembolsar los gastos nace directamente de la Ley y protege la confianza de la persona en el acuerdo de contraer matrimonio. En consecuencia, la Ley impone la obligación de indemnizar los daños causados cuando un sujeto ha roto su promesa de matrimonio sin causa o con culpa. Es, pues, claro, indican A. WeILl y H. BATIFFOL, que la obligación de indemnizar los gastos realizados propter nuptias tras una promesa de matrimonio presenta una naturaleza extracontractual ${ }^{113}$. No deriva de un compromiso libremente asumido por una persona ni de un contrato incumplido. No se basa en los derechos y deberes de familia ni forma parte del régimen económico matrimonial o para matrimonial.

En segundo lugar, como ha indicado J.D. GonZÁlez CAMPos, la regulación jurídica de la inmensa mayoría de las Leyes de los distintos en relación con la ruptura de esponsales y de la promesa de matrimonio, se limita a la posibilidad de un resarcimiento de los gastos efectuados por la víctima en razón del matrimonio proyectado y no celebrado. La acción que se ejercita no apunta al cumplimiento de la promesa de matrimonio sino a la recuperación de los gastos realizados en vistas de un matrimonio prometido. Se trata de una reclamación económica de carácter resarcitorio y que se funda en la ley, porque la ley recoge la posibilidad de accionar en este caso ${ }^{114}$.

En tercer lugar, y de nuevo con J.D. GonZÁLEZ CAMPOS, la promesa de matrimonio debe calificarse como un supuesto concreto de Derecho de daños porque el objetivo de política legislativa de las normas materiales radica en proteger la confianza de la parte víctima de la ruptura de la promesa. Dicha persona ha realizado gastos en consideración al matrimonio y los ha realizado porque ha confiado en la promesa recibida, promesa que posteriormente se ha desvanecido. Por tanto, "los intereses de Ia parte lesionada, de este modo, aparecen como dominantes". En consecuencia, no procede una calificación familiar de la ruptura de la promesa de matrimonio sino una calificación que gira en torno a la idea de "reparación del daño". Un daño que se verifica al margen de las relaciones de familia y al margen de todo contrato.

responde a objetivos e intereses distintos. La solución adecuada desde este planteamiento sería estar a la ley de la residencia habitual de la parte perjudicada por la ruptura. La sustitución de la ley nacional (conexión de base en nuestro sistema) por la residencia habitual se justifica en atención que ésta expresa la conexión directa de la víctima con su medio social, que es donde se han manifestado los efectos de la ruptura injustificada y donde, de ordinario, se han sufrido los daños cuyo resarcimiento cabe exigir". Vid., en el mismo sentido, J.M. EsPINAR VICENTE, El matrimonio y las familias en el sistema español de Derecho internacional privado, Civitas, Madrid, 1996, pp. 110-111.

${ }^{112}$ Vid. nota anterior.

${ }^{113}$ A. WeILl, "Fiançailles", Encyclopedie Dalloz droit international, París, 1968-69 (dir. Ph. Franceskakis), vol.II, 1969, pp. 22-24; H. BATIFFOL, Aspects philosphiques du droit international privé, Paris, Dalloz, 1956, p. 35.

114 J.D. GonzÁlez Campos, "El matrimonio en el Derecho civil internacional”, en M. Aguilar Navarro, Derecho civil internacional, Facultad de Derecho, Universidad Complutense, Madrid, $4^{\mathrm{a}}$ ed, 1975 (reimpresión 1979), pp. 243-371, esp. pp. 261-262: “... el efecto exclusivo que el Código civil considera relevante en el supuesto de ruptura de esponsales sin causa es la posibilidad de un «resarcimiento de gastos» efectuados por la otra parte con razón del matrimonio (art. 44 Código civil)". 
65. Por todo lo anterior, puede afirmarse que la obligación de resarcir tales daños a la víctima en casos de gastos realizados en vistas de un matrimonio que no se celebra tras la ruptura de una promesa de matrimonio, deriva de la ley y no de la voluntad de una persona. Por tanto, la calificación extracontractual debe prevalecer en Derecho internacional privado europeo. En consecuencia, la determinación de los tribunales competentes se realizará con arreglo al Reglamento Bruselas I-bis y la precisión de la Ley estatal que regula el fondo de la reclamación se regirá por la Ley determinada con arreglo al Reglamento Roma II, como ha subrayado O. Boskovic ${ }^{115}$.

\section{Competencia judicial internacional}

\section{Reglamento Bruselas I-bis y responsabilidad extracontractual}

66. La competencia judicial internacional de los jueces españoles en relación con las reclamaciones por los gastos realizados y las obligaciones contraídas en razón de matrimonio cuando se ha roto un promesa de matrimonio, se determina con arreglo al Reglamento Bruselas I-bis. En efecto, la ruptura de la promesa de matrimonio origina, como se ha indicado, una responsabilidad extracontractual por esos gastos realizados y otros daños, esto es, una responsabilidad que no deriva de contrato ni tampoco de ninguna otra institución legal concreta, como el matrimonio. En los casos no cubiertos por el Reglamento Bruselas I-bis, -casos residuales que se verfican, por ejemplo, cuando el demandado tiene su domicilio en un Estado no miembro de la UE-, se aplican, en España, los foros recogidos en el art. 22 LOPJ.

\section{Foros de competencia internacional}

\section{A) Foros generales: sumisión y domicilio del demandado}

67. En el contexto del Reglamento Bruselas I-bis, el Capítulo II del mismo recoge los foros de competencia internacional que deben considerarse en casos de reclamaciones de daños por ruptura de la promesa de matrimonio (arts. 2-35 RB I-bis). Los tribunales de los Estados miembros en el Reglamento Bruselas I-bis se declararán competentes siempre que les otorgue competencia judicial internacional uno de los siguientes foros recogidos en el reglamento citado.

En primer lugar, el foro de la "sumisión expresa o tácita de las partes" al tribunal (arts. 25 y 26 RB I-bis). Es competente el tribunal de un Estado miembro al que las partes en la litis se hayan sometido voluntariamente de modo expreso o tácito. En el caso de existir dicho acuerdo, ningún otro tribunal de ningún otro Estado miembro puede conocer del litigio. La competencia por sumisión se convierte en una competencia única.

En segundo lugar, disponen también de competencia internacional los tribunales del Estado miembro donde el demandado tiene su domicilio (art. 4 RB I-bis).

En tercer lugar, disponen también de competencia internacional los tribunales del Estado miembro donde se haya verificado el hecho dañoso (art. 7.2 RB I-bis).

Estos dos foros son alternativos entre sí. El demandante elige cuál emplear. Indica el Cons. 16 RB I-bis que "[e]l foro del domicilio del demandado debe completarse con otros foros alternativos a causa de la estrecha conexión existente entre el órgano jurisdiccional y el litigio o para facilitar una buena administración de justicia". Así lo confirma la STJCE 25 febrero 2010, C-381/08, Car Trim, FD $48^{116}$. En suma, los "foros especiales por razón de la materia" y el "foro del domicilio del demandado"

${ }^{115}$ O. Boskovic, "Règlement Rome II", Répertoire Dalloz Droit international, 2a ed., septiembre 2010; O. BosKovIC, La réparation du préjudice en droit international privé, LGDJ, 2003, París, 2003, pp. 11-19.

${ }^{116}$ STJUE 25 febrero 2010, C-381/08, Car Trim GmbH vs. KeySafety Systems Srl., Recopilación, 2010, p. I-1255 [ECLI:EU:C:2010:90], FD 48: "Constituye jurisprudencia reiterada que la regla de competencia especial en materia contractual prevista en el artículo 5, número 1, del Reglamento, que completa la regla de principio de la competencia del foro del 
operan de modo alternativo. El actor puede accionar contra el demandado ante cualquiera de estos dos foros, como reitera la jurisprudencia europea y española ${ }^{117}$.

\section{B) Foro del lugar donde ha ocurrido el hecho dañoso}

\section{a) Teoría de la ubicuidad}

68. En estos casos, el hecho dañoso se presenta de modo articulado del siguiente modo: (a) Promesa de matrimonio; (b) Ruptura de la promesa de matrimonio; (c) Daño emocional o moral y daño económico producido por dicha ruptura. Es claro que el daño es el perjuicio, emocional y/o patrimonial, que experimenta la víctima. Muchas más dificultades suscita la determinación del hecho causal del daño. Para identificar cuál es el hecho causal del daño, deben tenerse presentes varios aspectos relativos a la estructura interna de este ilícito civil.

Primero. Las normas jurídicas que regulan la responsabilidad del sujeto que incumple su promesa protegen la confianza que dicha promesa ha suscitado en la otra persona. Por tanto el elemento primordial para identificar el hecho causal del daño debe girar en torno a la confianza de la víctima

Segundo. La confianza de la víctima se protege ante una posible quiebra de la misma. Si dicha confianza se ve frustrada, -porque se confía en una declaración de voluntad que resulta fallida-, entonces surge la responsabilidad civil. Por tanto, el hecho causal del daño gira en torno a la quiebra de tal confianza. Es, en efecto, la fractura de dicha confianza la que hace que el daño se materialice. Si existe promesa de matrimonio y gastos posteriores realizados por parte de uno de los prometidos en consideración al matrimonio, entonces no hay daño ni responsabilidad.

Tercero. La confianza se crea con la promesa matrimonial. Ésta es una afirmación solemne de una persona, no una mera declaración de intenciones o deseos. Por eso se crea la confianza, porque la declaración de querer contraer matrimonio es seria, firme, sólida: es una promesa. No es la simple sola mera negativa a contraer matrimonio lo que genera el daño, sino la ruptura de una promesa de matrimonio.

Cuarto. Como se verá seguidamente, la ruptura de la promesa matrimonial puede tener lugar, a su vez en dos fases diferentes. En primer lugar, la promesa se formula, esto es, se hace evidente, se escribe o se pronuncia y se plasma de alguna manera en un concreto país. Por ejemplo, el prometido escribe una carta, un e-mail o graba un audio. En segundo lugar, la declaración de ruptura se envía y se recibe en otro lugar, donde la otra parte recibe y conoce el contenido del mensaje, el país donde la víctima es consciente de la ruptura.

En consecuencia, parece claro que la ruptura de la promesa de matrimonio es el elemento que desencadena un daño que se materializa posteriormente y que recae sobre una persona, la víctima. La ruptura de la promesa de matrimonio rompe la confianza de la víctima y es lo que le causa el daño. En conclusión, en estos casos, el lugar donde ha ocurrido el hecho causal del daño es aquél en el que la promesa se ha roto. Es éste el elemento inicial del ilícito, porque sin ruptura de la promesa no hay daños ni hay tampoco indemnización posible. El hecho causal no es la promesa, pues una promesa de matrimonio no genera daños. El hecho causal es la ruptura de la promesa de matrimonio. Dicha ruptura es la que causa los daños.

69. En estos supuestos, la promesa puede haberse realizado o formalizado en un país determinado (= donde se hace contar por escrito, por ejemplo), puede romperse en otro país distinto (= país desde donde se escribe una carta o e-mail o desde el que se envía un audio en el que una persona declara que

\footnotetext{
domicilio del demandado, responde a un objetivo de proximidad y viene motivada por la existencia de un estrecho vínculo de conexión entre el contrato y el tribunal que debe conocer del mismo".

117 Vid. en este sentido, entre otros muchos pronunciamientos, STJUE 4 octubre 2018, C-337/17, Feniks sp. z o.o. vs. Azteca Products \& Services, S.L., [ECLI:EU:C:2018:805], FD 36; Auto J Mercantil Madrid 23 abril 2019 [JUR\2019\136573] [transporte terrestre]; AAP Madrid 27 junio 2012 [contrato internacional de concesión de venta y postventa de vehículos holandeses] [CENDOJ 28079370212012200196], como ha expuesto J. CARRASCosa GonZÁLEZ, "Foro del domicilio del demandado y Reglamento Bruselas I-is 1215/2012. Análisis crítico de la regla actor sequitur forum rei”, Cuadernos de Derecho transnacional, 2019, vol. 11, n. 1, pp. 112-138.
} 
no va a contraer el matrimonio proyectado) y puede recibirse en otro (= país donde la otra persona tiene acceso al mensaje, carta, mail, audio en el que se indica que la promesa va a quedar en promesa y no se va a celebrar el matrimonio). La promesa, además, puede romperse sin declaración previa. Los actos mismos de la persona confirman que no tiene intención alguna de contraer el matrimonio que antes había prometido contraer. Debido a esta estructura del hecho ilícito, estos casos de reclamaciones por los gastos realizados con vistas de un matrimonio previa ruptura de una promesa matrimonial suelen constituir "ilícitos a distancia": el hecho causal del perjuicio se verifica en un país y el daño ocurre en otro Estado. Ello obliga a precisar cuál es, en tales supuestos, el lugar donde ha ocurrido el "hecho dañoso", esto es, el lugar donde se ha verificado la ruptura de la promesa de matrimonio ${ }^{118}$.

70. A tal efecto, el TJUE ha seguido la hiper-famosa "tesis de la ubicuidad" (Principle of Ubiquity). Indica, así, el TJUE que, en los casos de ilícitos a distancia, el "lugar donde se hubiere producido o pudiere producirse el hecho dañoso", es tanto el lugar del Estado miembro donde ha ocurrido el "hecho causal", como el lugar del Estado miembro en cuyo territorio se verifica el "resultado lesivo" o el "daño". La tesis fue creada por el TJUE en la fundamental STJCE 30 noviembre 1976, 21/76, Mines de Potasse d'Alsace. La tesis ha sido posteriormente corroborada por numerosa jurisprudencia ${ }^{119}$. Su fundamento básico es la idea de previsibilidad del tribunal competente para las partes. En efecto, tanto demandante como demandado pueden razonablemente prever que el tribunal del lugar del hecho causal y el tribunal del lugar del daño se encuentran en las mejores condiciones posibles para pronunciarse sobre un litigio consecuencia de un ilícito a distancia. Este foro dual es previsible para las partes y así lo subraya el TJUE ${ }^{120}$. Más de cuarenta

${ }^{118}$ R.H. WebB / D.J. Latham Brown, "Engagements to Marry and the Conflict of Laws", The International and Comparative Law Quarterly, vol. 15, n. 4, 1966, pp. 947-995.

${ }^{119}$ Vid. STJCE 5 febrero 2004, C-18/02, Torline, Recopilación, 2004, p. I-1441 [ECLI:EU:C:2004:74]; STJCE 10 junio 2004, C-168/02, Rudolf Kronhofer, Recopilación, 2004, p. I-6022. [ECLI:EU:C:2004:364]; STJCE 16 julio 2009, C-189/08, Zuid-Chemie, Recopilación, 2009, p. I-6917. [ECLI:EU:C:2009:475]; STJUE 25 octubre 2011, C-509/09 y C-161/10, eDate, Recopilación, 2011, p. I-10269 [ECLI:EU:C:2011:685] FD 52; STJUE 19 abril 2012, C-523/10, Wintersteiger [ECLI:EU:C:2012:220] FD 19; STJUE 25 octubre 2012, C-133/11, Folien Fischer [ECLI:EU:C:2012:664] FD 39; STJUE 16 mayo 2013, C-228/11, Melzer [ECLI:EU:C:2013:305] FD 25; STJUE 3 octubre 2013, C-170/12, Peter Pinckney [ECLI:EU:C:2013:635] FD26; STJUE 16 enero 2014, C-45/13, Andreas Kainz. [ECLI:EU:C:2014:7] FD23; STJUE 3 abril 2014 , C-387/12, Hi Hotel [ECLI:EU:C:2014:215] FD 27; STJUE 5 junio 2014, C-360/12, Coty Germany [ECLI:EU:C:2014:1318] FD 46; STJUE 22 enero 2015, C-441/13, Pez Hejduk [ECLI:EU:C:2015:28] FD 18; STJUE 28 enero 2015, C-375/13, Harald Kolassa [ECLI:EU:C:2015:37] FD 45; STJUE 21 mayo 2015, C-352-/13, Cartel Damage Claims [ECLI:EU:C:2015:335] FD 36-39;STJUE 10 septiembre 2015, C-47/14, Ferho [ECLI:EU:C:2015:574] FD 72; STJUE 21 diciembre 2016, C-618/15, Concurrence SARL vs. Samsung Electronics France SAS, Amazon Services Europe Sàrl [ECLI:EU:C:2016:976] FD 25; STJUE 17 octubre 2017, C-194/16, Bolagsupplysningen OÜ, Ingrid Ilsjan vs. Svensk Handel AB, [ECLI:EU:C:2017:766] FD 31-33; STJUE 5 julio 2018, C-27/17, flyLAL [ECLI:EU:C:2018:533] FD 28 y 46; STJUE 12 septiembre 2018, C-304/17, Helga Löber [ECLI:EU:C:2018:701] FD 22; STJUE 29 julio 2019, C-451/18, Tibor-Trans [ECLI:EU:C:2019:635] FD 25; STJUE 9 julio 2020, C-343/19, Verein für Konsumenteninformation vs. Volkswagen AG [ECLI:EU:C:2020:534] FD 23.

${ }^{120}$ Vid. STJUE 16 enero 2014, C-45/13, Andreas Kainz [ECLI:EU:C:2014:7] FD 24-28: "la atribución de competencia al tribunal del lugar de fabricación del producto de que se trate responde, por lo demás, a la exigencia de previsibilidad de las normas de competencia, en la medida en que tanto el fabricante demandado como la víctima demandada pueden razonablemente prever que ese tribunal estará en las mejores condiciones posibles para pronunciarse sobre un litigio que implique, en particular, la comprobación de un defecto de tal producto"; STJUE 3 octubre 2013, C-170/12, Peter Pinckney vs. KDG Mediatech AG [ECLI:EU:C:2013:635] FD 27: "la existencia de una conexión particularmente estrecha entre la controversia y el órgano jurisdiccional del lugar en que se ha producido o puede producirse el hecho dañoso, que justifica una atribución de competencia a dicho órgano jurisdiccional por razones de buena administración de la justicia y de una sustanciación adecuada del proceso". También STJUE 21 abril 2016, C-572/14, Austro-Mechana Gesellschaft zur Wahrnehmung mechanisch-musikalischer Urheberrechte GmbH vs. Amazon [ECLI:EU:C:2016:286] FD 26; STJUE 18 julio 2013, C-147/12, ÖFAB, Östergötlands Fastigheter AB vs. Frank Koot, Evergreen Investments BV. [ECLI:EU:C:2013:490] FD 49-51; STJUE 16 mayo 2013, C-228/11, Melzer vs. MF Global UK Ltd. [ECLI:EU:C:2013:305] FD 27; STJUE 19 abril 2012, C-523/10, Wintersteiger AG vs. Products 4U Sondermaschinenbau GmbH. [ECLI:EU:C:2012:220] FD 32; STJCE 7 marzo 1995, C-68/93, Fiona Shevill, Ixora Trading Inc., Chequepoint SARL y Chequepoint International Ltd. vs. Presse Alliance S.A., Recopilación, 1995, pp. 415-466. [ECLI:EU:C:1995:61] FD 20-21; STJUE 25 octubre 2011, C-509/09 y C-161/10, eDate Advertising GmbH vs. X y Olivier Martinez, Robert Martinez y MGN Limited, Recopilación, 2011, p. I-10269 [ECLI:EU:C:2011:685] FD 41. 
años la contemplan: el TJUE sigue la teoría de la ubicuidad con romántica fidelidad a través del tiempo y del espacio, escribe J. CARRASCOSA GonZÁLEZ ${ }^{121}$.

71. En consecuencia, el demandante dispone de una opción (optio fori), pues puede decidir a qué tribunales estatales desea acudir. En efecto, el actor puede presentar su demanda ante los tribunales del Estado miembro donde se produjo el "hecho generador del daño" o ante los tribunales del Estado miembro en cuyo territorio se verificó el "daño" o lesión. El demandante es completamente libre de accionar en un Estado miembro o en otro. En ningún caso se puede acusar al demandante de "fraude procesal" por presentar su demanda en el Estado miembro donde tiene su domicilio si el lugar del hecho causal o del resultado lesivo se localizan en dicho Estado. Ambos lugares manifiestan una igual "dosis de proximidad" con el ilícito.

72. La disociación del foro de competencia judicial internacional recogido en el art. 7.2 RB I-bis presenta un alcance objetivo asimétrico. Así, cuando se demanda ante el tribunal del Estado miembro que corresponde al lugar del hecho causal de un ilícito a distancia (art. 7.2 RB I-bis), dicho tribunal es competente para conocer de la responsabilidad por los daños producidos, en su caso, en todo el mundo (STJCE 7 marzo 1995, Shevill, FD 33) ${ }^{122}$. La explicación radica en que el hecho causal da origen a todos los daños que, posteriormente, se producen en otros países. Frente a ello, cuando, en el caso de un ilícito a distancia, se demanda ante el tribunal del Estado miembro que corresponde al lugar del daño, dicho tribunal es competente para conocer de la controversia relativa a los daños producidos, exclusivamente, en dicho país, en el país del daño, como precisa la STJUE 22 enero 2015, C-441/13, Pez Hejduk vs. EnergieAgentur.NRW GmbH, FD 36-37123. La explicación yace ahora en el hecho de que un tribunal está sólo correctamente situado para conocer de los daños ocurridos en el territorio del Estado al que pertenece.

\section{b) Precisión del lugar donde ha ocurrido el hecho causal}

73. Como se ha indicado, el hecho causal del daño es la ruptura de la promesa de matrimonio. En los supuestos en los que la promesa se realiza en un lugar y se recibe en otro lugar, existen buenos argumentos para afirmar que el lugar donde al promesa se rompe es el primero, esto es, el territorio donde el sujeto declara no querer contraer el matrimonio proyectado. Se trata, pues, del lugar desde el que se envía la declaración de voluntad de no contraer matrimonio: es el lugar desde el que se envía la carta, el e-mail o el audio o vídeo en el que el sujeto manifiesta que no va a contraer matrimonio. En el caso de ruptura de la promesa por comportamientos evidentes del prometido, el lugar del hecho causal es aquél en el que los actos del sujeto ponen de manifiesto, en mayor medida, su voluntad de no contraer matrimonio ${ }^{124}$. En todos

${ }^{121}$ J. CARRascosa GonzÁLEz, "Distance torts: the Mines de Potasse decision forty years on", Yearbook of private international law, 2016/2017, vol 18 pp. 19-38.

${ }^{122}$ STJCE 7 marzo 1995, C-68/93, Fiona Shevill, Ixora Trading Inc., Chequepoint SARL y Chequepoint International Ltd. vs. Presse Alliance S.A., Recopilación, 1995, pp. 415-466 [ECLI:EU:C:1995:61] FD 32: „Si bien es cierto que la apreciación de los distintos aspectos de un mismo litigio por distintos órganos jurisdiccionales presenta inconvenientes, no obstante, el demandante siempre puede plantear todas sus pretensiones bien ante el órgano jurisdiccional del domicilio del demandado, bien ante el del lugar del establecimiento del editor de la publicación difamatoria“.

${ }^{123}$ STJUE 22 enero 2015, C-441/13, Pez Hejduk vs. EnergieAgentur.NRW GmbH [ECLI:EU:C:2015:28] FD 36: „No obstante (.....) el órgano jurisdiccional que conozca de un asunto en virtud del lugar de materialización del daño alegado sólo será competente para conocer del daño causado en el territorio de ese Estado miembro (...)“ “y FD 37: „En efecto, los tribunales de los demás Estados miembros siguen siendo, en principio, competentes, en virtud del artículo 5, punto 3, del Reglamento $n^{\circ}$ 44/2001 y del principio de territorialidad, para conocer del daño causado a los derechos de autor y a los derechos afines a los derechos de autor en el territorio de su respectivo Estado miembro, habida cuenta de que están en mejores condiciones de valorar, por una parte, si efectivamente se han vulnerado esos derechos garantizados por el Estado miembro de que se trate y, por otra parte, para determinar la naturaleza del daño causado (...)“.

${ }^{124}$ A. WeIll, "Fiançailles", Encyclopedie Dalloz droit international, París, $1968-69$ (dir. Ph. Franceskakis), vol.II, 1969, pp. 22-24. 
estos supuestos, ese lugar debe ser previsible para la otra parte. Es decir, si el lugar desde el que se envía la ruptura de la promesa de matrimonio es puramente casual, anecdótico, fortuito, accidental (= promesa rota desde país de paso, desde país de vacaciones, etc.), no podrá operar este foro del hecho causal, porque dicho lugar se vuelve imprevisible para las partes, ya que depende circunstancias inciertas, dudosas, imprecisas. En cambio, este foro sí operará si el país desde el que se envía la ruptura de la promesa de matrimonio es el país de residencia habitual del prometido que rompe su promesa, o el país donde trabaja habitualmente, por ejemplo. Debe recordarse que el TJUE ha indicado que el art. 7.2 RB I-bis hace competente al tribunal del Estado miembro que corresponde al lugar donde se produce el daño pero siempre que dicho lugar sea "previsible" para las partes implicadas ${ }^{125}$. En ese dato, precisamente, radica la razonabilidad del foro, en que el lugar del hecho dañoso es "previsible" para las partes implicadas. Por eso está justificado litigar ante los tribunales de dicho Estado. En dicha línea, el TJUE subraya que el objetivo del Reglamento Bruselas I-bis consiste en "establecer atribuciones de competencia ciertas y previsibles". Si concurren circunstancias azarosas que hacen imposible prever para las partes, cuál es el lugar donde se produce el hecho dañoso, éste ya no puede cumplir con su misión de designar de manera clara, directa y previsible, el tribunal competente. El foro, en dicha hipótesis, traiciona uno de los principios fundamentales del Reglamento: la previsibilidad de la competencia del tribunal que debe fallar el caso. En tal supuesto, esto es, si el foro atribuye competencia a un tribunal imprevisible para las partes, el TJUE ha descartado el foro del lugar del daño cuando dicho foro no permite designar, de modo previsible, el tribunal competente. Por ello el TJUE indica que "[e]n efecto, la determinación del órgano jurisdiccional competente dependería entonces de circunstancias inciertas (.....)". Ello es así porque sólo en el caso de que el foro sea verdaderamente "previsible", el art. 7.2 RB I-bis cumple su función de proporcionar un foro en el que litigar sea posible a un coste reducido para actor y demandado. En diversa jurisprudencia el TJUE ha descartado toda interpretación del art. 7.2 RB I-bis que conduzca a un tribunal imprevisible para las partes. Por tanto, si el lugar del hecho causal o el lugar daño son "imprevisibles" para el demandado, el art. 7.2 RB I-bis debería someterse a una reducción teleológica y, en consecuencia, no debe aplicarse.

\section{c) Precisión del lugar donde se ha verificado el daño}

74. En estos litigios se producen daños emocionales a la víctima y/o también perjuicios patrimoniales directos: se han gastado unas cantidades y/o se han contraído unas obligaciones en consideración al matrimonio prometido. El lugar del daño es aquél en el que se produce el "perjuicio material directo" para la "víctima directa". Se trata de lugar en el que el acto generador despliega sus "efectos perjudiciales", es decir, el lugar donde el perjuicio ocasionado se ha producido de forma concreta, precisa el TJUE $^{126}$. En definitiva, el lugar donde se ha producido el daño es aquél "donde el hecho del que puede derivarse una responsabilidad delictual o cuasidelictual haya ocasionado un daño" (STJUE 19 abril 2012, C-523/10, Wintersteiger, FD 21; STJUE 3 octubre 2013, C-170/12, Pinckney, FD 33) $)^{127}$.

75. Visto que la precisión del lugar del daño en los casos aquí examinados es necesaria también para determinar la Ley aplicable en el contexto del art. 4.1 del Reglamento Roma II, se remite infra al

${ }^{125}$ STJCE 19 septiembre 1995, C-364/93, Antonio Marinari vs. Lloyd's Bank plc, Recopilación, 1995, p. I-2719. [ECLI:EU:C:1995:289] FD 19: "Por consiguiente, la interpretación del número 3 del artículo 5 del Convenio en función del régimen de responsabilidad civil extracontractual aplicable, tal como ha propuesto el Gobierno alemán, carece de fundamento. Por otra parte, dicha interpretación resulta incompatible con el objetivo del Convenio consistente en establecer atribuciones de competencia ciertas y previsibles (....). En efecto, la determinación del órgano jurisdiccional competente dependería entonces de circunstancias inciertas, tales como el lugar en donde el patrimonio de la víctima hubiera sufrido perjuicios sucesivos o el régimen de responsabilidad civil aplicable".

${ }^{126}$ STJUE 12 septiembre 2018, C-304/17, Helga Löber vs. Barclays Bank plc [ECLI:EU:C:2018:701] FD 23-24; STJUE 21 mayo 2015, C-352-/13, Cartel Damage Claims (CDC) Hydrogen Peroxide vs. Akzo Nobel NV, Solvay SA/NV, Kemira Oyj, FMC Foret, S.A. [ECLI:EU:C:2015:335] FD 52; STJCE 22 marzo 1983, 34/82, Peters vs. Zuid Nederlandse Aannemers Vereniging, Recueil, 1983, pp. 987-1012. [ECLI:EU:C:1983:87] FD 26-28.

${ }^{127}$ STJUE 3 octubre 2013, C-170/12, Peter Pinckney vs. KDG Mediatech AG. [ECLI:EU:C:2013:635]; STJUE 19 abril 2012, C-523/10, Wintersteiger AG vs. Products $4 U$ Sondermaschinenbau GmbH. [ECLI:EU:C:2012:220]. 
apartado correspondiente (IV, 2, C) ${ }^{128}$. Basta ahora indicar que en virtud del art. 7.2 RB I-bis, la víctima podrá demandar al presunto responsable, al "fidanzato recalcitrante", ante los tribunales del Estado miembro donde tuvo lugar la ruptura de la promesa ( = lugar del hecho causal) por todos los daños sufridos, y también, a su elección, ante los tribunales del Estado miembro en cuyo territorio la víctima sufre el daño personal y/o perjuicio económico (= lugar del daño) pero sólo por los daños sufridos en dicho Estado $^{129}$. Litigar ante los tribunales del lugar donde se han verificado los efectos principales de la ruptura de la promesa de matrimonio comporta una litigación eficiente en el plano transfronterizo, afirma J.R. REIDENBERG ${ }^{130}$. Además, la víctima puede también accionar ante los tribunales del Estado miembro donde el demandado tiene su domicilio (art. 4 RB I-bis) por todos los daños sufridos.

\section{Ley aplicable a la ruptura de la promesa de matrimonio. Reglamento Roma II}

\section{Responsabilidad extracontractual y aplicación del Reglamento Roma II}

76. No existe ninguna norma de Derecho internacional privado europeo ni español que señale expresamente la Ley aplicable a la existencia de la promesa de matrimonio ni tampoco la Ley aplicable a los daños derivados de una ruptura de la misma. Sin embargo, como antes se ha indicado la obligación de pagar los daños a la víctima en casos de gastos realizados en vistas de un matrimonio que no se celebra tras la ruptura de una promesa de matrimonio, deriva de la ley y no de la voluntad de una persona. Por tanto, estas reclamaciones, cuando se verifican en casos internacionales, presentan carácter extracontractual, de modo que la determinación de la Ley estatal que regula el fondo de las mismas se debe realizar con arreglo al Reglamento Roma II, como ha indica O. BosKovIC ${ }^{131}$. El Reglamento Roma II se aplica a las obligaciones extracontractuales incluidas en su ámbito de aplicación material con total independencia de la nacionalidad, domicilio y residencia habitual de las partes implicadas y de los litigantes, y con independencia, también, de cuál sea la Ley reguladora de las obligaciones extracontractuales (art. 3 RR-II). Sus normas de conflicto son erga omnes. En consecuencia, las normas de Derecho internacional privado nacionales de los Estados miembros ya no pueden aplicarse a los supuestos regidos por el Reglamento Roma II.

77. El sistema general para determinar la Ley aplicable a las obligaciones extracontractuales en el Reglamento Roma II recoge diversos puntos de conexión que se estructuran del siguiente modo (arts. 14 y 4 RR-II). En primer lugar, las obligaciones extracontractuales se regirán por la Ley elegida por las partes en los términos del art. 14 RR-II. En segundo lugar, esto es, en defecto de Ley elegida en las condiciones del art. 14 RR-II, las obligaciones extracontractuales se rigen por la Ley del Estado en el que la persona cuya responsabilidad se alega y la persona perjudicada tengan su residencia habitual común en el momento en que se produzca el daño (art. 4.2 RR-II). En tercer lugar, en defecto de los criterios anteriores, las obligaciones extracontractuales se regirán por la Ley del país donde se produce el daño, independiente-

\footnotetext{
${ }^{128}$ Reglamento (CE) 864/2007 del Parlamento Europeo y del Consejo de 11 de julio de 2007 relativo a la ley aplicable a las obligaciones extracontractuales («Roma II») (DOUE L 199 de 31 julio 2007).

${ }^{129}$ Vid.STJUE 17 octubre2017,C-194/16,Bolagsupplysningen Ö̈,IngridIlsjanvs. SvenskHandelAB,[ECLI:EU:C:2017:766] FD 31-33; STJUE 25 octubre 2011, C-509/09 y C-161/10, eDate, Recopilación, 2011, p. I-10269 [ECLI:EU:C:2011:685] FD 48 y 51; STJUE 3 octubre 2013, C-170/12, Peter Pinckney vs. KDG Mediatech AG. [ECLI:EU:C:2013:635] FD 36; STJUE 17 octubre 2017, C-194/16, Bolagsupplysningen OÜ, Ingrid Ilsjan vs. Svensk Handel AB, [ECLI:EU:C:2017:766] FD 33; SAP Madrid 24 octubre 2011 [difamación contra víctima española residente en España realizada por Internet en lengua francesa y contenida en periódico digital marroquí] [ECLI:ES:APM:2011:13719].

${ }^{130}$ J.R. Reidenberg, "The Yahoo Case and the International Democratization of the Internet", Fordham Law \& Economics, Research Paper No. 11, April 2001, available at SSRN: https://ssrn.com/abstract=267148 or http://dx.doi.org/10.2139/ ssrn.267148.

${ }^{131}$ Reglamento (CE) No 864/2007 del Parlamento Europeo y del Consejo de 11 de julio de 2007 relativo a la ley aplicable a las obligaciones extracontractuales («Roma II») (DOUE L 199 de 31 julio 2007). Vid. O. Boskovic, "Règlement Rome II", Répertoire Dalloz Droit international, $2^{\mathrm{a}}$ ed., septiembre 2010; O. BosKovic, La réparation du préjudice en droit international privé, LGDJ, 2003, París, 2003, pp. 11-19.
} 
mente del país donde se haya producido el hecho generador del daño y cualesquiera que sean el país o los países en que se producen las consecuencias indirectas del hecho en cuestión (art. 4.1 RR-II).

No obstante, y salvo el caso en el que las partes hayan elegido la Ley aplicable con arreglo al art. 14 RR-II, si del conjunto de circunstancias se desprende claramente que el hecho dañoso presenta vínculos manifiestamente más estrechos con otro país distinto del indicado en el art. 4.1 ó 4.2 RR-II, se aplicará la ley de este otro país (art. 4.3 RR-II).

\section{Primer punto de conexión. Ley elegida por las partes y promesa de matrimonio}

78. Con arreglo al Reglamento Roma II, es aplicable en primer término la Ley que las partes elijan para regular las obligaciones extracontractuales (art. 14 RR-II). El acuerdo de elección de Ley debe ser "posterior al hecho generador del daño", o bien si todas las partes implicadas desarrollan una actividad comercial, -que no es el caso-, el acuerdo de elección de Ley puede también haberse concluido antes del hecho generador del daño. La elección de Ley deberá manifestarse expresamente o resultar de manera inequívoca de las circunstancias del caso. Esta elección de Ley no perjudicará los derechos de terceros. El legislador europeo no ha excluido la posibilidad de elección de la Ley aplicable en estos casos de ruptura de la promesa de matrimonio (arts. 6 y 8 RR-II a contrario sensu).

79. No será frecuente dicha elección de Ley, porque el estado habitual de las partes será de enfado mutuo y entonces será también difícil que las partes alcancen un acuerdo sobre la ley aplicable a los daños derivados de la ruptura de la promesa de matrimonio. Aunque nunca se sabe. La Ley elegida por las partes es aquélla que permite resolver el litigio extracontractual a un coste más reducido para las partes. Al colocar a la Ley elegida por las partes en la cúspide de la pirámide conflictual de las conexiones del Reglamento Roma II, se ha producido una véritable révolution en el Derecho internacional privado de varios Estados europeos, España incluida, antes hostiles a este punto de conexión en el sector de las obligaciones extracontractuales, como ha indicado O. Boskovic ${ }^{132}$.

\section{Segundo punto de conexión. Ley de la residencia habitual común de las partes y promesa de matrimonio}

80. En defecto de elección de Ley por las partes, se aplicará la Ley del país de la común residencia habitual de las partes en el momento de la ruptura de la promesa de matrimonio (art. 4.2 RR-II). Este precepto señala que "cuando la persona cuya responsabilidad se alega y la persona perjudicada tengan su residencia habitual en el mismo país en el momento en que se produzca el daño, se aplicará la ley de dicho país". Este punto de conexión contenido en el art. 4.2 RR-II se justifica porque el legislador europeo presupone que en el caso de que víctima y presunto responsable tengan su residencia habitual en el mismo Estado, la aplicación de la Ley de dicho Estado comporta, para las partes, costes conflictuales menores que los que les supondría la aplicación de la Ley del lugar donde se verifica el daño. Con otras palabras, puede afirmarse que el legislador europeo presupone que el país de la residencia habitual de las partes es el más vinculado con la situación jurídica y representa la "mayor proximidad" con el caso. La Ley de la residencia habitual común es la Ley que las partes están en situación mejor para conocer a un coste más reducido. La controversia, así, se resolverá del modo más eficiente para ambas partes, como apunta S. DNES ${ }^{133}$.

81. Gracias a este punto de conexión se evita la aplicación de la Ley del lugar donde se ha producido el daño en casos en los que aplicar dicha Ley supondría costes elevados para las partes, que

\footnotetext{
${ }^{132}$ O. Boskovic, "Règlement Rome II”, Répertoire Dalloz Droit international, $2^{\mathrm{a}}$ ed., septiembre 2010, p. 4.

${ }^{133}$ S. Dnes, "Promoting efficient litigation?", en P. Beaumont et AL., Cross-border litigation in Europe, Oxford, Hart, 2017, pp. 463-473.
} 
se hayan situadas en otro contexto legal muy diferente. Así, por ejemplo, la Ley aplicable a los daños derivados de la ruptura de una promesa de matrimonio que tiene lugar en Grecia durante un viaje romántico de una pareja que reside habitualmente en España debe ser la Ley española y no la Ley griega. Esta solución, apunta J. CARRASCOSA GonZÁlez, responde a un fundamento económico ${ }^{134}$. Para estas partes, litigar con arreglo al Derecho griego resultaría muy caro, pues deberían, en tal caso, informarse sobre el ordenamiento jurídico griego, del que nada saben. Es más eficiente, para ambos, litigar en los términos del Derecho español, pues ambos tienen en España su centro social de vida. Se supone que ambos conocen mejor tal Derecho o están en posición para informarse mejor y a un coste reducido sobre el mismo.

82. El art. 23 RR-II contiene varias reglas para precisar la residencia habitual de los sujetos a los efectos del art. 4.2 RR-II. En los casos de ruptura de la promesa de matrimonio, debe subrayarse que el concepto de residencia habitual de las personas físicas no profesionales no se recoge de modo expreso en el Reglamento Roma II. Puede afirmarse que, en términos de Derecho europeo, la residencia habitual de la persona física se localiza en el lugar donde ésta tiene su centro social de vida. Es el lugar donde la persona física se encuentra de hecho (domus colere) con intención de permanecer de modo estable (animus manendi). La residencia habitual se identifica con el lugar donde la persona está realmente arraigada, donde tiene su centro social de vida. También puede sostenerse que, ante el silencio aludido del Reglamento Roma II, la residencia habitual de una persona física se determinará con arreglo a los criterios vigentes en cada Estado miembro. En España, se aplicará el art. 40 CC y la interpretación que el TS y la DGRN hacen del concepto "residencia habitual" resulta en un concepto nacional español de residencia habitual muy similar al concepto europeo de la misma noción. Es el centro social de vida de la persona, que se concreta en el lugar donde ésta tiene presencia física con intención de permanencia.

\section{Tercer punto de conexión. Ley del país donde se ha producido el daño y promesa de matrimonio}

\section{A) Aspectos previos. Justificación del punto de conexión "lugar del daño"}

83. Finalmente, en tercer lugar, y a falta de elección de Ley por las partes (art. 14 RR-II) y de residencia habitual común de las partes (art. 4.2 RR-II), se aplicará la Ley del país donde se ha producido el daño (art. 4.1 RR-II). Bienvenidos todos al fascinante mundo de la conexión Lex Loci Damni: ley del lugar donde se ha producido el daño. Más de mil años contemplan esta conexión, que se utiliza desde tiempos del bueno y viejo Derecho Romano.

84. El criterio Lex Loci Delicti Commissi, explican A.-L. Calvo Caravaca / J. Carrascosa GonZÁLEZ, permite una identificación segura y veloz de la Ley aplicable ${ }^{135}$. Conduce, en circunstancias normales, a la Ley del Estado cuya aplicación al caso es la más previsible para las partes implicadas. Ello significa que la Lex Loci Delicti Commissi suele ser la Ley cuya aplicación suscita los costes conflictuales más reducidos para los sujetos implicados en los casos internacionales de obligaciones extracontractuales. Les permite litigar al menor coste jurídico, es una conexión eficiente. Dicha Ley sintoniza perfectamente con las expectativas de los sujetos implicados, explican los clásicos ${ }^{136}$. La Lex Loci Delicti Commissi suele corresponder al país "más estrechamente vinculado" al supuesto. Los costes de información de dicha Ley y los costes de adaptación de los particulares al contenido de dicha Ley, son reducidos para ambas partes.

${ }^{134}$ J. CARRASCOSA GonZÁlez, "Règle de conflit et théorie économique", Revue critique de droit international privé, vol. 101, 2012-3 (juillet-septembre 2012), pp. 521-538; J. CARrascosa GonzÁlez, Conflicto de Leyes y teoría económica, Ed. Colex, Madrid, 2011, pp. 200-201.

135 A.-L. Calvo Caravaca / J. Carrascosa González, "Obligaciones extracontractuales", en A.-L. Calvo Caravaca / J. Carrascosa González (directores), Tratado de Derecho internacional privado, primera edición, editorial Tirant Lo Blanch, València, vol. III, 2020, pp. 3679-3674.

${ }^{136}$ G. Beitzke, "Les obligations delictuelles en droit international privé", Recueil des Cours de l'Académie de Droit international de La Haye, 1965, vol.115, pp. 67-146; P. Bourel, "Du rattachement de quelques délits spéciaux en droit international privé”, Recueil des Cours de l'Académie de Droit international de La Haye, 1989, vol.214, pp. 251-398. 
La explicación de ello es sencilla: las personas que se hallan en el territorio de un concreto Estado y/o que dirigen sus actividades hacia el territorio de un determinado Estado están en una posición óptima para prever, razonablemente, que las actividades que desarrollan en dicho territorio están sujetas al Derecho de dicho Estado (When in Rome, do as Romans do, máxima sabia donde las haya cuyo origen se encuentra en las enseñanzas de San Ambrosio). Y las personas que sufren daños en un Estado se hallan, igualmente, en una situación idónea para prever que los daños que puedan sufrir en ese Estado debe sujetarse a la Ley de dicho Estado. De ese modo, se alcanza, como indica el Cons. (16) RR-II: "[...] un equilibrio razonable entre los intereses de la persona cuya responsabilidad se alega y los de la persona perjudicada. La conexión con el país donde se produzca el daño directo (lex loci damni) crea un justo equilibrio entre los intereses de la persona cuya responsabilidad se alega y la persona perjudicada [....]". Así la conexión suscita costes conflictuales reducidos para ambas partes (= costes "globales" reducidos, no sólo para una parte). Por otro lado, el elemento fundamental en los ilícitos civiles es la reparación del perjuicio causado y no la punición de conductas. El perjuicio surge porque existe un "daño", con independencia de cuál sea el hecho generador y del lugar donde éste se haya producido. El lugar relevante es el lugar del daño, es el lugar que permite a todos los sujetos implicados calcular de manera sencilla cuál es la Ley aplicable a un hecho ilícito. Esta conexión no tiene nada que ver con la protección de la soberanía del Estado en cuyo territorio se ha verificado el daño. Por otro lado, la regla potencia la buena administración de la Justicia, pues el lugar donde el daño se ha producido es el lugar donde, normalmente, se encontrarán las pruebas de dicho daño y de la posible responsabilidad del sujeto, como ha señalado la jurisprudencia ${ }^{137}$.

85. Por otro lado, el Reglamento Roma II solventa de raíz, y de forma muy simple, la cuestión de la Ley aplicable a los ilícitos a distancia, asunto que había ocupado y preocupado a varias generaciones de juristas. El reglamento acoge la tesis francesa al respecto, esto es, la postura seguida por los tribunales franceses durante años al aplicar la regla Lex Loci Dlicti Commissi. Con arreglo a la misma, en los supuestos de ilícitos a distancia, se aplica la Ley del país en cuyo territorio se produce el "daño". No es relevante el país donde se haya tenido lugar el "hecho generador del daño" (= lugar donde se ha roto la promesa matrimonial). Tampoco es relevante el país donde "se manifiesta el daño" (= el país en el que se encuentra una persona cuando descubre que la otra persona no tiene ya intención de contraer matrimonio pese a su anterior promesa). Con esta conexión, -el lugar del daño-, los sujetos que sufren un perjuicio en el territorio de un país pueden estar seguros de que la Ley aplicable a la responsabilidad derivada de tal daño es la Ley de dicho Estado, cualquiera que sea el país donde se haya producido el hecho generador del daño, esto es, la ruptura de la promesa. El país donde se rompe la promesa de matrimonio puede, en efecto, resultar totalmente imprevisible para la víctima. en suma, puede decirse que, a efectos del art. 4.1 RR-II es indiferente e irrelevante el lugar donde se haya formulado la promesa de matrimonio el lugar donde ésta se haya roto.

86. Sin embargo, como advierten A. Weill y J.D. GonZÁlez CAmpos, no siempre es sencillo determinar cuál es el lugar donde se ha producido el daño ${ }^{138}$. Ello se debe a dos razones.

87. En primer lugar, es preciso concretar el carácter del daño, esto es, en qué consiste el daño por el que la víctima solicita una indemnización. En este punto, dos circunstancias deben precisarse.

Primera circunstancia: estas reclamaciones se mueven en el ámbito del Derecho Privado. Se trata de derechos disponibles por las partes. Por ello, cada persona decide qué quiere reclamar, qué fundamentos jurídicos va a utilizar al respecto y hasta qué punto va a reclamar. La parte perjudicada delimita el ámbito de su reclamación con total libertad procesal. Una víctima de una promesa de matrimonio

${ }^{137}$ Vid. ad ex. SAP Baleares 13 diciembre 2018 [daño a cable submarino] [ECLI:ES:APIB:2018:2410].

${ }^{138}$ A. WeILl, "Fiançailles", Encyclopedie Dalloz droit international, París, 1968-69 (dir. Ph. Franceskakis), vol.II, 1969, pp. 22-24; J.D. GonzÁlez CAMpos, "El matrimonio en el Derecho civil internacional", en M. Aguilar Navarro, Derecho civil internacional, Facultad de Derecho, Universidad Complutense, Madrid, 4ª ed,. 1975 (reimpresión 1979), pp. 243-371, esp. pp. 261-262, si bien referido al "hecho dañoso" o al "ilícito" y no al "daño": "Soluciones positivas que no dejan de presentar dificultades, pues, si se admite que nos encontramos ante un supuesto de "hecho ilícito», no es fácil determinar el lugar de producción del mismo a los fines de indicar la ley aplicable a la ruptura («lex loci delicti commissi»)". 
incumplida puede reclamar sólo los daños materiales sufridos y no los emocionales y morales, así como puede reclamar sólo los daños que ha experimentado en un país o países determinados. Es libre al efecto. El objeto del proceso lo determinan las partes con su demanda y contestación.

Segunda circunstancia: las normas de conflicto del Reglamento Roma II no deciden qué tipo de daño es resarcible: ¿daños económicos, daños morales o emocionales? Esa decisión corresponde la Ley estatal que rige el fondo de la reclamación (Lex Causae). Por tanto, el daño que la víctima alega haber sufrido es el daño que se debe tener presente para concretar la Ley aplicable en el contexto del art. 4.1 RR-II, sea cual fuere dicho daño y su naturaleza.

88. En segundo lugar, puede suceder que los elementos del daño se encuentren dispersos por varios países: puede que la promesa de matrimonio se haya roto en un país A, que la residencia habitual de la víctima se localice en otro país $\mathrm{B}$, que el lugar del primer domicilio conyugal proyectado se concrete en otro país $\mathrm{C}$ y que los gastos realizados por dicha víctima en consideración del matrimonio se hayan realizado en varios países distintos, B, C, D y E, vista la facilidad de compras a distancia en la sociedad actual. También puede suceder que la víctima de la promesa incumplida tenga su residencia habitual en un país X pero disponga de intereses económicos, -inversiones, patrimonio-, y/o laborales, -lugar habitual de trabajo-, en otros países distintos W y Z. Las combinaciones son infinitas. La vida del siglo XXI es así.

89. Por ambas razones resulta conveniente distinguir diversos supuestos de daños derivados de la ruptura de una promesa matrimonial.

\section{B) Daños morales y emocionales y promesa de matrimonio. Conexión residencia habitual de la víc- tima}

90. La ruptura de la promesa de matrimonio puede provocar daños emocionales y morales en la persona que creyó que el matrimonio se iba a celebrar. Si la víctima reclama una indemnización para compensar tales daños, debe afirmarse que el país donde tales daños se producen es el país donde la persona tiene su residencia habitual. No presenta relevancia, en el contexto del art. 4.1 RR-II, el país donde se encuentra la persona cuando conoce la ruptura de la promesa de matrimonio. Dicho país puede ser casual o anecdótico, y más hoy día, cuando una persona puede acceder, desde cualquier país, a su correo electrónico o servicio de mensajería instantánea, así como al teléfono y redes sociales.

91. Varias razones avalan esta interpretación en favor del "lugar de la residencia habitual de la víctima" como "lugar del daño".

En primer lugar, puede afirmarse que la persona experimenta el daño emocional o moral en el país donde tiene su centro social de vida, su sede personal, su centro de intereses principales. La persona sufre daños emocionales en el país donde se normalmente se encuentra, en el país donde tiene su lugar natural en la vida, precisa B. AudiT ${ }^{139}$. Es el país de su residencia habitual. Como indica A. Weill, es ése el país donde se localiza «el centro de los daños personales» ${ }^{140}$. En el caso de reclamación de daños personales, morales y/o emocionales, esto es, daños no patrioniales, la aplicación de la Ley del país de la residencia habitual de la víctimas es previsible para ambas partes. El criterio cumple a la perfección con el «test de previsibilidad» recogido en el Considerando (16) RR-II, antes citado.

\footnotetext{
${ }^{139}$ B. Audit, Droit international privé, $5^{\mathrm{a}}$ ed., Issy-les-Moulineaux, LGDJ, 2006, p. 514: «Il est vrai que la localisation du délit peut faire difficultés en particulier lorsque les fiancés ne résident pas dans le même pays. Si l'on se prononce pour la loi du dommage, celui-ci, principalement d'ordre moral, pourra être considéré comme localisé au domicile de la victime».

${ }_{140}$ A. WeILl, "Fiançailles", Encyclopedie Dalloz droit international, París, 1968-69 (dir. Ph. Franceskakis), vol.II, 1969, pp. 22-24: «Les difficultés de détermination du lieu du délit pourraient être évitées si, systématiquement, on considérait le domicile de la victime de la rupture des fiançailles comme étant l'élément essentiel du rattachement du délit: le préjudice qui est invoqué est, le plus souvent, d'ordre moral (atteinte à la réputation, trouble psychologique); à cet égard, le domicile représente le véritable centre de la relation dommageable car il correspond au milieu social où vit normalement la victime de la rupture et où par conséquent, ses intérêts personnels sont lésés».
} 
En segundo lugar, se puede también reforzar esta interpretación con lo afirmado por el TJUE en la STJUE 25 octubre 2011, C-509/09 y C-161/10, eDate Advertising GmbH vs. X y Olivier Martinez, Robert Martinez y MGN Limited ${ }^{141}$. El TJUE afirmó que, en relación con los daños a derechos de la personalidad, esto es daños a bienes inmateriales, verificados en Internet, el lugar donde se debe considerar que se ha producido el «daño mayor» es el lugar en la víctima tiene su «centro de intereses», que es, normalmente, el Estado donde dispone de su «residencia habitual». El lugar donde la víctima dispone de su «centro de intereses» es el lugar en el que, en principio, el daño emocional, personal y moral causado por la ruptura de la promesa de matrimonio se verifica de manera más significativa. Es el lugar del «daño mayor», como también indica la STJUE 17 octubre 2017, C-194/16, Handel, FD $33^{142}$. Es el lugar de la sede natural de la persona, como afirmó ya hace años J.D. GonzÁlez CAMPos ${ }^{143}$. En estos casos, "los intereses de Ia parte lesionada, de este modo, aparecen como dominantes" y dichos intereses se concretan en el país de la sede normal de la víctima, en el país de su residencia habitual, que es el país donde la ruptura de la promesa de matrimonio ha surtido sus efectos. Es el país que se corresponde con el medio social de la víctima. Suele coincidir con el país donde la víctima recibe la noticia de la ruptura de la promesa de matrimonio.

\section{C) Daños económicos y promesa de matrimonio}

\section{a) Aspectos generales. El lugar del daño económico}

92. La quiebra de la promesa de matrimonio puede producir daños económicos en el patrimonio de la persona que confiaba en la celebración del matrimonio se iba a celebrar. Dicha persona puede haber realizado gastos y haber contraído obligaciones con vistas al matrimonio en uno o más países. Pues bien, en ese caso, el daño consiste, básicamente, en las cantidades de dinero gastadas por la víctima con vistas al matrimonio. Ese gasto representa unas cantidades que se emplearon con el propósito de contribuir a la vida matrimonial, pero que ahora carecen de todo sentido tras la ruptura de la promesa de matrimonio: adquisición de una vivienda para la pareja casada, ajuar doméstico, regalos a la otra parte y/o a su familia, etc. Un gasto ya inútil, un gasto sin causa. Precisamente por ello ahora la víctima reclama al "fiancé récalcitrant» que le restituya tales cantidades. El daño económico no es la ruptura de la promesa, sino el gasto sin sentido realizado por una de las partes que confió en una promesa de matrimonio que se incumplió.

93. No resulta sencillo concretar cuál es el concreto lugar donde ha ocurrido el daño, como advierte J.D. GonZÁLEZ CAMPOS ${ }^{144}$. En realidad, se trata, ahora, de concretar en qué país se encontraba el dinero de la víctima cuando éste se gastó. Para precisar cuál es ese país, puede recurrirse a la jurispru-

${ }^{141}$ STJUE 25 octubre 2011, C-509/09 y C-161/10, eDate Advertising GmbH vs. Xy Olivier Martinez, Robert Martinez y MGN Limited, Recopilación, 2011, p. I-10269. [ECLI:EU:C:2011:685].

${ }_{142}$ STJUE 17 octubre 2017, C-194/16, Bolagsupplysningen Ö̈, Ingrid Ilsjan vs. Svensk Handel AB, [ECLI:EU:C:2017:766].

${ }_{143}$ J.D. GonZÁlez CAMPos, "El matrimonio en el Derecho civil internacional”, en M. Aguilar Navarro, Derecho civil internacional, Facultad de Derecho, Universidad Complutense, Madrid, 4 ed,. 1975 (reimpresión 1979), pp. 243-371, esp. pp. 261-262: "En función de estos elementos, podría sostenerse que el objetivo de política legislativa de las normas materiales del Derecho español es el de proteger a la parte por el hecho de esa ruptura sin justa causa, tras haber iniciado los actos preparatorios del matrimonio. Y la protección se concreta en la posibilidad de un resarcimiento del daño patrimonial ocasionado por el incumplimiento de la promesa. Los intereses de Ia parte lesionada, de este modo, aparecen como dominantes. Por ello, en la perspectiva del Derecho internacional privado debe descartarse una construcción analógica con el régimen matrimonial, que responde a objetivos e intereses distintos. La solución adecuada desde este planteamiento sería estar a la ley de la residencia habitual de la parte perjudicada por la ruptura. La sustitución de la ley nacional (conexión de base en nuestro sistema) por la residencia habitual se justifica en atención que ésta expresa la conexión directa de la víctima con su medio social, que es donde se han manifestado los efectos de la ruptura injustificada y donde, de ordinario, se han sufrido los daños cuyo resarcimiento cabe exigir".

144 J.D. González CAmpos, "El matrimonio en el Derecho civil internacional”, en M. AguILAR Navarro, Derecho civil internacional, Facultad de Derecho, Universidad Complutense, Madrid, 4ª ed, 1975 (reimpresión 1979), pp. 243-371, esp. pp. 261262: “... si se admite que nos encontramos ante un supuesto de «hecho ilícito», no es fácil determinar el lugar de producción del mismo a los fines de indicar la ley aplicable a la ruptura («lex loci delicti comissi»)". 
dencia del TJUE relativa a los daños financieros, esto es, daños producidos por pérdidas de cantidades de dinero invertidas o gastadas tras un engaño o falta información en los mercados financieros. Este tribunal ha indicado, en tales sentencias, que el lugar del daño ("le lieu du préjudice financier") es aquél donde la víctima ha situado su dinero para invertirlo posteriormente (= "lieu de la partie du patrimoine endommagée"). Es ése el lugar donde el capital se pierde o merma (= lugar donde se produce la disminución del patrimonio de la persona) ${ }^{145}$. El lugar del daño económico, en estos casos, se produce en el país desde donde la cantidad se gasta o invierte: es el lugar donde está situado el dinero cuando se gasta o se invierte. En efecto, "por lo que se refiere a la materialización del daño (...) el daño se produce en el lugar en el que lo ha sufrido el inversor" 146.

94. En relación con los gastos realizados y las obligaciones contraídas en consideración al matrimonio prometido y no celebrado, debe distinguirse entre los gastos efectuados en compras directas y en compras a distancia, esto es, desde el país de la residencia habitual de la víctima.

En primer lugar, los gastos realizados en compras directas son los que han tenido lugar en un país concreto al que la víctima se ha desplazado y donde ha pagado bienes y/o servicios. El dinero se pierde en ese país, porque la víctima se traslada a otro país para gastar allí su dinero. El dinero está en su patrimonio hasta que lo gasta y ello se produce en el país al que se desplaza la víctima. Ejemplo: si un varón con residencia habitual en Marruecos se traslada a Francia y allí adquiere bienes destinados a la vivienda común de la pareja casada, tras una promesa de matrimonio realizada por su novia española con residencia habitual en España, el daño se ha producido en Francia. En efecto, el dinero fue suyo hasta que lo gastó, y en ese momento, en dinero estaba en Francia.

En segundo lugar, los gastos realizados en compras a distancia son los que se realizan mediante transferencias o envíos monetarios desde el país donde la víctima tiene su dinero, que suele ser el país de su residencia habitual. El dinero está en su patrimonio hasta que lo gasta y ello se produce en el país de la residencia habitual de la víctima. Ejemplo: una mujer con residencia habitual en Argelia adquiere por Internet bienes destinados a la vivienda común de la pareja casada. Tres meses antes, su novio español le había prometido matrimonio. El dinero se gastó en establecimientos de venta por Internet situados en China, Estados Unidos, Francia y Hong-Kong. En este caso, el daño se ha producido en Argelia. En efecto, el dinero pertenecía a la víctima hasta que lo gastó, y en ese momento, en dinero estaba en Argelia.

95. El lugar del daño es el lugar donde se gasta o invierte el dinero de la víctima, el lugar en el que la víctima se desprende de su dinero. Suele coincidir con el lugar donde ésta recibe la nada agradable noticia de la ruptura de la promesa matrimonial y con el país donde la víctima tiene su residencia habitual. En este sentido debe leerse la antigua jurisprudencia francesa que ha indicado que el lugar del daño es aquél en el que la víctima recibe la ruptura de la promesa. Debe entenderse que dicho lugar se corresponde con el país donde la víctima tiene su residencia habitual y donde ha realizado los gastos en consideración del matrimonio prometido ${ }^{147}$.

${ }^{145}$ Vid. STJUE 12 septiembre 2018, C-304/17, Helga Löber vs. Barclays Bank plc [ECLI:EU:C:2018:701]; STJUE 28 enero 2015, C-375/13, Harald Kolassa vs. Barclays Bank plc. [ECLI:EU:C:2015:37] FD 52-53; STJCE 10 junio 2004 , C-168/02, Rudolf Kronhofer vs. Marianne Maier, Christian Möller, Wirich Hofius, Zeki Karan, Recopilación, 2004, p. I-6022. [ECLI:EU:C:2004:364]; STJCE 19 septiembre 1995, C-364/93, Antonio Marinari vs. Lloyd's Bank plc, Recopilación, 1995, p. I-2719. [ECLI:EU:C:1995:289]. Vid. también Ordinanza della Corte di Cassazione (Italia) de 8 abril 2001, Rivista di Diritto internazionale privato e processuale, 2011, p. 1103 [instrumentos financieros suscritos en Italia]; Ordinanza della Corte di Cassazione (Italia) 5 julio 2011 [daños futuros derivados de una transacción en el Reino Unido que comporta perjuicios patrimoniales para una sociedad italiana], Rivista di Diritto internazionale privato e processuale, 2012, p. 432; Sentencia de la Cour de Cassation Com. (Francia) 7 janvier 2014 [daño financiero], Revue critique de droit international privé, 2014, pp. $432-445$.

${ }^{146}$ STJUE 28 enero 2015, C-375/13, Harald Kolassa vs. Barclays Bank plc. [ECLI:EU:C:2015:37] FD 52-53.

${ }^{147}$ En toco caso, esta jurisprudencia es útil para dejar claro que el daño no se produce en el país donde se rompe la promesa ni en el país desde donde se envía un mensaje por el que se rompe la promesa. En efecto, en el caso de que la ruptura se haya emitido en un país pero se haya recibido en otro país, cierta jurisprudencia francesa defendió que el lugar del hecho dañoso debía concretarse en el país donde la ruptura se recibe por la víctima. Así se puede apreciar en la sentencia del tribunal civ. Seine (Francia) de 16 junio 1936, Recueil Sirey, 1939, I, p. 305, con nota de J.-P. Niboyet. Vid. H. Batiffol / P. Lagarde, Droit international privé, t.II, $7^{\mathrm{a}}$ ed., LGDJ, Paris, 1983, n. 415 nota 4 bis, pp. 39-40: «Le lieu du délit a été jugé celui ou la lettre de 
96. El lugar del daño económico no es el lugar donde el "fiancé récalcitrant» rompe su promesa de matrimonio. En dicho país no se produce ningún daño económico para la víctima. Además, la ruptura de la promesa puede haberse realizado en un país que no presenta la más mínima conexión con la víctima. Ello conduciría a la aplicación de la Ley de un país totalmente imprevisible para la parte perjudicada, por lo que cabe afirmar que dicha conexión no supera el «test de previsibilidad» recogido en el Considerando (16) RR-II. La citada jurisprudencia francesa confirma que el daño no se produce en el país donde la promesa se rompe ${ }^{148}$.

97. En ciertas ocasiones no es sencillo identificar el lugar donde se ha verificado el daño en casos de gastos hechos y obligaciones contraídas en consideración al matrimonio prometido. pues los elementos del daño pueden encontrarse muy dispersos en diferentes países. Ello exige un acercamiento analítico a estos casos complejos. Dicho acercamiento debe arrancar del principio de previsibilidad de la Ley aplicable a las obligaciones extracontractuales.

98. En efecto, para seleccionar y concretar el lugar exacto donde se ha producido el daño, debe subrayarse que dicho lugar debe conducir a una Ley de aplicación previsible para víctima y responsable del daño. Muy bien lo indica el Considerando (16) RR-II, que expresa: "[u]nas normas uniformes deben incrementar la previsibilidad de las resoluciones judiciales y garantizar un equilibrio razonable entre los intereses de la persona cuya responsabilidad se alega y los de la persona perjudicada. La conexión con el país donde se produzca el daño directo (lex loci damni) crea un justo equilibrio entre los intereses de la persona cuya responsabilidad se alega y la persona perjudicada, y corresponde también a la concepción moderna del Derecho de responsabilidad civil y al desarrollo de los regímenes de responsabilidad objetiva".

\section{b) Daños económicos producidos en el mismo país}

(a) Daños económicos producidos íntegramente en el país de la residencia habitual de la víctima

99. En el caso de que la víctima haya realizado todos sus gastos en el país de su residencia habitual, bien en compras directas, o bien a distancia, es en ese país donde se ha producido el daño patrimonial a efecto del art. 4.1 RR-II. La Ley del país de residencia habitual de la víctima regirá la responsabilidad civil de la persona que rompió la promesa de matrimonio por los gastos realizados y las obligaciones contraídas en consideración al matrimonio prometido y no celebrado. En este caso, la aplicación de la Ley del país de la residencia habitual de la víctima es perfectamente previsible para ambas partes. En este supuesto, el país de la residencia habitual de la víctima suele coincidir con el país donde

\footnotetext{
rupture a été reçue». Más clara, todavía, en favor del lugar donde se recibe la ruptura de la promesa, resulta la sentencia de la cour de cassation civ. (Francia) de 28 marzo 1973, si bien la cour resuelve una cuestión de competencia judicial internacional y no de Ley aplicable a la promesa de matrimonio (Sentencia cour cassation civ. (Francia) 28 marzo 1973, Gazette du palais, 1973, p. 123 y https://www.legifrance.gouv.fr/juri/id/JURITEXT000006989189/ y Bulletin des arrêts Cour de Cassation Chambre civile, 2 n.113, p. 88: «attendu qu'il est fait grief a l'arrêt d'avoir déclare que le tribunal de Lyon était compétent, alors, d'une part, que le fait dommageable serait constitue par la réception du télégramme rompant la promesse de mariage, et que, par suite, serait compétent le tribunal dans le ressort duquel, ce télégramme a été reçu par sa destinataire, alors, d'autre part, que la cour d'appel n'aurait pu, sans se contredire, affirmer qu'un second télégramme, reçu a Lyon par Demoiselle (...) .... estimer que la réalisation du dommage prétendu s'était produite a Lyon, tant pour Demoiselle A... que pour son Z... et décider, en conséquence, que le tribunal de cette ville avait été compétemment saisi». Se trataba de una ruptura de promesa de matrimonio que fue comunicada por telegrama recibido en Mónaco y confirmada por un segundo telegrama, con extremos y datos más explícitos sobre la ruptura, recibido en Lyon (Francia), ciudad donde se iba a celebrar el enlace matrimonial. La cour consideró que el hecho dañoso consistía en el «recibo del telegrama que rompió la promesa de matrimonio, y que, por lo tanto, es competente el tribunal en cuya jurisdicción, este telegrama ha sido recibido». Dicho lugar suele coincidir, como se ha avanzado, con el país de la residencia habitual de la víctima y con el país donde ésta ha realizado gastos en consideración al matrimonio prometido.

${ }^{148} \mathrm{Vid}$. nota anterior.
} 
la promesa matrimonial se realizó y se rompió. Así puede comprobarse en la sentencia del tribunal de Valenciennes de 19 diciembre 1935. Este tribunal aplicó la Ley francesa a las consecuencias de la ruptura de una promesa de matrimonio entre dos ciudadanos polacos porque la promesa y la ruptura habían tenido lugar en Francia ${ }^{149}$. La sentencia del tribunal de Pontoise de 23 abril 1969 también defendió la aplicación de la Ley del lugar donde se había realizado el hecho, esto es, la promesa y su ruptura posterior y presumiblemente, también donde se habían realizado todos los gastos a indemnizar ${ }^{150}$.

100. Por tanto, en el caso de que la víctima haya realizados todos los gastos con vistas al matrimonio en el país de su residencia habitual, al solución es sencilla. El lugar del daño es precisamente, ese país. En dicho Estado la persona ha gastado su dinero y su patrimonio se ha visto mermado. Ejemplo: un varón español con residencia habitual en Madrid, promete matrimonio, por Internet, a una ciudadana egipcia. Ambos tienen previsto que ella viaje a España e instalar en Madrid el hogar conyugal. En consideración a dicho enlace matrimonial, la mujer realiza numerosos gastos todos ellos en Egipto. Un mes después, el varón comunica a la mujer que se niega a contraer matrimonio con ella. Pues bien, la Ley egipcia debe regular las consecuencias de la ruptura de dicha promesa (art. 4.1 RR-II). Es la Ley del lugar donde ha ocurrido el daño: en Egipto se han realizado todos los gastos y en ese mismo país tiene su sede natural la persona víctima de la ruptura de la promesa matrimonial. No hay duda de que es España el país que se corresponde con el "lugar del daño". Es el país donde se ha materializado el perjuicio en su totalidad.

(b) Daños económicos producidos realizados íntegramente en un país distinto al de la residencia habitual de la víctima

101. Puede suceder que la víctima se traslade a un país concreto distinto al país en el que tiene su residencia habitual y realice, en ese otro país, todos los gastos en consideración al matrimonio prometido y no celebrado. El caso no será frecuente, pero un acercamiento analítico exige diferenciar dos supuestos diferentes.

102. Primer supuesto: promesa de matrimonio y lugar estable de primer domicilio conyugal proyectado. En ocasiones, las partes residen en países diferentes pero tienen la intención de instalar el domicilio conyugal en un tercer país, país donde se llevan a cabo todos los gastos. Pues bien, en este supuesto, el daño tiene lugar en ese otro país, en el país donde la pareja, una vez casada tenía la intención de fijar su residencia conyugal. Ejemplo: una ciudadana española con residencia habitual en Madrid se traslada a Varsovia para adquirir una vivienda que será destinada a ser el hogar común de la pareja una vez celebrado el matrimonio. Un mes antes de dicha compra, su novio italiano, residente en Milán, le había prometido matrimonio. Sin embargo, una semana antes de la boda, él decide no contraer matrimonio. En este caso, el daño se ha producido en Polonia, pues el dinero pertenecía a la víctima hasta que lo gastó, y en ese momento, en dinero estaba en Polonia. La aplicación de la Ley polaca, de la Ley del país donde se ha realizado el gasto, que es, además la Ley del país de la residencia habitual proyectada de la pareja, una vez casada, es perfectamente previsible para ambas partes. En este sentido, la jurisprudencia anglosajona, aunque por razones muy específicas propias del Common Law, mostró una querencia muy acusada en favor de la Ley del país del proyectado primer domicilio conyugal ${ }^{151}$. En suma, en este primer supuesto, el lugar del daño (art. 4.1 RR-) se concreta en el país donde la pareja tenía perfectamente decidido instalar el primer domicilio conyugal si todos los gastos se han realizado en dicho país.

\footnotetext{
${ }^{149}$ Sentencia del tribunal Valenciennes de 19 diciembre 1935, Nouveau revue de droit international privé, 1936, p. 325, muy bien analizada por E. Rabel, The conflict of laws: A comparative study. Vol. 1: Introduction: Family Law, $2^{\mathrm{a}}$ ed., Ann Arbor, The university of Michigan press, Chicago, Callaghan \& company, 1958, pp. 215-221, esp. 217, nota [9].

${ }^{150}$ Sentencia tribunal de Pontoise de 23 abril 1969, Journal de droit international Clunet, 1979, p. 928 y nota de R. DAYANT.

${ }^{151}$ Vid. Kremezi vs. Ridgway (1949) 1 All E. R. 662; Hansen vs. Dixon, (1906) 96 L.T. 32, (1906) 23 T.L.R. 56; caso Guggenheim v. Rosenbaum, fallado por un tribunal de Sudáfrica, referenciado en E. SpIRo, «Breach of Promise (Based on Guggenheim v. Rosenbaum», The International and Comparative Law Quarterly, 1962, vol. 11, n.1 (January 1962), pp. 260-266.
} 
103. Segundo supuesto: promesa de matrimonio y lugar indefinido de primer domicilio conyugal proyectado. En otros casos, el lugar del primer domicilio conyugal no ha sido fijado o resulte dudoso, resultaría que el lugar del daño se localizaría en un país imprevisible para las partes: un país donde han sido realizado todos los gastos pero que no es el país del primer domicilio proyectado de la pareja. El país donde los gastos se han realizado puede, además, ser totalmente desconocido para el presunto demandado. En consecuencia, el lugar del daño es, en efecto, ese país donde el dinero ha sido gastado (art. 4.1 RR-II). Sin embargo, debe afirmarse que el caso presenta vínculos más estrechos con el país donde la víctima tiene su residencia habitual. Ese país es el centro de gravedad del litigio y de la reclamación: es el país donde tiene su sede natural la víctima del ilícito, persona cuya confianza en la promesa de matrimonio ha sido dañada. Por ello, conviene activar la cláusula de excepción prevista en el art.4.3 RR-II y aplicar, como ley del país más estrechamente conectado con el supuesto, la Ley del país de residencia habitual de la víctima.

\section{c) Daños económicos producidos en varios países}

(a) Daños en varios países incluido el país de residencia habitual de la víctima

104. Puede resultar frecuente es el caso de gastos realizados en consideración al matrimonio prometido y no celebrado y realizados en diferentes países. Un ejemplo puede resultar ilustrativo. Una mujer con residencia habitual en Almería se traslada a Portugal y Francia y en estos dos países realiza gastos con vistas a su matrimonio. También adquirió bienes en España. Un año antes de estas adquisiciones, su novio portugués, residente habitual en Lisboa, le había prometido matrimonio. Sin embargo, el día de la boda, el novio rompe su promesa y el matrimonio nunca tiene lugar. En este caso, el daño se ha producido en Portugal, en Francia y en España, pues el dinero pertenecía a la víctima hasta que lo gastó, y en ese momento, en dinero estaba en esos tres países. En estos casos plurilocalizados no resulta fácil concretar cuál es el país o países donde se ha producido el daño económico.

105. Una primera interpretación, más estricta, conduce a localizar el "lugar del daño" en el país o países donde se han efectuado los gastos propter nuptias. Una aplicación literal del criterio del "lugar donde se gasta el dinero" llevaría a aplicar varias Leyes estatales distintas a la responsabilidad civil de la persona que prometió el matrimonio. En el ejemplo anterior, las cantidades gastadas en Francia deberían ser devueltas, o no, con arreglo a la Ley francesa. Las cantidades gastadas en Portugal quedarían sometidas a la Ley portuguesa y así las gastadas en España se sujetan a la Ley española. El resultado no supera el «test de previsibilidad» recogido en el Considerando (16) RR-II, antes citado. La aplicación de tales múltiples leyes no sólo es complicada, -pues obliga a una aplicación distributiva de varios ordenamientos jurídicos estatales a modo de «mosaico de leyes» para recuperar todo el dinero gastado-, sino que resulta imprevisible para el sujeto que rompe su promesa de matrimonio. Éste puede perfectamente no conocer los países donde la otra persona ha realizado sus gastos.

106. Una segunda interpretación aboga por identificar el lugar del daño con el país en el que la pareja habría fijado su primera residencia habitual común en el caso de haberse celebrado el matrimonio (the intended home theory). Es éste el país en el que la ruptura de la promesa produce sus efectos principales: la no celebración del matrimonio. Es el país donde se ha producido el "daño económico", podría pensarse. Se trata de una interpretación muy del gusto anglosajón ${ }^{152}$. Sin embargo, esta interpretación

${ }^{152}$ Ello se explica porque la jurisprudencia inglesa entiende que la promesa de matrimonio es un contrato cuyo lugar de ejecución se localiza en el país donde la pareja, ya casada, instalará su domicilio conyugal. Desde este punto de vista, la ejecución del contrato cristaliza en la vida matrimonial. De ese modo, si la promesa (= el contrato de promesa matrimonial) se incumple, el daño derivado de tal incumplimiento se concreta en el país donde los prometidos tenían pensado fijar su domicilio conyugal, el país que tenían in mente los prometidos como lugar en el que la promesa matrimonial se iba a hacer realidad. Vid. la célebre sentencia inglesa, también antes citada, Kremezi vs. Ridgway (1949) 1 All E. R. 662. Vid. P.R.H. WebB / D.J. Latham Brown, "Engagements to Marry and the Conflict of Laws", The International and Comparative Law Quarterly, vol. 15, n. 4, 1966, pp. 
suscita grandes incertezas, pues el lugar de la primera residencia del matrimonio puede ser discutido o no haberse fijado ex ante de ninguna manera. Además, esta apreciación está basada en hipótesis de futuro, pues en verdad, nunca se sabrá si el matrimonio, en el caso de haberse celebrado, habría fijado su residencia común en dicho país. Además, puede ser que no se haya realizado ningún gasto económico en dicho país. Todo ello permite afirmar que esta interpretación conduce a un resultado contrario al «test de previsibilidad» contemplado en el Considerando (16) RR-II. En suma, en estos casos de gastos en varios países, la aplicación de la Ley del país del futurible domicilio común de la pareja no es previsible para las partes y puede, por ello, conducir a la aplicación de una Ley que las partes no conocen en absoluto y cuyo conocimiento les comporta elevados gastos.

107. Una tercera visión de la cuestión identifica el lugar del daño con el lugar donde la persona cuya confianza se ha sido dañada y que ha realizado gastos con vistas al matrimonio, tiene su sede natural. La sede natural de una persona radica en el país donde la misma tiene, en el momento de la ruptura de la promesa, su residencia habitual. En ese país, normalmente, habrá realizado también gastos. Por tanto se trata de localizar un daño extendido por varios países, incluido el país de la residencia habitual de la víctima.

108. La interpretación en favor de la residencia habitual de la víctima como lugar de localización del daño, en estos casos de gastos realizados en múltiples países, parece la más razonable en el contexto del art. 4.1 RR-II.

Esta interpretación conduce a aplicar una sola Ley estatal a todas las consecuencias patrimoniales de la ruptura de la promesa de matrimonio, sin que sean relevantes los países en los que el dinero se ha gastado o invertido. Permite la concentración de daños en un país: accessorium sequitur principale. Todos los daños deben regirse por la Ley del Estado donde se verifica el daño más importante. En el país de la residencia habitual de la víctima es donde los daños económicos suelen haberse producido en mayor medida y también, sin duda, el país donde la confianza de la víctima se ha visto dañada.

Por otro lado, la aplicación de esta Ley es perfectamente previsible para ambas partes (Considerando (16) RR-II). La persona que rompe la promesa puede no ser consciente de los países en los que ha gastado su dinero la otra persona. Ambos pueden ignorar el país en el que el matrimonio habría instalado su primer domicilio o primera residencia conyugal si es que se llegó a concretar dicho lugar. Sin embargo, ambos sujetos son siempre conscientes de cuál es el país de residencia habitual de los dos. Por tanto, la aplicación de la Ley del país de residencia habitual de la víctima es previsible para ambas partes y es la Ley del país donde el daño económico es mayor, pues es el país desde donde salen los fondos económicos gastados en previsión de un matrimonio que ya no se celebrará. La persona que rompe la promesa de matrimonio sabe perfectamente, en todo momento, cuál es el país donde reside habitualmente la otra persona, la víctima del incumplimiento de su promesa de matrimonio. En cierto sentido, puede afirmarse que, al romper dicha promesa, el responsable dirige su actividad dañosa al país donde la víctima tiene su residencia habitual. Por ello es previsible y por eso es justo que se aplique la Ley de dicho país, porque es la Ley que ambas partes estiman como de más previsible aplicación al supuesto.

947-995, así como P.M. NoRTH, "Varying the proper law", Multum Non Multa. Festschrift für Kurt Lipstein aus Anlass seines 70. Geburtstages, Heidelberg, Karlsruhe, 1980, pp. 205-220. También E. RABEL, The conflict of laws: A comparative study. Vol. 1: Introduction: Family Law, $2^{\mathrm{a}}$ ed., Ann Arbor, The university of Michigan press, Chicago, Callaghan \& company, 1958, pp. 215-221, esp. p. 216. Según los tribunales ingleses, la Ley del país más conectado con el caso (the proper law of the contract) era, a falta de indicación al respecto de las partes, la Ley del país donde los sujetos habían pensado establecer su primer domicilio conyugal, explica N. Boschiero, “Art. 26”, en S. Bariatti (a cura di), Legge 31 maggio 1995 n. 218, Riforma del sistema italiano di diritto internazionale privato. Commentario, en Nuove leggi civili commentate, 1996, pp. 1149-1156. En este mismo sentido favorable a la Ley del lugar donde las partes tenían la intención de situar el hogar matrimonial se pronunció el caso Hansen vs. Dixon, (1906) 96 L.T. 32, (1906) 23 T.L.R. 56. Vid. E. RABEL, The conflict of laws: A comparative study. Vol. 1: Introduction: Family Law, $2^{\mathrm{a}}$ ed., Ann Arbor, The university of Michigan press, Chicago, Callaghan \& company, 1958, pp. 215-221, esp. p. 216. Vid. también el antes citado caso Guggenheim v. Rosenbaum, fallado por un tribunal de Sudáfrica, muy bien analizado por E. SPIRo, «Breach of Promise (Based on Guggenheim v. Rosenbaum», The International and Comparative Law Quarterly, 1962, vol. 11, n.1 (January 1962), pp. 260-266. 
109. Un ejemplo puede ayudar a comprender esta interpretación. Una mujer española con residencia habitual en Cádiz promete matrimonio a un varón ucraniano con residencia habitual en Kiev a través de una web de citas que es visible en España y Ucrania, países de residencia habitual respectiva de ambos. El sujeto ucraniano adquiere bienes en Ucrania, Alemania y España con vistas a la vivienda que ambos piensan compartir en Varsovia tras la celebración del matrimonio. La mujer española decide no contraer matrimonio y se lo comunica al ciudadano ucraniano por mensaje de texto enviado desde España a Ucrania. En este supuesto, la ruptura de la promesa de matrimonio ha producido daños económicos al ciudadano ucraniano. Pues bien, estimar que tales daños se han producido fundamentalmente en Ucrania es lo más lógico y previsible. Es el país donde se ha verificado el "daño mayor", el país donde el patrimonio del ciudadano ucraniano se ha visto mermado por gastos realizados en varios países. La Ley de la residencia habitual de la víctima es la Ley cuya aplicación es más previsible para ambos sujetos. La mujer española es consciente de que, con su actitud, iba a producir daños económicos a una persona que reside habitualmente en Ucrania, mientras que puede no saber en qué países ha gastado su dinero dicha persona. La Ley ucraniana debe regir este caso, pues Ucrania es el "lugar del daño" (art. 4.1 RR-II) y dicha Ley decidirá si tales gastos son reembolsables y en qué medida en favor del ciudadano ucraniano.

(b) Daños en varios países excluido el país de residencia habitual de la víctima

110. Un caso especialmente complejo, aunque en realidad, residual, surge en el caso de que la víctima haya realizado gastos en consideración a un futuro matrimonio prometido, en diferentes países pero no en país de su residencia habitual. En este supuesto, una interpretación literal de la regla "lugar del daño", conduciría, de modo inevitable, a la aplicación de múltiples leyes: una Ley por cada país en el que se hayan realizado gastos directos por parte de la víctima. En este caso, el resultado no supera «test de previsibilidad» que contempla el Considerando (16) RR-II. En efecto, la aplicación de esas múltiples leyes no resulta previsible para el presunto responsable, que bien puede no conocer en qué países ha gastado su dinero la víctima.

111. En efecto, en el caso anterior es claro que la reclamación por los gastos realizados en consideración al matrimonio prometido y no celebrado presenta vínculos más estrechos con un país que no coincide con los países en los que los gastos se han llevado a cabo. El país más vinculado con el supuesto es aquél donde la víctima tiene su residencia habitual. Se trata del contexto natural de la promesa de matrimonio, esto es, el escenario social, jurídico y personal en el que las partes se encuentran situadas. Es el país donde la confianza de una persona se ha visto dañada. Por ello, es posible que dicha Ley sea la que las partes tenían in mente cuando se produce la promesa y su ruptura. De ese modo, parece conveniente recurrir a la cláusula de excepción recogida en el art. 4.3 RR-II y aplicar la Ley del país de la residencia habitual de la víctima.

112. Así, por ejemplo, considérese el caso de un varón tunecino con residencia habitual España que, en Túnez, promete matrimonio a una mujer también tunecina con residencia habitual en Túnez. La mujer adquiere bienes en España, Francia y Portugal en consideración al matrimonio prometido y no celebrado. El varón rompe su promesa de matrimonio y la le víctima reclama los gastos realizados en España, Francia y Portugal en consideración al matrimonio. La Ley aplicable a este caso debe fijarse con arreglo al art. 4.3 RR-II: el país más estrechamente vinculado con el litigio es Túnez, país donde la víctima tiene su residencia habitual. La aplicación de esta Ley es previsible para víctima y para presunto responsable. La aplicación de la Ley de Túnez a este caso genera para ambos costes de información jurídica más reducidos que los que provocaría la aplicación múltiple de todas las leyes que corresponden a los países donde se han realizado los gastos. Debe por ello operar la cláusula recogida en el art. 4.3 RR-II, de forma que, excepcionalmente, la Ley de Túnez debe aplicarse. 


\section{D) Daños morales, emocionales y económicos}

113. En el caso de que la víctima reclame daños morales, emocionales y económicos realizados en consideración al matrimonio prometido y no celebrado, todos ellos en la misma demanda, la localización del supuesto se vuelve complicada. Sin embargo, existen buenos argumentos para sostener que la Ley aplicable debe ser la que corresponde al país de la residencia habitual de la víctima.

114. En primer lugar, los daños morales y emocionales se han verificado, indudablemente, en el país donde la víctima tiene su centro social de vida, su sede personal, su centro de intereses principales. Se tratará, normalmente, del país de su residencia habitual.

En segundo lugar, si parte de los gastos económicos se han realizado también en dicho país, la conexión con el mismo se hace más fuerte, de modo que la aplicación de la Ley del país de la residencia habitual de la víctimas es previsible para ambas partes.

En tercer lugar, es posible afirmar que en ese país se ha producido el «daño mayor». Por tanto, en virtud del principio accessorium sequitur principale, parece conveniente que todos los daños queden sujetos a la Ley del Estado donde se verifica el daño más relevante. El daño se define, así, a través de concepto de «daño mayor»o «daño más relevante». En el país de la residencia habitual de la víctima es donde los daños morales y emocionales se han producido y también el país donde los gastos o una parte de ellos suelen haberse producido. Ese país es el lugar del daño (art. 4.1 RR-II).

\section{F) Daños recíprocos}

115. En el supuesto de que ambas partes se reclamen daños la una la otra por haber roto ambos una promesa de matrimonio, caso extraño pero posible, debe tenerse presente que la determinación de la Ley aplicable se debe realizar de modo separado. Los daños que X reclama a $Z$ se regirán por la Ley del lugar donde $\mathrm{X}$ a sufrido el daño (art. 4.1 RR-II). Los daños que Z solicita a X quedan sujetos a la Ley del lugar donde $\mathrm{Y}$ a sufrido el daño (art. 4.1 RR-II). Si un mismo tribunal conoce de ambos daños, -lo que es posible vista la regla de la reconvención recogida en el art. 8.4 RB I-bis-, deberá aplicar dos Leyes estatales diferentes, una por reclamación ${ }^{153}$.

\section{V. Ámbito de la Ley aplicable a la ruptura de la promesa de matrimonio}

\section{Cuestiones reguladas por la Ley que rige la reclamación por ruptura de la promesa de matri- monio}

116. La Ley que rige la responsabilidad por ruptura de la promesa de matrimonio regula diversas cuestiones.

117. En primer lugar, esta Ley determinada con arreglo al Reglamento Roma II fija el régimen jurídico de fondo de la promesa de matrimonio: admisibilidad de la promesa o de los esponsales, así como el contenido que debe presentar una promesa o esponsales para ser considerados como tales. Regula también la validez sustantiva de dicha promesa, los requisitos de fondo exigibles para su existencia y validez. Así, por ejemplo, existen las Leyes de algunos Estados no conocen la promesa unilateral de matrimonio, sino sólo la promesa bilateral o contrato de esponsales entre los prometidos. Así se recoge en los arts. 5-8 de la Al-Moudawana marroquí (código de familia) ${ }^{154}$.

\footnotetext{
${ }^{153}$ Art. 8.3 RB I-bis: “Una persona domiciliada en un Estado miembro también podrá ser demandada: (....) Si se trata de una reconvención derivada del contrato o hecho en que se fundamente la demanda inicial, ante el órgano jurisdiccional que esté conociendo de esta última".

${ }^{154}$ Texto en http://www.intermigra.info/archivos/CodFamiliaMarruecos.pdf.
} 
118. En segundo lugar, esta Ley rige no sólo, como se ha indicado, la existencia de la promesa de matrimonio y su validez, sino también las consecuencias de su ruptura. En efecto, es lógico que la Ley que regula la misma existencia y la validez de una promesa de matrimonio sea la misma Ley que rija las consecuencias de su ruptura. Así lo sostienen innumerables autores, como A. Weill, F. Mosconi / C. CAmpiglio, B. Barel / St. Armellini y T. Ballarino / A. Bonomi y también, en España, J.D. González Campos ${ }^{155}$. El daño producido tras la ruptura de la promesa matrimonial tiene su fundamento en la Ley y no en el acuerdo entre las partes, como ha indicado N. BosCHIERO ${ }^{156}$. Por tanto, la existencia y validez de la promesa de matrimonio debe regirse por la misma Ley que regula la responsabilidad civil extracontractual a tenor del Reglamento Roma II. Esta solución unitaria es más previsible para las partes, garantiza la proximidad de la ley aplicable con el supuesto y es eficiente, puesto que ofrece una solución eficiente, como remarca A. SARAVALLE ${ }^{157}$.

Por tanto, la ley aplicable al fondo de la reclamación, determinada con arreglo al Reglamento Roma II, rige cuestiones como la restitución de bienes regalados consideración al matrimonio prometido y no celebrado, el resarcimiento de los daños, la entidad del daño resarcible, la existencia de culpa en una de las partes, la necesidad de justa causa o simplemente de "causa" para romper la promesa sin obligación de pagar los gastos o viceversa, las consecuencias de la presencia de culpa en la ruptura de la promesa, así como la prescripción y la caducidad de las acciones ${ }^{158}$. Es preciso recordar, con E. RABEL, que las consecuencias de la ruptura de la promesa de matrimonio se regulan de modo muy diversos en las distintas legislaciones nacionales. Algunas confirman el deber de pagar daños y perjuicios, otras no admiten dicho deber, otras permiten reclamar daños compensatorios por lesiones especiales, daños por dolor y sufrimiento mental, o incluso permiten reclamar los famosos daños punitivos ${ }^{159}$.

${ }^{155}$ F. Mosconi / C. CAmpiglio, Diritto internazionale privato e processuale. Vol. 2: Statuto personale e diritti reali, $4^{\mathrm{a}} \mathrm{ed}$., Milano, 2016, p. 86: “.... qui la disciplina è unitaria (....) mentre per la violazione dei diritti della personalità la disciplina delle conseguenze è stata rimessa legge regolatrice della responsabilità per fatto illecito (art. 62), qui si è preferita una soluzione diversa"; B. BARel / St. ARmellini, Manuale breve Diritto internazionale privato: tutto il programma d'esame con domande e risposte commentate, Milano, Giuffrè, 2006, p. 136: “L'ambito della disposizione copre: ammissibilità e contenuto della promessa, forma e conseguenze della sua violazione"; T. BALlarino / A. Bonomi, Diritto internazionale privato, $3^{\mathrm{a}} \mathrm{ed}$., Cedam, 1999, p. 374: "La legge designata dall'art. 26 è chiamata a regolare la promessa di matrimonio e le conseguenze della sua violazione: vi rientrano tutte le questioni relative alla restituzione dei doni o al risarcimento dei danni, all'entità del danno risarcibile, alle conseguenze della colpa uno dei nubendi, al termine prescrizionale". J.D. GonzÁlEz CAMPOS, "El matrimonio en el Derecho civil internacional", en M. Aguilar NAVArro, Derecho civil internacional, Facultad de Derecho, Universidad Complutense, Madrid, 4 ed,. 1975 (reimpresión 1979), pp. 243-371, esp. pp. 258-262: "Para un sector doctrinal, se considera que el problema del incumplimiento posee autonomí, independientemente de la promesa matrimonial que ha sido el origen del acto de ruptura; y la consecuencia de esta posición es reclamar una regulación especial del incumplimiento dentro del Derecho internacional privado. Posición esta dificilmente aceptable, pues los efectos de la promesa (en caso de ruptura) no pueden separarse de forma radical del negocio jurídico que ha sido su causa. De este modo, el problema se desplaza hacia la calificación del negocio jurídico, de la promesa matrimonial". A. WeILL, "Fiançailles", Encyclopedie Dalloz droit international, París, 1968-69 (dir. Ph. Franceskakis), vol.II, 1969, pp. 22-24: «La détermination de la loi compétente pour apprécier la responsabilité du fiancé auteur d'une rupture fautive ne peut dissociée de la nature juridique des fiançailles (...) conduit à au statut délictuel la responsabilité du fiancé auteur d'une rupture fautive».

${ }^{156}$ N. Boschiero, “Art. 26”, en S. Bariatti (a cura di), Legge 31 maggio 1995 n. 218, Riforma del sistema italiano di diritto internazionale privato. Commentario, en Nuove leggi civili commentate, 1996, pp. 1149-1156, esp. p. 1153.

${ }^{157}$ A. SARavalle, "Articolo 26", en Riforma del sistema italiano di diritto internazionale privato legge 31 maggio 1995 n. 218, Rivista di Diritto internazionale privato e processuale, 1995, pp. 1043-1046: "Con una decisione molto opportuna, il legislatore ha disposto espressamente che la medesima legge disciplini sia la promessa di mattimonio sia le conseguenze della sua violazione. Quanto alle conseguenze, ricadono sotto l'impero della legge determinata dalla nonna in esame solo quelle tipiche, espressamente ricollegate alla rottura della promessa di matrimonio".

158 J.A. Tomás Ortiz de la Torre, "Celebración del matrimonio", en M. Aguilar Benítez de Lugo y otros, Lecciones de Derecho civil internacional, Ed. Tecnos, Madrid, 1996, pp. 088-116, esp. p. 94: "La aplicación de la Ley extranjera debe quedar limitada a los aspectos de qué gastos y obligaciones se consideran hechos en razón del proyectado matrimonio (por ejemplo, el costo de una previa intervención quirúrgica a la que no se habría sometido él o la interesada de conocer que el matrimonio después no llegaría a celebrarse, ¿es gasto hecho con ocasión del matrimonio?...), cuantía de la indemnización, modalidades y formas del resarcimiento, etc.”.

${ }^{159}$ E. RABEL, The conflict of laws: A comparative study. Vol. 1: Introduction: Family Law, $2^{\mathrm{a}}$ ed., Ann Arbor, The university of Michigan press, Chicago, Callaghan \& company, 1958, pp. 215-221, esp. p. 217: “with respect to the duty to pay damages the laws vary from non-recognition of any such duty to recognition of a duty to pay compensatory damages for special injury, damages for mental pain and suffering, or even punitive damages". 


\section{Ley aplicable a la capacidad para formular una promesa de matrimonio}

119. La capacidad para formular una promesa de matrimonio debe sujetarse a la Ley nacional del sujeto en cuestión (art. 9.1 CC). Así, por ejemplo, en el caso Guggenheim v. Rosenbaum", fallado por un tribunal de Sudáfrica, se cuestionó la capacidad legal de un varón para obligarse en virtud de una promesa de matrimonio. La cuestión era muy relevante, pues con arreglo a la Ley personal de dicho sujeto, que era la Ley de Nueva York, y visto que en tal Derecho no existe la promesa de matrimonio y no produce efecto jurídico alguno, resulta que el sujeto carecía de capacidad legal para formular una promesa matrimonial. Sin embargo, la Ley reguladora de la ruptura de la promesa, que en el caso concreto era la Ley de Sudáfrica, sí que admitía dicha capacidad ${ }^{160}$.

12. La capacidad para formular una promesa de matrimonio constituye una cuestión importante, pues algunos ordenamientos jurídicos admiten que la promesa de matrimonio la realice no sólo la persona que pretende contraer matrimonio con otra, sino un sujeto distinto como el padre del novio o novia. Pues bien, con F. Mosconi / C. CAMPIGLIO, cabe afirmar que esta posibilidad debe ser calificada como una cuestión de capacidad para formular la promesa. Es, pues aplicable, la Ley nacional del sujeto prometido para saber si la promesa puede realizarla dicho sujeto o también otra persona en su nombre (art. 9.1 CC) ${ }^{161}$. De todos modos, muy claro quede quedar que una Ley que permite a un padre prometer el matrimonio de su hijo, por ejemplo, resulta radicalmente contraria al orden público internacional español (art. 12.3 CC), pues la promesa debe considerarse como un acto jurídico personalísimo.

\section{Ley aplicable a la forma de la promesa de matrimonio}

121. La Ley reguladora de la promesa de matrimonio, fijada con arreglo a los arts. 14 y 4 RRII, no alcanza a la regulación de la forma de dicha promesa y de los esponsales ${ }^{162}$. Esta cuestión está

${ }^{160}$ E. SPIRO, "Breach of Promise (Based on Guggenheim v. Rosenbaum", The International and Comparative Law Quarterly, 1962, vol. 11, n.1 (January 1962), pp. 260-266: "According to both English and South African law the proper law of the contract is the law of the country which the parties have agreed or intended or are presumed to have intended shall govern $i t$; and in the case of a contract concluded in one country to be performed in another, it can be presumed, in the absence of an express term or any other indication to the contrary, that the proper law is the law of the latter (lex loci solutionis). Applying these principles, the learned judge found on the proved facts that the proper law of the contract to marry was the law of South Africa. The irresistible inference from all the facts appeared to the learned judge to be that both parties intended that the law of South Africa, where they were to rejoin one another as soon as possible and arrange to get married, should govern their contract, and that they could not possibly have intended that the New York law should apply to their relationship, for which conclusion the learned judge found strong support in the decision in Hansen Dixon".

${ }^{161}$ F. Mosconi / C. CAMpiglio, Diritto internazionale privato e processuale. Vol. 2: Statuto personale e diritti reali, $4^{\mathrm{a}} \mathrm{ed}$., Milano, 2016, p. 85: “Analogamente la disposizione dell'art. 81 cod. civ. in tema di capacità offre una forte sottolineatura del carattere assolutamente individuale e personale che per il nostro ordinamento deve rivestire la manifestazione di volontà di ciascuno degli interessati: indizio chiaro, ancora una volta, della necessità di invocare il limite dell'ordine pubblico in relazione ad una legge straniera in conformità alla quale nel caso di specie la promessa non provenisse direttamente dall'interessato ma per esempio dal genitore, senza che l'interessato gliene avesse conferito 'speciale incarico"'. Ya antes, vid. E. VITTA, Diritto internazionale privato, vol. II, UTET, Torino, 1973, pp. 167-171, esp. p. 167: "Non è dubbio che la capacita a centrarte gli sponsali è stabilita dalla legge nazionale dei futuri sposi e, in caso di loro diversa cittadinanza, dalla legge nazionale di ciascuno di essi. Mentre la forma degli sponsali stessi cadrá sotto una delie leggi di cui all'art. 26"' También, para Italia, vid. inter alia, R. MonACO, L'efficacia della legge nello spazio, Utet, 1964, pp. 153-157: "Ne consegue che la promessa di matrimonio è regolata dalla legge dello Stato al quale appartengono le persone tra le quali essa interviene (art. 17 disp. prel.). Tale norma non si riferisce peraltro a tutti gli element! dell'atto: ne sono escluse la capacitó dei soggetti, nonché la forma che la promessa deve rivestire. Quanto alla capacità deve applicarsi la norma, contenuta nel medesimo art. 17, che riguarda la capacité di agire delle persone, con l'avvertenza che, trattandosi di rapporti di famiglia", así como P. Fedozzi, Il diritto internazionale privato: Teorie generali e diritto civile, Cedam, Padova, 1939, pp. 402-405: "La capacità dei promittenti sarà regolata dalla legge nazionaie comune o dalla legge nazionale propria di ciascun di essi”. Para el Derecho internacional privado español, W. Goldschmidt, Sistema y filosofía del Derecho internacional privado, t.I, Ed.Bosch, Barcelona, 1948, pp. 227-229: "Si. en cambio, ambos contrayentes no fuesen católicos, se aplica a la forma de los esponsales de futuro el art. 11 Cc. y a la capacidad, la ley nacional de cada uno de los contrayentes, según el art. 9 Cc.".

${ }^{162}$ Para Italia, vid. inter alia, R. MonAco, L'efficacia della legge nello spazio, Utet, 1964, pp. 153-157: "Ne consegue che la promessa di matrimonio è regolata dalla legge dello Stato al quale appartengono le persone tra le quali essa interviene (art. 17 
sujeta a la norma de conflicto específica sobre la forma, en particular, al art. 21 RR-II, como sugiere C. FoCARELLI $^{163}$. El art. 21 RR-II indica que un acto jurídico unilateral relativo a una obligación extracontractual será válido en cuanto a la forma si reúne las condiciones formales de la ley que rige la obligación extracontractual o de la ley del país donde se haya celebrado el acto. Por tanto, el precepto abre la posibilidad de que la promesa sea válida en cuanto a la forma si se ajusta a la Lex Loci Actus aunque no se ajuste a la Lex Causae y viceversa El citado art. 21 RR-II parece cubrir tanto la forma ad probationem como la forma ad solemnitatem. Dicho precepto hace inaplicable, para España, el art. $11 \mathrm{CC}$ en general y el art. 11.2 CC en particular ${ }^{164}$.

122. Las exigencias formales de la promesa de matrimonio son relevantes. Por ello es importante fijar con atención la Ley aplicable a estos aspectos formales. En línea con lo afirmado por I. QueIroLo, las cuestiones de validez formal están relacionadas con los requisitos formales para exteriorizar la voluntad del sujeto en su promesa de matrimonio, mientras que las cuestiones de existencia y validez sustancial están más bien relacionadas con la cuestión diferente de determinar los requisitos mínimos para calificar la promesa como "un acto jurídico existente"165.

Así, el Derecho italiano exige, para solicitar la indemnización por daños provocados por los gastos realizados y por las obligaciones contraídas con vistas al matrimonio, que la promesa de matrimonio conste por escrito, bien en documento público o privado o que se hayan publicado las amonestaciones matrimoniales (art. 81 codice civile italiano). Pues bien, si un varón español con residencia habitual en España efectúa promesa de matrimonio a ciudadana italiana con residencia habitual en Roma, y la promesa se realiza en Londres, la Ley que rige las consecuencias de la ruptura de dicha promesa es la Ley italiana. Es, en efecto, la Ley del lugar del daño (art. 4.1 RR-II). Pues bien, para poder exigir tal responsabilidad, es preciso que la promesa sea formalmente válida. A tal efecto, se considerará que la promesa es formalmente válida si se ajusta a las exigencias formales revistas en el Derecho italiano (Lex Causae) o bien a las recogidas en el Derecho inglés (Lex Loci Actus), como precisa el art. 21 RR-II. Si el art. 21 RR-II no existiera, podría sostenerse, como tradicionalmente y con acierto hizo la siempre sugerente doctrina italiana, que la forma ad solemnitatem de la promesa de matrimonio debe regirse por la Ley que rige la promesa misma ${ }^{166}$. A esa misma solución habría que llegar a través del art. 11.2 CC si la promesa de matrimonio no se regulase por el Reglamento Roma II. Sin embargo, no es el caso: los as-

disp. prel.). Tale norma non si riferisce peraltro a tutti gli element! dell'atto: ne sono escluse la capacitó dei soggetti, nonché la forma che la promessa deve rivestire. Quanto alla capacità deve applicarsi la norma, contenuta nel medesimo art. 17, che riguarda la capacité di agire delle persone, con l'avvertenza che, trattandosi di rapporti di famiglia". Del mismo modo, $\mathrm{P}$. FEDozzi, Il diritto internazionale privato: Teorie generali e diritto civile, Cedam, Padova, 1939, pp. 402-405: “ $L$ 'osservanza di determinate forme sarà retta dalla legge del luogo in cui l'atto si compie oppure, dovendosi fare applicazione dell'art. 9 delle preliminari o delle analoghe disposizioni di altre legislazioni, dalla legge nazionale comune dei contraenti”. PAra España, W. Goldschmidt, Sistema y filosofía del Derecho internacional privado, t.I, Ed.Bosch, Barcelona, 1948, pp. 227-229: "Si. en cambio, ambos contrayentes no fuesen católicos, se aplica a la forma de los esponsales de futuro el art. 11 Cc. y a la capacidad, la ley nacioal de cada uno de los contrayentes, según el art. 9 Cc.".

${ }^{163}$ C. Focarelli, Lezioni di diritto internazionale privato, Morlacchi Ed., Perugia, 2006, p. 94.

${ }^{164}$ Por analogía, vid. F. Mosconi / C. CAmpiglio, Diritto internazionale privato e processuale. Vol. 2: Statuto personale e diritti reali, $4^{\mathrm{a}}$ ed., Milano, 2016, p. 86, así como C. FoCARelli, Lezioni di diritto internazionale privato, Morlacchi Ed., Perugia, 2006, p. 94: "In mancanza di altre disposizioni si presume che l'art. 26 disciplini sia la sostanziale che la validità formale della promessa". En consecuencia, el art. 21 RR-II evita que la forma de la promesa de matrimonio quede sujeta, necesariamente, a la Ley que regula el fondo de la misma.

${ }^{165}$ I. Queirolo, “Art. 21 Rome II Regulation”, en U. Magnus / P. Mankowski (Eds.), Rome II Regulation, European Commentaries on Private International Law, Köln, Verlag Dr. Otto Schmidt, 2019, pp. 611-616: "It should preliminary be recalled that the issue of the formal validity of unilateral acts is a different matter from the issue of substantial validity of such acts, which is governed by the law of the non-contractual obligation to which the unilateral act relates. In particular, issues of formal validity are connected to the formal requirements to externalize the will of the subject, while issues of existence and substantial validity are rather connected with the different issue of determining the minimum requirements to qualify the act as 'existing"'.

166 T. Ballarino / A. Bonomi, Diritto internazionale privato, 3a ed., Cedam, 1999, p. 374: "L'art. 26 non precisa se la legge richiamata debba disciplinare anche la forma richiesta dalla legge affinché la promessa produca $i$ suoi effetti. A nostro giudizio, la risposta dev'essere positiva: la portata derogatoria che la promessa di matrimonio ha rispetto al fondamentale principio della libertà matrimoniale induce ad escludere che possa operare, nella materia in esame, quel favor validitatis che sta a fondamento di una disciplina speciale della forma dei contratti e di altri negozi giuridici". 
pectos formales de la promesa de matrimonio se rigen por la Ley a la que remite el art. 21 RR-II y dicho precepto permite salvar la validez formal de la promesa de matrimonio a través, como se ha indicado, de una conexión alternativa.

\section{Aplicación de la Ley reguladora de la reclamación por ruptura de la promesa de matrimonio}

\section{A) Lex Causae y segunda calificación}

123. La Ley estatal aplicable a la reclamación tras la ruptura de la promesa de matrimonio, la Lex Causae indicará si la situación privada internacional presenta relevancia legal, cuál es su naturaleza jurídica y cuáles son los efectos jurídicos que produce. Esto es, una vez declara la aplicación a la promesa de matrimonio de un concreto Derecho estatal, dicha promesa es objeto de una "segunda calificación" (califications en sous-ordre) que se debe realizar con arreglo a tal Derecho aplicable al fondo de la cuestión jurídica suscitada (Lex Causae ${ }^{167}$. En tal sentido, por ejemplo, si la norma de conflicto europea conduce al Derecho alemán porque en Alemania se ha producido el daño (art. 4.1 RR-II) y dicho ordenamiento jurídico considera que la promesa de matrimonio es una cuestión que pertenece al Derecho de familia, se calificará nuevamente la cuestión con arreglo al Derecho alemán y se aplicarán las normas germanas que regulan las cuestiones de Derecho de familia ${ }^{168}$.

\section{B) Prohibición del reenvío tradicional y del reenvío de calificaciones}

124. E1 Reglamento Roma II prohibe todo reenvío ${ }^{169}$. Sea bienvenida esta prohibición, pues además de potenciar la seguridad jurídica, evita los intrincados problemas de reenvíos de calificaciones que

${ }^{167}$ La cuestión de la segunda calificación es clásica en Derecho internacional privado desde hace innumerables años. Vid. inter alia, B. ANCEL, "L'objet de la qualification", Journal de droit international Clunet, 1980, vol.107, pp. 227-268; G. BARILE, "Qualificazione (Diritto internazionale privato)", AA.VV., Enciclopedia del diritto, Giuffrè, Milano, 1988, vol. XXXVIII, pp. 1-22; Рн. Franceskakis, "Qualifications”, Encyclopedie Dalloz droit international, Paris, $1968-69$ (dir. Ph. Franceskakis), vol.II, 1969, pp. 703-708; E. JAYME, “Zur Qualifikationsverweisung im internationalen Privatrecht”, Zeitschrift für Rechtsvergleichung, 17, 1976, pp. 93-109; E. RABEL, "Das Problem der Qualifikation”, RabelsZ., 5, 1931, pp. 241-288 y Revue critique de droit international privé, 1933, pp. 1-62. Muy bien explicada la cuestión con ejemplos basados en la ruptura de la promesa de matrimonio aparece en D. Holleaux / J. FoYer / G. DE GeOufFré DE LAPRAdelle, Droit international privé, París, Masson, 1987, pp. 276-277: «Mais soit une question de réparation du dommage résultant de la rupture de fuançailles. D'après la qualification française primaire, inspirée des solutions du droit c'est là, sauf controverse, un problème de responsabilité civile extracontractuelle, dépendant de la règle de conflit lex loci delicti. Admettons, en réservant la difficulté de localiser le délit ou le dommage, que la loi applicable, étrangère, classe la question dans le droit des contrats ou le droit familial. Appliquerons-nous des règles étrangères traduisant une conception différente de celle qui nous a conduits à leur donner compétence? Il convient de répondre que la différence entre la qualification française primaire et la qualification étrangère secondaire ne constitue pas en soi une raison de rejeter cette dernière et la règle matérielle qu'elle indique. On ne saurait tout d'abord substituer aux règles étrangères que la qualification secondaire indique celles correspondant à notre qualification primaire, par exemple appliquer à une rupture de fiançailles survenue dans un pays X les règles de ce pays relatives à la responsabilité extracontractuelle, au lieu de ses dispositions de droit familial, seules applicables en l'occurrence, selon la loi X. il faut ou bien appliquer les règles appropriées suivant le système étranger, ou bien renoncer à toute référence â ce système. En réalité, le contraste des qualifications primaire et secondaire peut refléter une différence des traitements matériels, français et étranger, de la question. Mais cette différence n'est pas non plus en soi une cause de rejet de la règle matérielle étrangère (sinon, il ne servirait jamais à rien de désigner une loi étrangère aux fins de régir un point de droit quelconque). Peu importe, en définitive, que la loi étrangère soumette les fiançailles à des règles familiales ou à des règles contractuelles, pourvu que, substantiellement, elle ne méconnaisse pas un principe jugé par nous fondamental (ici, le principe de la liberté du mariage). Au contraire, si la loi étrangère portait atteinte à un semblable principe, mariage). Au contraire, si la loi étrangère portait atteinte à un semblable principe, l'ordre public international français (que seul le contenu et non la classification d'une règle étrangère peut heurter) interviendrait et provoquerait son éviction».

${ }^{168}$ Mutatis mutandis, E. Rabel, The conflict of laws: A comparative study. Vol. 1: Introduction: Family Law, $2^{\mathrm{a}}$ ed., Ann Arbor, The university of Michigan press, Chicago, Callaghan \& company, 1958, pp. 215-221, esp. p. 218.

${ }^{169}$ Art. 24 RR-II: «Exclusión del reenvio. Cuando el presente Reglamento establezca la aplicación de la ley de un país, se entenderá por tal las normas jurídicas vigentes en ese país con exclusión de las normas de Derecho internacional privado». 
se planteaban, con cierta frecuencia, en relación con los esponsales y la promesa de matrimonio, como escriben D. Bureau / H. Muir Watt y T. Ballarino ${ }^{170}$. Así, explican M.-L. Niboyet / G. De Geouffre de La Pradelle, la ruptura de los esponsales se considera, en el Derecho internacional privado francés, como una cuestión de responsabilidad civil extracontractual, como sucede, según se ha visto, en Derecho europeo. Pues bien, la Ley aplicable es, por tanto, en Derecho internacional privado europeo, a falta de elección de Ley y de residencia habitual común de las partes, la Ley del lugar del daño (art. 4.1 RR-II). Por otro lado, el Derecho internacional privado alemán califica los esponsales y la promesa de matrimonio como una cuestión de estatuto personal, sujeta, por tanto, a la Ley nacional de las personas. Si el daño tiene lugar en Alemania y están implicados dos prometidos franceses, uno con residencia habitual en Francia y otro en Alemania, el Reglamento Roma II designará como aplicable al Derecho alemán. Éste, -sorpresa sorpresa-, califica la cuestión como atinente al estatuto personal. De ese modo, la norma de conflicto alemana reguladora del estatuto personal indica que es aplicable la ley nacional común de las partes. Con ello efectúa un reenvío de primer grado en favor del Derecho francés, debido a la diferencia de calificaciones entre los dos ordenamientos jurídicos ${ }^{171}$. Pues bien, al eliminar todo reenvío, en el ejemplo anterior, el art. 4.1 RR-II remitirá al Derecho alemán, ley del lugar del daño, y no se admitirá ninguna remisión en favor del Derecho francés o de cualquier otro que pueda efectuar el Derecho alemán por el motivo de que tal ordenamiento considere que la promesa de matrimonio debe ser calificada como una cuestión incluida en el «estatuto personal» de los prometidos.

\section{C) Orden público internacional y reclamaciones tras la ruptura de la promesa del matrimonio}

\section{a) Negación de la actio matrimonialis. Admisión e inadmisión de la demanda}

125. El orden público internacional español presenta una incidencia notable en los casos de reclamaciones tras la ruptura de promesas de matrimonio cuando la cuestión queda sujeta a leyes extranjeras como resultado de la aplicación del Reglamento Roma II.

126. En primer lugar, resulta indudablemente contraria al orden público internacional español la aplicación de una Ley extranjera que pudiera imponer la obligación de contraer matrimonio derivada de una previa promesa de matrimonio. Así lo indica de manera unánime la doctrina española y extranjera ${ }^{172}$.

${ }^{170}$ D. Bureau / H. Muir Watt, Droit international privé, Tome II Partie spéciale, $3^{\mathrm{a}}$ ed., Presses universitaires de France (PUF), Paris, 2014, p. 114. T. Ballarino, Diritto internazionale privato, Cedam, Padova, 1982, pp. 706-707: “La qualificazione della rottura del fidanzamento fornita da ciascuna delle leggi applicabili non ha rilievo: il fatto può essere considerato, come nel diritto francese, un illecito civile e tuttavia, se uno dei fidanzati è francese, le relative norme avranno applicazione nel quadro della sua legge personale".

${ }_{171}$ M.-L. Niboyet / G. De Geouffre de La Pradelle, Droit international privé, $6^{a}$ ed., Paris, Lextenso éditions, LGDJ, 2017, p. 248, n. 285: «Un exemple permettra de mieux comprendre ce problème, La rupture des fiançailles est regardée, en droit international privé français, comme une question de responsabilité civile extra-contractuelle. La loi applicable est en conséquence la loi du lieu de la rupture. En revanche, le droit international privé allemand y voit une question de statut personnel, qu'il soumet à la loi nationale. Si la rupture se produit en Allemagne entre deux Français, le droit français désignera le droix allemand qui renverra à la loi française, en raison de la divergence de qualifications entre les deux systèmes". Tambien en relación con un caso de reenvío de calificaciones, vid. E. RABEL, The conflict of laws: A comparative study. Vol. 1: Introduction: Family Law, $2^{\mathrm{a}}$ ed., Ann Arbor, The university of Michigan press, Chicago, Callaghan \& company, 1958, pp. 215-221, esp. p. 218.

${ }_{172}$ N. Boschiero, “Art. 26”, en S. Bariatti (a cura di), Legge 31 maggio 1995 n. 218, Riforma del sistema italiano di diritto internazionale privato. Commentario, en Nuove leggi civili commentate, 1996, pp. 1149-1156; D. Anzillotтi, Corso di lezioni di diritto internazionale privato, Athenaeum, 1918, p. 219; G. Bosco, Corso di diritto internazionale privato, Castellani, 1939 , p. 222; G. Morelli, Elementi di diritto internazionale privato italiano, Jovene, 1962, p. 96; M. MIELE, Scritti di diritto matrimoniale, Cedam, 1964, p. 25; R. Monaco, L'efficacia della legge nello spazio, Utet, 1964, 155; R. DE Nova, "voce Matrimonio (promessa di), diritto internazionale privato", Novissismo Digesto italiano, X, Utet, 1964, pp. 426-429; A. WeILl, "Fiançailles", Encyclopedie Dalloz droit international, París, $1968-69$ (dir. Ph. Franceskakis), vol.II, 1969, pp. 22-24; R. DE NovA, "Gli sponsali in diritto internazionale privato", Il Foro Italiano, 1955, vol. 78, N. 2, pp. 25-38. C. FocARelLi, Lezioni di diritto internazionale privato, Morlacchi Ed., Perugia, 2006, p. 94: “ $E$ da notare che la questione della promessa di matrimonio si pone soltanto rispetto al risarcimento dei danni, o al rimborso delle spese incorse 'propter nuptias', e alla restituzione dei doni in caso di inadempimento, e non rispetto all'esecuzione in forma specifica della promessa, e cioè al matrimonio forzato, il quale ove fosse 
En efecto, una Ley que así lo estableciera resulta contraria al principio fundamental de libertad conyugal, recogido en el Derecho europeo y español, ya que no existe matrimonio sin un consentimiento matrimonial libre e informado ${ }^{173}$. Una Ley estatal que obligara a la celebración del matrimonio vulneraría la libertad que es esencial al consentimiento matrimonial, por lo que daña de manera evidente y flagrante el orden público internacional español (art. 26 RR-II, art. 12.3 CC). Incluso el Código de Derecho canónico de 1917, cuya regulación de estas cuestiones había influido de manera decisiva en las legislaciones de muchos Estados europeos y de sudamericanos, había ya eliminado en su canon 1017 la obligación de contraer matrimonio tras una ruptura de promesa matrimonial, como recuerdan E. RABEL y M. DE LASALA LLANAS $^{174}$. Esta postura ha sido confirmada por el canon 1062 del actual Código de Derecho canónico vigente desde el 25 enero $1983^{175}$.

127. Es curioso recordar, con H. CoRnejo ChÁvez y W. Goldschmidt, que una ley noruega de 31 mayo 1918 recogía el derecho de la novia embarazada a solicitar el matrimonio, esto es, la actio matrimonialis $^{176}$. La aplicación en España de una Ley extranjera de dicho tenor resulta contraria al orden público internacional español, ya que vulnera la libertad de contraer matrimonio, derecho fundamental y principio básico del Derecho de familia español.

ammesso da una legislazione straniera sarebbe contrario all'ordine pubblico italiano stante il principio fondamentale della libertà di sposarsi”. G. Balladore Pallieri, Diritto internazionale privato, en "Trattato di diritto civile e commerciale", Giuffrè, Milano, 1974, pp. 173-174: "Si tratta dunque esclusivamente di una obbligazione 'ex lege'. Non solo, ma quelle conseguenze che discenderebbero direttamente dalla promessa, e avrebbero lo scopo di ottenere il mantenimento di questa, sono esclude dal nostro diritto in modo del tutto generale, per un principio di ordine pubblico, onde salvaguardare appieno la libertà dei promittenti, e pertanto non potrebbero sussistere da noi nemmeno in virtù di una legge straniera che la sancisse"; J.R. DE ORÚE Y ARREGUI, Manual de Derecho internacional privado, $3^{\mathrm{a}}$ ed., Madrid, Ed.Reus, 1952, p. 642: "Como curiosa diversidad, el derecho de la novia embarazada a solicitar el matrimonio (Ley noruega de 1918), en franca contradicción con nuestro orden público». Para el Derecho internacional privado alemán, ya a principios del siglo XX, vid. M. WolfF, Derecho internacional privado, Ed. Labor, Barcelona 1936, traducción de José Rovira y Ermengol, pp. 286-287: «En el Derecho de esponsales entra en juego el orden público (art. 30 de la Ley de Intr. al CCA): el juez alemán no puede aplicar una ley extranjera si con ello restringe mas de lo que permite la ley alemana la libertad de contraer matrimonio. En consecuencia, tampoco puede condenar a celebrar un matrimonio, ni siquiera en el caso de que el Derecho nacional de los novios admitiera tal juicio». P. FEDOzZI, Il diritto internazionale privato: Teorie generali e diritto civile, Cedam, Padova, 1939, pp. 402-405: “... il principio della libertà del consenso al matrimonio mi sembra di così straordinaria importanza da dover essere assicurata nel territorio in confronto di tutti, cittadini e stranieri”. D. HolleauX / J. Foyer / G. De GeOUfFré de Lapradelle, Droit international privé, París, Masson, 1987, pp. 276-277: «Peu importe, en définitive, que la loi étrangère soumette les fiançailles à des règles familiales ou à des règles contractuelles, pourvu que, substantiellement, elle ne méconnaisse pas un principe jugé par nous fondamental (ici, le principe de la liberté du mariage). Au contraire, si la loi étrangère portait atteinte à un semblable principe, l'ordre public international français (que seul le contenu et non la classification d'une règle étrangère peut heurter) interviendrait et provoquerait son éviction».

${ }^{173}$ Vid. art. 8 de la Carta de los derechos fundamentales de la Unión Europea hecha en Niza el 7 de diciembre de 2000 (DOUE C 326 de 26 octubre 2012 [versión consolidada 2012]); art. 12 del Convenio para la protección de los derechos humanos y de las libertades fundamentales (Consejo de Europa) hecho en Roma el 4 noviembre 1950 (BOE núm. 243 de 10 octubre 1979); art. 23.3 del Pacto Internacional de Derechos Económicos, Sociales y Culturales adoptado y abierto a la firma, ratificación y adhesión por la Asamblea General en su Resolución 2200 A (XXI), de 16 diciembre 1966; art. 45 CC. Vid. también art. 16 Declaración Universal de los Derechos humanos adoptada y proclamada por la Asamblea General en su resolución 217 A (III), de 10 diciembre 1948.

${ }^{174}$ E. RaBel, The conflict of laws: A comparative study. Vol. 1: Introduction: Family Law, $2^{\mathrm{a}}$ ed., Ann Arbor, The university of Michigan press, Chicago, Callaghan \& company, 1958, pp. 215-221, esp. p. 216 nota [5]. M. DE Lasala Llanas, Sistema español de Derecho civil internacional e interregional, Ed. Rev. Derecho privado, Madrid, 1933, pp. 110-111: “Para los católicos españoles, además, no existe ya discrepancia entre el Derecho civil y el canónico; el canon 1.017 del Codex Juris Canonici, promulgado en 1917, abrogó realmente también la institución de los "esponsales", en cuanto ya no pueden dar lugar a ningún efecto, si la promesa se ha hecho privadamente, y sólo dan acción para la reparación de daños ante los Tribunales, dejando reducida al fuero de conciencia la obligación de contraer matrimonie, si la promesa se hizo en escritura suscrita por ambos contrayentes, por el párroco o por el ordinario, o, al menos, por dos testigos".

${ }^{175}$ Canon $1062 \S$ del Código de Derecho canónico vigente desde el 25 enero 1983: “1. La promesa de matrimonio, tanto unilateral como bilateral, a la que se llama esponsales, se rige por el derecho particular que haya establecido la Conferencia Episcopal, teniendo en cuenta las costumbres y las leyes civiles, si las hay. \& 2. La promesa de matrimonio no da origen a una acción para pedir la celebración del mismo; pero si para el resarcimiento de daños, si en algún modo es debido".

${ }^{176}$ H. Cornejo ChÁvez, "Los esponsales”, Revista Derecho PUCP, 1949, n.9, pp. 11-25; W. GoldsChMidt, Sistema y filosofia del Derecho internacional privado, t.I, Ed.Bosch, Barcelona, 1948, pp. 227-229: "El derecho de la novia embarazada a pedir el matrimonio, que. p. ej., concede la Ley noruega de 1918, infringe el orden público español (art. 11, pár. 3, y art. 43)”. 
128. Por otra parte, la aplicación de una Ley extranjera que, de uno u otro modo, penaliza a una persona por no haber respetado su promesa de matrimonio resulta también "manifiestamente incompatible con el orden público" español (art. 26 RR-II). Por ello, puede afirmarse que también es contraria al orden público internacional español la aplicación en España de una Ley extranjera que admitiera que deben pagarse daños y perjuicios como consecuencia de la ruptura de una promesa de matrimonio. E igualmente, resulta contraria al orden público internacional español la aplicación en España de una Ley extranjera que obligara a pagar una cláusula penal en dinero, pactada entre las partes, en el caso de que la persona que ha prometido contraer matrimonio rechace cumplir con su promesa. Es indudable que el principio de libertad nupcial se integra, en su máxima extensión, en el orden público internacional español y que tales pactos permitidos por una Ley extranjera, coartan la libertad nupcial, como ha indicado J.A. TomÁs OrTIZ DE LA TORRE ${ }^{177}$. De nuevo, puede afirmarse que, en ese caso, el principio fundamental de la libertad nupcial se vería vulnerado, como indica A. WeILL ${ }^{178}$. También contraria al orden público internacional español resulta la aplicación de una Ley extranjera que imponga un resarcimiento económico por el simple, solo y mero hecho de la ruptura de la promesa de matrimonio, esto es, aunque no se hayan verificado daños morales, personales, emocionales o patrimoniales. Uno de los principios cardinales del Derecho español de daños es que sin daño no hay responsabilidad civil. Además, en este caso, de puede afirmar que el resarcimiento económico impuesto al prometido que cambia de idea coarta su libertad nupcial.

129. Es oportuno preguntarse, visto el tenor de los arts. 42 y $43 \mathrm{CC}$, si se admitirá a trámite una demanda presentada ante los tribunales españoles fundada en un Derecho extranjero que persiga obligar a una persona a cumplir con su promesa de matrimonio, aunque posteriormente se falle contra dicha pretensión al considerar que la Ley extranjera que pudiera dar validez a tal pretensión fuera rechazada por resultar contraria el orden público internacional español. La cuestión debe responderse mediante un acercamiento analítico en buena dogmática jurídica. Así, debe recordarse que, en Derecho español, los requisitos para la admisión / inadmisión de las demandas son requisitos de carácter procesal, no sustantivo. En consecuencia, las condiciones y requisitos para admitir una demanda presentada ante los jueces españoles se rigen, en todo caso, por las normas procesales españolas (arts. 3, 403 y 247 LEC, art. 11 LOPJ). Es cierto que en Derecho procesal español no existe el llamado «juicio de accionabilidad», característico del Derecho alemán. No se examinan las demandas con carácter preliminar para averiguar si pueden o no tener buen fin, si están bien fundadas o no. Las demandas que cumplen con los requisitos procesales mínimos se admiten siempre. Ahora bien, este principio procesal básico conoce algunas excepciones y una de ellas es la recogida en el art. $42 \mathrm{CC}$ [promesa de matrimonio]. De este modo, dicho precepto, aunque se halle en el Código civil, es una disposición de tipo procesal, por lo que se aplica a toda demanda que se presente ante tribunales españoles sea cual fuere el Derecho regulador del fondo. En conclusión, no se admitirá, en ningún caso, a trámite la demanda en que se pretenda el cumplimiento de una promesa de matrimonio, aunque dicha promesa se rija por un Derecho extranjero

${ }_{177}$ J.A. Tomás Ortiz de la Torre, "Celebración del matrimonio", en M. Aguilar Benítez de Lugo y otros, Lecciones de Derecho civil internacional, Ed. Tecnos, Madrid, 1996, pp. 88-116, esp. p. 94: “... bien entendido que, en todo caso, cualquiera que fuese la Ley extranjera aplicable el orden público nacional español impediría aplicar aquellas normas que fuesen contrarias a los artículos 42 y 43 del Código Civil vigente. Es decir, no tendrá aplicación una Ley extranjera que imponga la celebración del matrimonio prometido, o que admita el cumplimiento de estipulaciones que se hubieren hecho para caso de no celebración (por ejemplo, una cláusula penal), y, a nuestro parecer, tampoco sería de aplicación la Ley extranjera que concediese, a la parte demandante y perjudicada por la negativa, otros derechos o indemnizaciones que no sean los que se limiten a resarcir de los gastos hechos y obligaciones contraídas en consideración al matrimonio prometido y no celebrado. Estos dos preceptos, creemos, marcan el límite del orden público, en consecuencia se estima que si una ciudadana alemana demandase en España la indemnización especial contra su novio por desfloración, nuestros tribunales no deberían En aplicar el artículo 1.300 del BGB que la concede, en el supuesto de que el derecho alemán resultase aplicable". En sentido opuesto, para el Derecho internacional privado alemán, vid. M. WolfF, Derecho internacional privado, Ed. Labor, Barcelona 1936, traducción de José Rovira y Ermengol, pp. 286-287: "En el Derecho de esponsales entra en juego el orden público (art. 30 de la Ley de Intr. al CCA): el juez alemán (...) no tiene derecho a declarar nulas las penas contractuales estipuladas”.

${ }^{178}$ A. Weill, "Fiançailles", Encyclopedie Dalloz droit international, París, 1968-69 (dir. Ph. Franceskakis), vol.II, 1969, pp. 22-24: «L'exception d'ordre public empêcherait également que l'on puisse faire sortir effet à une clause pénale stipulée pour le cas où le mariage ne serait pas contracté». 
que sí permite instar su cumplimiento. Sin embargo, una demanda basada en un Derecho extranjero en la que se reclama una indemnización por incumplimiento de una promesa de matrimonio se debe admitir si se ajusta los requisitos procesales fijados en las leyes españolas, aunque posteriormente la demanda pueda ser desestimada una vez acreditada la contrariedad del Derecho extranjero con el orden público internacional español.

\section{b) Restricciones a nuevos matrimonios}

130. Interviene igualmente el orden público internacional español para rechazar la aplicación en España de una Ley extranjera que impida que un sujeto ligado por promesa de matrimonio o esponsales, pueda contraer matrimonio con un tercero/a, como sucedía en la antigua legislación sueca, precisa A. WEILL ${ }^{179}$.

\section{c) Indemnizaciones especiales}

131. Como destaca J.A. TomÁs Ortiz de LA ToRre, es contraria al orden público internacional español la aplicación en España de una norma extranjera que permitiera a una mujer solicitar, previa existencia de una promesa de matrimonio, una "indemnización especial contra su novio por desfloración”, como así se recogía en el antiguo art. 1300 BGB alemán ${ }^{180}$. Esta previsión legal es discriminatoria y atenta claramente contra la dignidad constitucional de la mujer.

132. Especial atención suscita el caso de la "seducción con promesa de matrimonio", que constituía, hasta 1996, en Derecho italiano, un caso específico de responsabilidad civil extracontractual (art. 526 codice penale italiano ${ }^{181}$. Este caso se rige por las normas generales del Reglamento Roma II $^{182}$. También el Derecho serbio admite una acción civil tras una seducción con promesa de matrimonio que permite obtener una indemnización en este caso ${ }^{183}$. En ambos supuestos se trata de una responsabilidad civil por el que deriva del hecho mismo de la seducción unido al acto jurídico de la promesa de matrimonio. No es necesario que la víctima haya realizado gasto económico alguno. En la mayor parte de los casos, el lugar del daño se concreta en el país donde tiene la residencia habitual persona seducida.

179 A. Weill, "Fiançailles", Encyclopedie Dalloz droit international, París, 1968-69 (dir. Ph. Franceskakis), vol.II, 1969, pp. 22-24: «Dans certaines législations, les fiançailles constituent un empêchement au mariage avec une tierce personne; ainsi, en Suède, l'état de fiancé, quand les fiançailles ont été célébrées régulièrement, constitue un obstacle au mariage avec un tiers».

180 J.A. Tomás Ortiz de la Torre, "Celebración del matrimonio", en M. Aguilar Benítez de Lugo y otros, Lecciones de Derecho civil internacional, Ed. Tecnos, Madrid, 1996, pp. 088-116, esp. p. 94: “... en consecuencia se estima que si una ciudadana alemana demandase en España la indemnización especial contra su novio por desfloración, nuestros tribunales no deberían aplicar el artículo 1.300 del BGB que la concede, en el supuesto de que el derecho alemán resultase aplicable".

${ }^{181}$ Art. 526 codice penale italiano: "Seduzione con promessa di matrimonio commessa da persona coniugata. Chiunque, con promessa di matrimonio, seduce una donna minore di età, inducendola in errore sul proprio stato di persona coniugata, è punito con la reclusione da tre mesi a due anni. Vi è seduzione quando vi è stata congiunzione carnale". Este precepto fue derogado por el art. 1 de la Legge de 15 febbraio 1996, n. 66.

182 A. Saravalle, "Articolo 26", en Riforma del sistema italiano di diritto internazionale privato legge 31 maggio $1995 \mathrm{n}$. 218, Rivista di Diritto internazionale privato e processuale, 1995, pp. 1043-1046: "Talora, invece, la rottura del fidanzamento non determina solo una domanda di restituzione dei doni o di risarcimento delle spese effettuate propter nuptias, ma anche una domanda di risarcimento per seduzione con promessa di matrimonio. In questo caso, la promessa di matrimonio diventa un presupposto della seduzione che, secondo la costante giurisprudenza della Suprema Corte, costituisce un illecito civile. Occorre, pertanto, distinguere le due fattispede: la promessa di matrimonio e le sue conseguenze saranno assoggettate alla legge personale dei nubendi, o in mancanza alla lex fori, mentre la seduzione e le sue conseguenze devono essere regolate dalla legge richiamata dall'art. 62 della presente legge".

${ }^{183}$ Vid. referencias al texto legal citado en: https://documents-dds-ny.un.org/doc/UNDOC/GEN/G09/439/00/PDF/G0943900. pdf?OpenElement 


\section{d) Leyes extranjeras que permiten reclamar daños morales y emocionales}

133. La cuestión de saber si el orden público internacional español debe operar para evitar la aplicación en España de una Ley extranjera que permite reclamar "daños morales" o "emocionales" derivados de una ruptura de promesa matrimonial es realmente controvertida.

134. Podría pensarse que tales leyes resultan contrarias al orden público internacional español. en efecto, en Derecho español, el daño emocional derivado de la no celebración del matrimonio no puede ser indemnizado en modo alguno. La decisión de una persona de no contraer matrimonio es una decisión lícita que deriva de la libertad humana de contraer matrimonio o no contraerlo. Esa decisión puede provocar un daño emocional a otra persona, pero se trata de un daño lícito y, por tanto, no indemnizable. Así lo ha estimado la STS 16 diciembre $1996^{184}$. En Derecho material español, pues, no hay acción para reclamar por los daños emocionales derivados de la ruptura de una promesa de matrimonio, porque toda persona tiene derecho a cambiar de opinión antes de contraer matrimonio y a decidir que no quiere contraer dicho matrimonio a pesar de haber prometido que iba a contraer matrimonio. En Derecho español, el único daño indemnizable consiste en haber realizado gastos y haber contraído obligaciones en consideración al matrimonio prometido: es un daño económico, un daño patrimonial, no un daño emocional o sentimental. En Derecho español, a pesar de mediar una promesa de matrimonio, los corazones rotos no se indemnizan, es un riesgo al que todo ser humano se halla expuesto en la vida. Podría, pues pensarse, que constituye un principio fundamental del Derecho español de daños la no indemnización de daños exclusivamente sentimentales, porque castigar tales daños con una indemnización por daños y perjuicios vulneraría el principio de libertad nupcial de la persona. El Derecho español, puede subrayarse, es abiertamente hostil a penalizar todo daño moral que sea consecuencia de la libre decisión de no contraer matrimonio. Por tanto, podría afirmarse que, en efecto, la aplicación en España de una Ley extranjera que obligara a pagar daños morales o emocionales derivados de la no celebración del matrimonio resulta contraria al orden público internacional español, como muy bien subraya P. FEDOzzi ${ }^{185}$.

135. Sin embargo, la perspectiva anterior olvida que varios aspectos. En primer lugar, el Derecho español está abierto a indemnizar, en ciertos casos, los daños derivados de la ruptura de una promesa de matrimonio. En segundo lugar, el principio fundamental del Derecho español en esta materia consiste en que nadie puede ser castigado por no contraer matrimonio con persona determinada. En tercer lugar, es la presencia de la promesa de matrimonio el elemento clave: la promesa de matrimonio genera una confianza en la celebración del matrimonio, una confianza que una persona destruye. Las Leyes extranjeras que conceden daños morales o emocionales derivados de la ruptura de una promesa de matrimonio no castigan a una persona por haber cambiado de opinión y no querer ahora contraer matrimonio. Estas leyes extranjeras sólo permiten reclamar indemnizaciones por daños morales y emocionales cuando el sujeto ha creado una expectativa razonable en otro sujeto mediante una promesa de matrimonio y luego ha

\footnotetext{
${ }^{184}$ STS 16 diciembre 1996 [ECLI: ES:TS:1996:7256]: “... no puede desconocerse pese al incorrecto planteamiento de los motivos (porque no respetan los hechos probados devenidos firmes) que, precisamente, con apoyo en estos hechos resulta desmesurada la interpretación del artículo 43 del Código civil, ya que estima "gastos hechos" y "obligaciones contraídas en consideración al matrimonio prometido", conceptos o partidas que se avienen mal con la relación de causalidad directa que deben guardar aquellos y estos con la promesa de matrimonio, conceptos que, además, no pueden incluir una especie de indemnización por daños morales ya que no existe ninguna obligación de indemnizar a la novia o novio abandonado, ni introducir reproches culpabilísticos en la libre decisión de no contraer matrimonio pese a la promesa, con las limitaciones que este precepto entraña en orden a las consecuencias económicas del incumplimiento (...) desde luego el daño moral, causado por la frustración del proyecto matrimonial no es indemnizable bajo ninguna cobertura legal y lo mismo cabe decir del estado de depresión reflejado en el informe forense que consta en las actuaciones. Los demás daños son reparables, conforme al artículo 1.902 del Código civil, invocado entre los reguladores de la culpa extracontractual en los fundamentos jurídicos de la demanda....".

${ }^{185}$ P. Fedozzi, Il diritto internazionale privato: Teorie generali e diritto civile, Cedam, Padova, 1939, pp. 402-405: “ $D$ 'altra parte l'obbligo del risarcimento, limitato dal nostro art. 54 alle spese fatte per causa del promesso matrimonio, è così profondamente diverso da quello di corrispondere un 'indennità per danni da non potere argomentare la liceità di quest'ultimo dalla liceità del primo. L'obbligo di pagare le spese non costituirà certo una remora a mantenere la propria libertà matrimoniale, mentre può ben assumere questo carattere l'obbligo di risarcire tutti i danni derivanti dalla rottura della promessa".
} 
roto su promesa y con ello ha causado daños emocionales y morales a la otra persona. Téngase presente que la promesa de matrimonio es una declaración de voluntad seria, firme, sólida. Es una declaración formal, no una mera afirmación de querer contraer matrimonio, es una "promesa". El legislador español ha regulado esta cuestión, -una cuestión de legalidad ordinaria-, de modo que no permite solicitar daños morales y emocionales derivados de esa ruptura de la promesa de matrimonio. Sin embargo, una Ley extranjera que concede daños en este caso no vulnera el principio de libertad nupcial porque lo que tales leyes castigan, como se ha dicho, no es que una persona decida no casarse con otra persona, sino haber roto una promesa de matrimonio que había hecho nacer expectativas razonables en la otra parte y, con ello, haber causado un daño moral y emocional a otra persona. Por tanto, debe admitirse que no existe en Derecho español un principio de orden público internacional que niegue las indemnizaciones como consecuencia de la ruptura de la promesa de matrimonio en los casos de daños morales o emocionales ${ }^{186}$.

\section{e) Leyes extranjeras que impiden reclamar daños derivados de la ruptura de la promesa de ma- trimonio}

136. También controvertida es la cuestión de decidir si resulta contraria al orden público internacional español la aplicación en España de una Ley extranjera que impida reclamar los daños económicos sufridos injustamente tras la ruptura de una promesa de matrimonio y que permita, por tanto, que una persona se beneficie del daño ilícito causado a otra, indica G. OBERTO ${ }^{187}$. La cuestión resulta dudosa y requiere un acercamiento analítico.

En la jurisprudencia alemana, la sentencia del Kammergericht (Alemania) de 11 enero 1939, citada por E. RABEL, declara expresamente que la Ley estadounidense que niega todo tipo de daños y perjuicios en favor de una persona que ha sido seducida con promesa de matrimonio no es contraria al orden público internacional alemán, aunque en Derecho alemán sí que exista acción para reclamar dichos daños y perjuicios ${ }^{188}$. En el mismo sentido se ha expresado, también en la doctrina alemana, M. WolfF, pese al parecer recogido en una antigua sentencia del OLG de Colonia de 1926 que, sin razón o motivo claro según el autor citado, indicó que debe excluirse la aplicación de leyes extranjeras cuando no concedan indemnización por ruptura de esponsales ${ }^{189}$.

Ponderados los elementos anteriores, corresponde a la Ley extranjera reguladora del supuesto a tenor del Reglamento Roma II decidir qué daños son ilícitos e indemnizables y hasta qué punto y qué daños no lo son. Varios argumentos apoyan esta afirmación. En primer lugar, debe respetarse la seguridad jurídica que proporcionan las normas de conflicto europeas (Cons. 14 RR-II). En principio, la regla general es que la ley que rige las obligaciones extracontractuales se rigen por la ley estatal designada por el Reglamento Roma II ${ }^{190}$. En segundo lugar, la intervención del orden público internacional es excep-

\footnotetext{
186 Vid. P. Fedozzi, Il diritto internazionale privato: Teorie generali e diritto civile, Cedam, Padova, 1939, pp. 402-405: “... e d'altra parte ammettendo l'indennità, sia pure entro ristretti confini, il nostro legislatore ha mostrato di non attribuire un carattere immorale alla domanda d'indennità genericamente considerata", cuya argumentación, realizada para el Derecho italiano, es válida también para el Derecho español.

${ }^{187}$ G. OвеRто, "La promessa di matrimonio", en VV.AA. Trattato di diritto di famiglia, diretto da I. Zatti, Famiglia e matrimonio, $2^{\mathrm{a}}$ ed., Milano, 2011, pp. 325-330.

${ }^{188}$ E. Rabel, The conflict of laws: A comparative study. Vol. 1: Introduction: Family Law, $2^{\mathrm{a}}$ ed., Ann Arbor, The university of Michigan press, Chicago, Callaghan \& company, 1958, pp. 215-221, esp. p. 219: "The decision of the Kammergericht of 1939 (supra n. 6), declares expressly that the American statute denying a claim for seduction of a betrothed woman is not contrary to the international public policy of the court, though contrary to the German Civil Code". Vid. también W. GoLDSCHMIDT, Sistema y filosofia del Derecho internacional privado, t.I, Ed.Bosch, Barcelona, 1948, pp. 227-229: "El derecho a pedir indemnización por injustificada resolución de los esponsales de futuro pertenece al orden público alemán, su denegación al orden público holandés". Vid. igualmente, G. Melchior, Die Grundlagen des deutschen internationalen Privatrechts, Institut für Ausländisches und Internationales Privatrecht, Berlin, 1932 (reprint 2016), De Gruyter (Verlag), § 255.

${ }^{189}$ M. WolfF, Derecho internacional privado, Ed. Labor, Barcelona 1936, traducción de José Rovira y Ermengol, pp. 286287: “¿Deberá, por el contrario, excluirse la aplicación de leyes extranjeras cuando no concedan indemnización por ruptura de esponsales? Así lo sostiene OLG de Colonia LeipzZ, 1926, 602".

${ }^{190}$ Considerando (14) RR-II: "La exigencia de seguridad juridica y la necesidad de hacer justicia en casos individuales son elementos esenciales en un área de justicia. El presente Reglamento establece los factores de conexión más apropiados
} 
cional y no puede invocarse cada vez que un Derecho extranjero regule una cuestión de Derecho Privado de modo diferente al Derecho español. Por ello, en este caso, parece adecuado invocar el orden público internacional español para evitar la aplicación de un Derecho extranjero que conceda indemnizaciones por no haber respetado una promesa de matrimonio.

\section{f) Leyes extranjeras que imponen indemnizaciones elevadas y daños punitivos}

137. Cabe preguntarse también si una Ley extranjera que admita indemnizaciones muy elevadas como consecuencia de la ruptura de la promesa de matrimonio resulta contraria al orden público internacional español. En el contexto del Derecho internacional privado alemán, M. WolfF sostuvo que en ese caso debe intervenir el orden público internacional del foro ${ }^{191}$. A estos efectos cabe diferenciar dos supuestos.

En primer lugar, debe indicarse que cuando se trata de leyes extranjeras que permiten reclamar daños en cuantía más elevada que la que habría que conceder según la Ley española por ruptura de la promesa de matrimonio, no existe contrariedad alguna con el orden público internacional español. Éste admite, es evidente, la reparación del daño causado como eje fundamental del Derecho de daños, como ya señalara hace años R. MonACO ${ }^{192}$. Por tanto, no debe intervenir el orden público internacional español si una Ley extranjera permite reclamar los daños sufridos en una cantidad superior o inferior a la que establece el Derecho español.

En segundo lugar, cuando se trata de pagar indemnizaciones punitivas como consecuencia del daño producido tras una ruptura de matrimonio, en realidad, el supuesto no es distinto de otros en los que se ha juzgado la contrariedad con el orden público internacional español de Leyes extranjeras que admiten la imposición de os llamados "daños punitivos" propios de algunos Estados de Common Law. En principio, el Tribunal Supremo español se ha mostrado favorable a la aplicación, en España, de Leyes extranjeras que admiten tales daños punitivos y a la ejecución en España, de sentencias extranjeras que imponen tales daños (ATS 13 noviembre 2001; STS 13 enero 2015; también AAP Barcelona 4 octubre 2019) ${ }^{193}$. El Considerando (32) RR-II señala que "en particular, la aplicación de una disposición de la ley designada por el presente Reglamento que condujera a la asignación de daños e intereses ejemplares o punitivos de naturaleza excesiva, puede, según las circunstancias del caso y el ordenamiento jurídico del Estado miembro del órgano jurisdiccional competente, considerarse contraria al orden público del foro". A la vista del art. 26 RR-II, del Cons. (32) RR-II y de la jurisprudencia española dominante, cabe, pues afirmar que el juez español puede aplicar una ley extranjera que conceda daños punitivos por la ruptura de una promesa de matrimonio si se supera un "triple test jurídico" de legitimidad de la Ley extranjera que admite la imposición de daños punitivos: un test de "moderación-exceso de los daños punitivos", un test de "oportunidad de los daños punitivos excesivos" y un test de "vinculación espacial" del supuesto fáctico como ha explicado la doctrina española ${ }^{194}$.

para conseguir dichos objetivos. Por ello, el presente Reglamento establece una regla general pero también reglas específicas y, en algunas disposiciones, una «cláusula de escape» que permite apartarse de estas reglas cuando se desprenda claramente de todas las circunstancias del caso que el hecho dañoso está manifiestamente más vinculado con otro país. Este conjunto de reglas crea de esta manera un marco flexible de normas de conflicto de ley. Del mismo modo, permite al órgano jurisdiccional competente tratar los casos individuales de forma adecuada".

${ }^{191}$ M. WolfF, Derecho internacional privado, Ed. Labor, Barcelona 1936, traducción de José Rovira y Ermengol, pp. 286287: "En el Derecho de esponsales entra en juego el orden público (art. 30 de la Ley de Intr. al CCA): el juez alemán (...) no tiene derecho a declarar nulas las penas contractuales estipuladas. Tampoco puede conceder los amplios derechos de indemnización que el Derecho inglés reconoce a la novia abandonada".

${ }_{192}$ Para Italia, vid. inter alia, R. Monaco, L'efficacia della legge nello spazio, Utet, 1964, pp. 155-156: “Invece deve ritenersi che non cada sotto il limite dell'ordine pubblico l'eventuale disposizione straniera che ammette, in caso di rottura della promessa, il risarcimento dei danni in misura più estesa di quella stabilita dalla legge italiana, e ciò per il motivo che il principio del risarcimento, sia pure in limiti ristretti, è riconosciuto anche dalla legge italiana".

${ }^{193}$ ATS 13 noviembre 2001 [ECLI:ES:TS:2001:1803A]; STS 13 enero 2015 [ECLI:ES:TS:2015:181]; AAP Barcelona 4 octubre 2019 [ECLI:ES:APB:2019:7550A].

${ }^{194}$ Así lo indica de modo expreso el citado AAP Barcelona 4 octubre 2019 [ECLI:ES:APB:2019:7550A]. El sistema del 


\section{g) Leyes extranjeras que permiten la ruptura de la promesa de matrimonio}

138. No hay vulneración alguna del orden público internacional español en el caso de que la Ley extranjera permita la ruptura de unos esponsales o contratos matrimoniales obligatorios para los novios o de una promesa de matrimonio obligatoria según el Derecho extranjero. Dicha ruptura significa que cesa la obligación de contraer matrimonio que nacía de dicho acuerdo, de modo que no se produce ningún efecto contrario al orden público internacional español ${ }^{195}$.

\section{Rechazo de la consideración de los arts. 42 y 43 CC como leyes de policía}

139. Resulta también preciso destacar que la regulación jurídica civil española de los esponsales y de la promesa de matrimonio no constituye un conjunto de leyes de policía, pese a lo sugerido en el pasado por algunos autores, como M. DE LASALA LlanAS y J.G. VeRPlaETSE, con cierta confusión y falta de sistemática ${ }^{196}$. El art. 16 RR-II indica que las disposiciones del citado reglamento "no afectarán a la aplicación de las disposiciones de la ley del foro en aquellas situaciones en que tengan carácter imperativo, cualquiera que sea la ley aplicable a la obligación extracontractual".

Debe entenderse por "normas imperativas", pese al silencio del Reglamento Roma II al respecto, lo mismo que se entiende en el ámbito del Reglamento Roma I (art. 9.1 RR-I). Indica la STJUE 31 enero 2019, C-149/18, Dekra, FD 27-28 que: "una disposición cuya observancia considera esencial un Estado para la salvaguardia de sus intereses públicos, tales como su organización política, social o económica, hasta el punto de exigir su aplicación a toda situación comprendida dentro de su ámbito de aplicación, cualquiera que sea la ley aplicable" ${ }^{197}$. Son disposiciones legales de aplicación e interpretación estricta que defienden "un interés que el Estado miembro de que se trate considera esencial" (STJUE 17 octubre 2013, C-184/12, Unamar, FD 50) ${ }^{198}$. Para averiguar si una disposición legal reviste tal carácter "esencial" debe procederse a un "análisis detallado de sus términos, de su estructura general, de sus objetivos y del contexto en que se haya adoptado". La importancia de dicha disposición en el ordenamiento jurídico nacional del foro debe ser tal que justifique "apartarse de la ley aplicable designada de conformidad con el art. 4 RR-II' (STJUE 31 enero 2019, C-149/18, Dekra, FD 31 [accidente de circulación en España entre vehículo portugués y vehículo español] $)^{199}$.

triple test había ya sido sugerido por cierta doctrina. Vid. inter alia, J. CARrascosa González, "Daños punitivos. Aspectos de Derecho internacional privado español y europeo" (Capítulo 8), en M.J. Herrador GuARdia (Coordinador), Derecho de Daños, Ed. Aranzadi, 2013, pp. 383-464; A. Hernández Rodríguez, "Accidentes aéreos y forum non conveniens. Algunas cuestiones en torno al asunto Honeywell en España”, Cuadernos de Derecho Transnacional, 2012, pp. 307-321; I. Lorente MARTínez, "El Tribunal Supremo y los daños punitivos", en A.-L. Calvo Caravaca/J. Carrascosa González (Dir.), El Tribunal Supremo y el Derecho Internacional Privado, vol. 1, Murcia, Rapid Centro Color S.L., 2019, pp. 249-258; P. MÉndez-Monasterio Silvela, Daños punitivos el "patito feo" de la responsabilidad civil, Fe d'erratas, Madrid, 2016; P. SALvador CordeCh, "Punitive Damages", Indret, septiembre 2001; M. ReQueJo Isidro, "Punitive damages y su notificación en el contexto del Convenio de La Haya de 15 de octubre de 1965", Revista española de Derecho internacional, 1996-II, pp. 71-98.

${ }^{195}$ En este sentido, vid. Decreto Corte Apello Torino 23 diciembre 2010, Rivista di Diritto internazionale privato e processuale, 2011, p. 478 [sentencia siria que procede a la ruptura del compromiso matrimonial "ktab ktab" propio del Derecho sirio]).

${ }^{196}$ M. DE Lasala Llanas, Sistema español de Derecho civil internacional e interregional, Ed. Rev. Derecho privado, Madrid, 1933, pp. 110-111: "El código civil, aceptando este criterio prohibitivo, establece una regla de orden público internacional, que, por consiguiente, no sólo es obligatoria para los españoles, "aunque residan en el extranjero (Iey personal art. 9 u orden publico interno), sino también para los extranjeros en España, como ley "prohibitiva" de orden moral o costumbres" (párrafo tercero del art. 11)". También oscuro y desordenado, con mezcla de calificación familiar de la cuestión y de aplicación de leyes de policía resulta el texto de J.G. VerplaEtSE, Derecho internacional privado, Ed. Estades, Madrid, 1954, p. 406: "Es de orden publico, asimismo, la prohibición y nulidad de los esponsales de futuro. La acción de indemnización y de resarcimiento del art. 44 del Código civil se rige por la Ley nacional en cuanto a los españoles. pero, en cuanto a los extranjeros en España, hay que tener en cuenta, a más de la Ley nacional, el Derecho español corno ley de policía y seguridad, que abarca la responsabilidad".

${ }_{197}$ STJUE31 enero 2019, C-149/18, Agostinhoda Silva Martins vs. Dekra Claims Services Portugal, S.A., [ECLI:EU:C:2019:84].

${ }^{198}$ STJUE 17 octubre 2013, C-184/12, Unamar NV vs. Navigation Maritime Bulgare. [ECLI:EU:C:2013:663].

${ }^{199}$ STJUE31 enero 2019, C-149/18, Agostinho da Silva Martins vs. Dekra Claims Services Portugal, S.A., [ECLI:EU:C:2019:84]. 
140. El legislador español no ha establecido un ámbito de aplicación espacial específico de la regulación jurídica española de la promesa de matrimonio. No impone su aplicación a casos internacionales. Dicha regulación no parece esencial para la salvaguardia de los sus intereses públicos, para la organización política, social o económica española.

\section{Ruptura de la promesa de matrimonio y obligación natural}

141. Es oportuno preguntarse, con A. WeILL, acerca del caso que se suscita cuando el «fiancé récalcitrant» haya realizado un pago a la otra parte como compensación por su negativa a contraer matrimonio ${ }^{200}$. En ciertos Derechos estatales este caso se califica como una obligación natural, de mod oque el sujeto que ha versado tal cantidad ya no puede reclamarla a la víctima. Las llamadas "obligaciones naturales" (naturalis obligatio: vid. entre otros, art. $1901 \mathrm{CC}$ ), surgen de la voluntad de una persona frente a otra sin que dicha obligación nazca de la Ley al margen de la voluntad de la persona. Así, el auxilio económico prestado por una persona a otra tras romper su promesa de matrimonio, presenta un carácter contractual. La persona ha querido entregar una cantidad a otra y lo ha hecho porque libremente así lo ha considerado. La Ley reguladora de esta obligación se determina con arreglo al Reglamento Roma $\mathrm{I}^{201}$. De ese modo, la Ley aplicable a la cuestión de saber si una persona que recibe una compensación entregada por el sujeto que rompió una promesa de matrimonio debe devolverla o no, se rige por la Ley elegida por el sujeto pagador, (art. 3.1 RR-I) y en su defecto, se regula por la Ley del país de la residencia habitual de dicho sujeto, que es el prestador característico (art. 4.2 RR-II).

\section{Donaciones por razón de matrimonio y ruptura de la promesa de matrimonio}

142. En este contexto, debe practicarse una distinción entre donaciones entre prometidos o personas unidas por una relación sentimental y donaciones que tiene lugar una vez realizada la promesa de matrimonio.

143. Las primeras donaciones, esto es, aquéllas que cubren los regalos, bienes y cantidades monetarias intercambiadas entre personas que se profesan afecto y que van a contraer matrimonio, pero entre las que no existe una promesa de matrimonio, deben ser calificadas, desde el punto de vista del Derecho europeo, como "obligaciones contractuales". Estos regalos, estas donaciones, son obligaciones que surgen de compromisos libremente asumidos por una persona. La Ley aplicable a estas donaciones se fija con arreglo al Reglamento Roma I. Si los regalos y otras donaciones se realizan entre cónyuges, habrá que distinguir. En el caso de que tales donaciones se realicen en el marco del régimen económico de los cónyuges, es aplicable el Reglamento 2016/1003. Si se trata de donaciones realizadas al margen del régimen económico matrimonial, es aplicable el Reglamento Roma I, como ha indicado doctrina autorizada $^{202}$.

${ }^{200}$ A. WeILl, "Fiançailles", Encyclopedie Dalloz droit international, París, 1968-69 (dir. Ph. Franceskakis), vol.II, 1969, pp. $22-24$.

${ }^{201}$ Vid. un caso de obligación natural de naturaleza contractual en la sentencia Trib. Bologna (Italia) 9 noviembre 2015 [transferencia de suma monetaria de sociedad panameña a persona física italiana] (https://aldricus.files.wordpress.com/2016/05/ sentenza-lex-panamense.pdf). Sobr ela Ley aplicable a las obligaciones naturales vid. A.-L. CAlvo CARAVACa / J. CARRASCoSA González, "Obligaciones extracontractuales", en A.-L. Calvo Caravaca / J. Carrascosa GonzÁlez (directores), Tratado de Derecho internacional privado, primera edición, editorial Tirant Lo Blanch, València, vol. III, 2020, pp. 3679-3674.

${ }^{202}$ En tal sentido, con matices muy sugerentes, vid. N. GoÑI URRIZA, "La ley aplicable a las donaciones internacionales", $C D T, 11,2$, Octubre 2019, pp. 100-116; L. GARCÍA-ÁlVAREZ, "Las donaciones entre cónyuges en Derecho internacional privado", Cuadernos de Derecho Transnacional, 2020, n.2, vol. 11, pp. 430-474; N. GoÑ URRIZA, Las donaciones en Derecho internacional privado, Aranzadi, Navarra, 2020; L. Fumagali, "La convenzione di Roma e la legge regolatrice delle donazioni", Rivista di Diritto internazionale privato e processuale, 1993, pp. 589-606; P. JiMÉnEZ BLANCO, "El derecho aplicable a las donaciones", REDI, 1997-I, pp. 63-90; G. PASSARELLI, "Donation: short notes between Italian Civil Law and EU Private International Law", Cuadernos de Derecho Transnacional, 2015, pp. 476-482; J. CARrascosa GonZÁLEz, "Apuntes sobre la competencia 
144. Las segundas donaciones, esto es, las donaciones y regalos realizados una vez que existe una promesa de matrimonio entre los prometidos deben analizarse a partir de una opción de la que dispone la persona que regaló bienes a su prometido. Así lo entiende, con carácter general, la STJUE 24 noviembre 2020, C-59/19, Wikingerhof, FD 26 in fine ${ }^{203}$. En primer lugar, si el demandante reclama la devolución de los bienes donados al prometido que rompió su promesa de matrimonio y basa su petición en las causas de revocación de las donaciones propter nuptias, como por ejemplo, que no se ha celebrado el matrimonio en el año siguiente a la donación (en Derecho español: art. 1242 CC), la reclamación presenta un claro carácter contractual. La Ley aplicable a dicha reclamación se fija con arreglo al Reglamento Roma I y ser, normalmente la Ley elegida por el donante y en su defecto la ley del país de su residencia habitual (art. 4.2 RR-I), salvo que se trate de donación de inmueble, caso en el que se aplicará la Ley del país de situación del mismo (art. 4.1.c) RR-I). En segundo lugar, si el perjudicado acciona contra el demandado y solicita la devolución de los regalos y se basa en que creyó en las palabras de la promesa de matrimonio y en que, por ello, éste se iba a celebrar, la reclamación de las cantidades empleadas en los bienes donados al otro prometido y/o a terceros presenta un claro carácter extracontractual. Como indican T. BALLARINo / A. Bonomi y N. Boschiero, en este caso, las donaciones y regalos realizados una vez que existe una promesa de matrimonio pueden ser considerados como "gastos hechos y obligaciones contraídas en consideración al matrimonio prometido", en palabras del art. $43 \mathrm{CC}^{204}$. En este caso, la obligación de resarcir de estos gastos y obligaciones post-promesa de matrimonio surge de la Ley, no de la declaración de promesa de matrimonio y es una obligación, por tanto, extracontractual. El Reglamento Roma II determinará, según lo expuesto, la ley aplicable a la revocación de tales donaciones.

\section{Reflexiones finales}

145. El análisis de la regulación jurídica de la promesa de matrimonio en Derecho internacional privado revela varios datos importantes.

En primer lugar, puede destacarse que no existe institución jurídica, por extraña o anacrónica que parezca, cuyo estudio no aporte elementos interesantes. En este sentido, la promesa de matrimonio nunca ha desaparecido de modo completo en Occidente y la globalización la ha traído de nuevo al primer plano de la escena judicial.

judicial internacional y la ley aplicable a las donaciones: antes y después del Reglamento Roma I", Cuadernos de Derecho Transnacional, 2009-II, pp. 320-327. Ya antes del Reglamento Roma I, con extrema lucidez, vid. A. WeILL, "Fiançailles", Encyclopedie Dalloz droit international, París, 1968-69 (dir. Ph. Franceskakis), vol.II, 1969, pp. 22-24.

${ }^{203}$ STJUE 24 noviembre 2020, C-59/19, Wikingerhof GmbH \& Co. KG vs. Booking.com BV [ECLI:EU:C:2020:950] FD 26: "Por lo que respecta, en primer lugar, a la sistemática del Reglamento n. 1215/2012, este se basa en la regla general de la competencia de los órganos jurisdiccionales del Estado miembro del domicilio del demandado, mientras que las reglas de competencia especial previstas en particular en su articulo 7 constituyen excepciones a esa regla general y, en cuanto tales, deben interpretarse en sentido estricto (...) y son mutuamente excluyentes en la aplicación de ese Reglamento"; FD 28: "Por lo que respecta, en segundo lugar, a los objetivos del Reglamento n.o 1215/2012, del considerando 16 de este se desprende que las reglas de competencia especial a las que puede acogerse el demandante en virtud, por una parte, del artículo 7, punto 1, del citado Reglamento y, por otra, del artículo 7, punto 2, del mismo Reglamento fueron introducidas teniendo en cuenta la existencia, en las materias contempladas en esas disposiciones, de un vinculo de conexión particularmente estrecho entre una demanda y el órgano jurisdiccional al que puede someterse esta, o bien para facilitar la buena administración de justicia (...)"; FD 29: "Por lo tanto, procede considerar que la aplicabilidad del artículo 7, punto 1, del Reglamento n. 1215/2012 o del artículo 7, punto 2, de este depende, por un lado, de la elección del demandante de acogerse o no a alguna de esas reglas de competencia especial y, por otro lado, del examen, por parte del órgano jurisdiccional al que se somete el asunto, de las condiciones especificas establecidas en dichas disposiciones"; FD 30: "A este respecto, cuando un demandante invoca una de las citadas reglas, es necesario que el órgano jurisdiccional que conoce del asunto compruebe si las pretensiones del demandante son, independientemente de su calificación en el Derecho nacional, de naturaleza contractual o, por el contrario, de naturaleza delictual o cuasidelictual en el sentido del antedicho Reglamento".

${ }^{204}$ N. Boschiero, “Art. 26”, en S. Bariatti (a cura di), Legge 31 maggio 1995 n. 218, Riforma del sistema italiano di diritto internazionale privato. Commentario, en Nuove leggi civili commentate, 1996, pp. 1149-1156; T. Ballarino / A. Bonomi, Diritto internazionale privato, $3^{\mathrm{a}}$ ed., Cedam, 1999, p. 374: “La legge designata dall'art. 26 è chiamata a regolare la promessa di matrimonio e le conseguenze della sua violazione: vi rientrano tutte le questioni relative alla restituzione dei doni o al risarcimento dei danni, all'entità del danno risarcibile, alle conseguenze della colpa uno dei nubendi, al termine prescrizionale". 
En segundo lugar, la promesa de matrimonio plantea, una vez más, su problema más agudo: la calificación jurídica de esta institución jurídica. Un examen del estado actual del Derecho internacional europeo permite concluir que los estos litigios derivados del incumplimiento de la promesa de matrimonio deben ser considerados como supuestos de obligaciones extracontractuales. En consecuencia, la competencia judicial internacional debe ser decidida con arreglo al Reglamento Bruselas I-bis y en su defecto, según los foros recogidos en la LOPJ en dicha materia. En especial, el art. 7.2 RB I-bis permite demandar tanto en el país donde la promesa de matrimonio se quiebra, como en el país donde la promesa produce daños personales y/o patrimoniales. La teoría de la ubicuidad es invencible.

En tercer lugar, por lo que hace referencia a la Ley aplicable a los daños derivados de la ruptura de la promesa de matrimonio, el Reglamento Roma II entra en acción. A falta de elección de Ley, será aplicable la ley del país de residencia habitual común de las partes. Y en ausencia de dicha residencia habitual común, es aplicable la Ley del lugar del daño. En la inmensa mayoría de los casos, el lugar del daño se localiza en el país de la residencia habitual de la víctima.

146. Más allá de las soluciones de Derecho positivo, el estudio de la promesa de matrimonio en Derecho internacional privado pone de relieve que una mayor dosis de dogmática jurídica en el análisis jurídico siempre conduce a resultados más justos. Ello es particularmente necesario en estos casos, en los que realidades sociales procedentes de escenarios sociales lejanos penetran en Occidente. El choque de valores y la diversa concepción de las instituciones jurídicas, hacen que resulte preciso argumentar mejor a fin de convencer al oponente en la discusión jurídica. Porque convencer significa "vencer con" dicho oponente. No se trata de persuadir, sino de exponer los argumentos jurídicos de un modo razonable, de forma que otros juristas puedan aceptar los puntos de vista adoptados y todos venzan juntos. En esta perspectiva, los principios de seguridad jurídica, previsibilidad de la Ley aplicable, solución eficiente de los conflictos de Leyes y protección de las expectativas sensatas de la víctima de la ruptura de la promesa de matrimonio son los baluartes sobre los que un discurso jurídico adquiere su fortaleza más acabada. 